\title{
Analysis of Automotive Damper Data and Design of a Portable \\ Measurement System
}

\author{
Presented in Partial Fulfillment of the Requirements for \\ the Degree of Bachelor of Science with Distinction
}

By

\section{Grant A. Malmedahl}

Advisor: Dr. Giorgio Rizzoni

\author{
$* * * * *$ \\ The Ohio State University \\ Department of Mechanical Engineering \\ Center for Automotive Research \\ May 20, 2005
}




\begin{abstract}
This research will review existing approaches to the estimation of the state of wear of an automotive damper, with the aim of developing a methodology for a quick and effective diagnostic procedure that could be carried out in any repair facility. It has always been desirable to leave the shock absorber in place at the time of such testing, and there are three general procedures that claim to be effective at determining damper wear. The general procedures are: to remove the shock and perform a dynamometer test, to leave the shock in place and vibrate the tire at known frequencies, and the last is to push on one corner at a time and observe the oscillations. This research investigates a method of controlling a short drop of each corner of the vehicle while measuring the acceleration. The acceleration data is then analyzed with the aim of estimating the decay rate of the resulting oscillation, which is known to be related to the damping ratio of the suspension system. The rate of decay, quantified by the damping ratio, is then used to infer the condition of the vehicle's damper. Multiple tests were conducted with shock absorbers of different degrees of wear to assure the capability of this methodology. Also, tests were run to examine the effects of spurious inputs to the test procedure, such as low tire pressure and the affect a failed damper on the opposite end of the axle has on the test results for a new damper. This thesis reviews the state of the art, describes the methodology and presents experimental validation of a new concept.
\end{abstract}




\section{Acknowledgements}

I have a lot of people who deserve some credit and thanks throughout the course of this research project. First, I would like to thank Dr. Giorgio Rizzoni for giving me this research opportunity, motivating me to pursue this to gain experience in research and development, and helping me learn to write a technical paper. He also gave me the necessary guidance to collect the data I need and make use of Ohio State University's Center for Automotive Research's (CAR) facilities.

On a similar note, I would like to thank Don Butler, Project Manager of CAR, whose technical background and business experience provided a continuous connection between myself, CAR, and Tenneco Automotive. Also at CAR, I need to thank Dr. Ahmed Soliman, Don Williams, and Professor Emeritus Ernest Doebelin, who all assisted in brainstorming sessions, and served as associates throughout the research process.

During my experimentation I received a great deal of assistance from Jim Shively, and Steve Guba. Mr. Shively set up the LabVIEW $^{\mathrm{TM}}$ program and data acquisition hardware to be used during the course of the research. Mr. Shively and Mr. Guba both assisted in running the experiments, which simply could not be done alone.

I would like to thank Mark Christiaanse and Ted Wittman of Tenneco Automotive who were the industry sponsors and technical contacts. They assisted in providing large amounts of data on shock absorbers, as well as providing new and worn shocks, along with their dynamometer data, for testing and analysis. 
VITA

April 3, $1982 \ldots \ldots \ldots \ldots \ldots \ldots \ldots \ldots \ldots \ldots \ldots \ldots \ldots \ldots \ldots \ldots \ldots \ldots$ Born - Chicago, Illinois

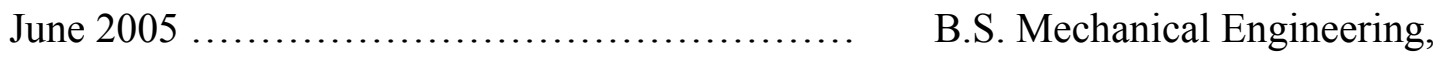

The Ohio State University

\section{FIELDS OF STUDY}

Major Field: Mechanical Engineering 


\section{TABLE OF CONTENTS}

\section{$\underline{\text { Page }}$}

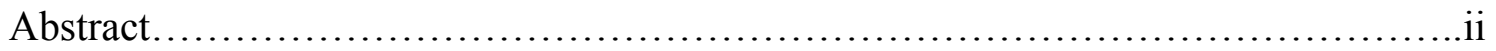

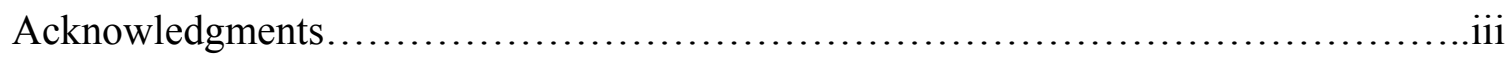

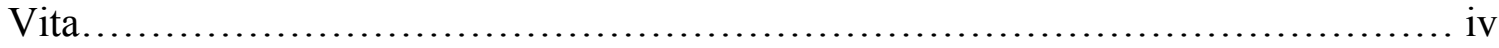

List of Figures..................................................................

Chapters:

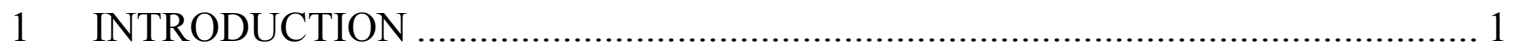

$1.1 \quad$ Suspension Components ........................................................................... 1

1.2 Suspension Parameter Testing ............................................................... 4

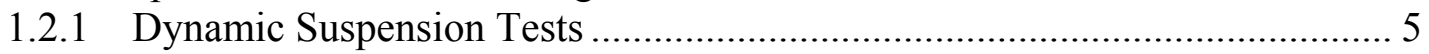

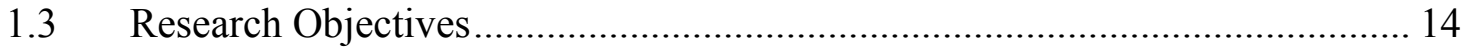

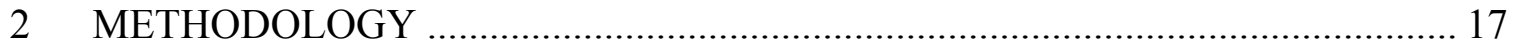

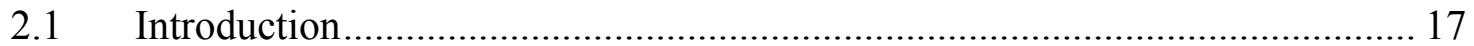

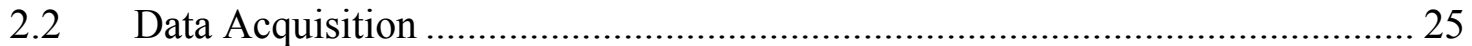

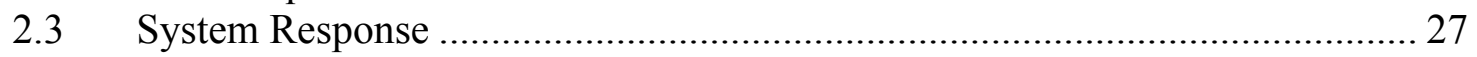

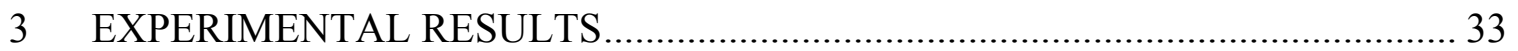

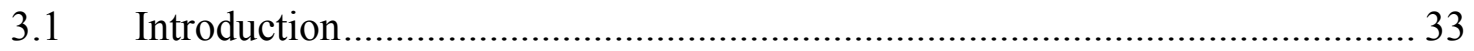

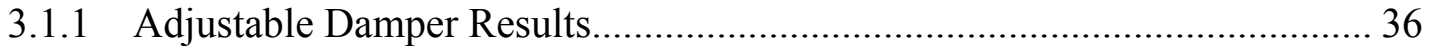

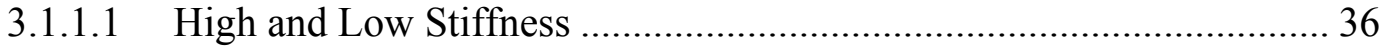

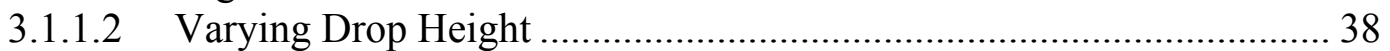

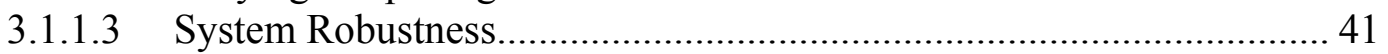

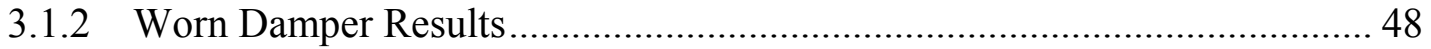

3.1.3 Test Clinic Results ................................................................................ 57

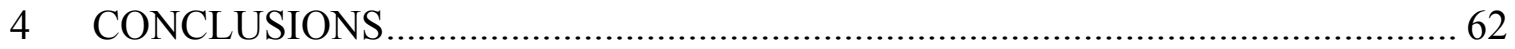

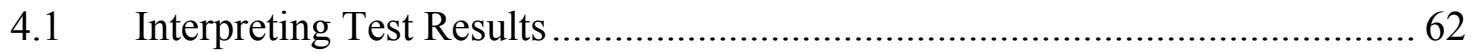




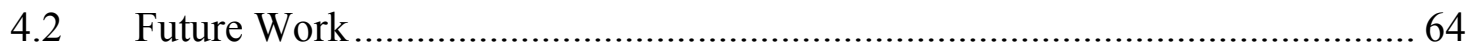

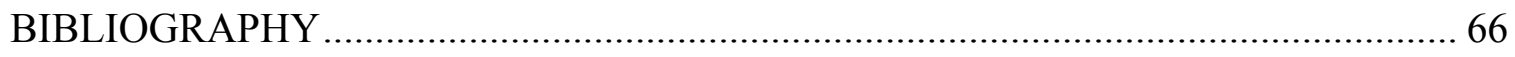

Appendix A

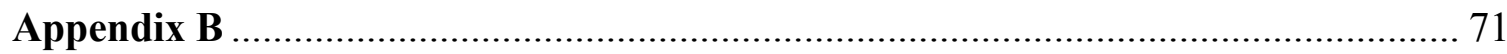

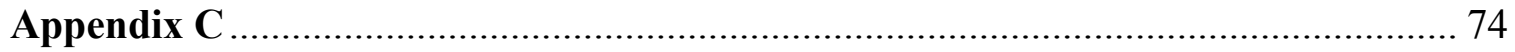




\section{LIST OF FIGURES, TABLES, AND EQUATIONS}

$\underline{\text { Figure }}$

Page

Figure 1-1: From Left to Right: Mono-tube, Twin-tube, and Typical Valve Construction3

Figure 1-2: Results Page for Typical Dynamometer Test 7

Figure 1-3: Output of the Hunter SA400 ................................................................ 9

Figure 1-4: Output for the Control Vehicular Argentino (CVA) ................................. 10

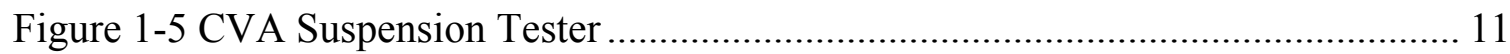

Figure 1-6: 'Big Red' Portable Suspension Tester .................................................. 11

Figure 1-7: Output for the M-Tronic Big Red Shock Absorber Test Device ................... 13

Figure 1-8: Display of Displacement Responses and Acceptable Damping Ratios for a

Push Test 14

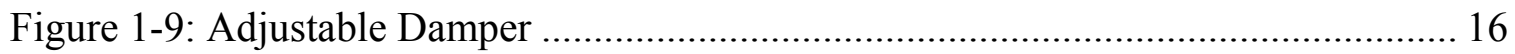

Figure 2-1: Two DOF Quarter-Car Model............................................................ 19

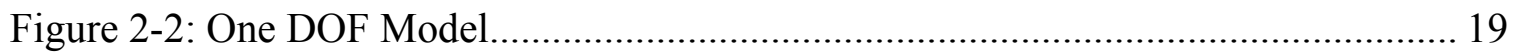

Figure 2-3: Quarter-car Response to Road, Tire, and Body Inputs [16]........................ 20

Figure 2-4: Sprung Mass Acceleration Response Gains to Body Force Inputs............... 21

Figure 2-5: Acceleration Impulse Response ........................................................ 23

Figure 2-6: "Buckling Knee" - Instant Drop Mechanism .............................................. 25

Figure 2-7: Test Instrumentation Affixed to Suction Bracket. ................................... 26

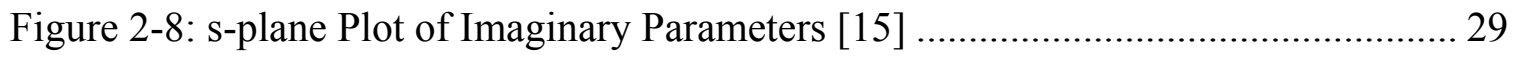

Figure 2-9: Labeled Peaks for the Typical Acceleration Response ............................... 30

Figure 2-10: Relationship between Acceleration and Displacement from a Drop Test ... 31 
Figure 3-1: Demonstrating the Predictability of the Drop Test Vibrations 35

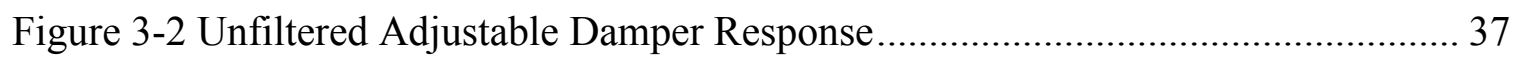

Figure 3-3 Filtered Adjustable Damper Response.................................................. 37

Figure 3-4 FFT of the Adjustable Damper ........................................................... 38

Figure 3-5 Unfiltered Response from Three Drop Heights ......................................... 39

Figure 3-6 Filtered Response from Three Drop Heights ......................................... 40

Figure 3-7 FFT of Responses from Three Drop Height ........................................ 40

Figure 3-8: Test Corner Set to Low Tire Pressure - Before Filter ............................... 42

Figure 3-9 Test Corner Set to Low Tire Pressure - After Filter ................................... 43

Figure 3-10 FFT of Test Corner Set to Low Tire Pressure ........................................ 43

Figure 3-11 Failed Shock on Opposite Corner ........................................................ 44

Figure 3-12 Failed Shock on Opposite Corner -Filtered......................................... 44

Figure 3-13 FFT of Failed Shock on Opposite Corner ............................................ 45

Figure 3-14: Low Tire Pressure and One Soft Damper ......................................... 45

Figure 3-15: Low Tire Pressure and One Soft Damper- Filtered ................................ 46

Figure 3-16: FFT of Low Tire Pressure and One Soft Damper ................................... 46

Figure 3-17: Force Velocity Data for the 75\% Damper .......................................... 48

Figure 3-18 Damper Worn to 75\% of Original Damping .......................................... 49

Figure 3-19 Damper Worn to 75\% of Original Damping - Filtered .............................. 49

Figure 3-20 FFT of Damper Worn to $75 \%$ of Original Damping................................. 50

Figure 3-21: Force Velocity Data for New, but Defective Shocks ................................ 50

Figure 3-22 Response of New, but Defective Shocks ............................................ 51 
Figure 3-23 Response of New, but Defective Shocks - Filtered.................................. 51

Figure 3-24 FFT of Response of New, but Defective Shocks .................................... 52

Figure 3-25: Force Velocity Data for the 50\% Damper .......................................... 52

Figure 3-26 Damper Worn to 50\% of Original Damping ......................................... 53

Figure 3-27 Damper Worn to 50\% of Original Damping - Filtered ............................... 53

Figure 3-28 FFT of Damper Worn to 50\% of Original Damping.................................. 54

Figure 3-29 Force Velocity Data For the 25\% Damper........................................... 54

Figure 3-30 Damper Worn to 25\% of Original Damping .......................................... 55

Figure 3-31 Damper Worn to 25\% of Original Damping - Filtered ............................... 55

Figure 3-32 FFT of Damper Worn to 25\% of Original Damping................................. 56

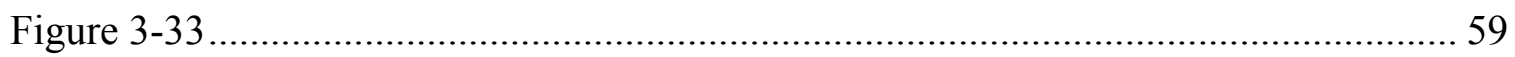

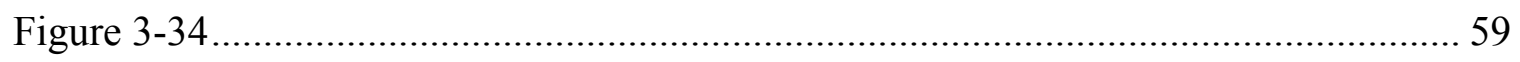

APPENDIX FIGURES

Figure

Page

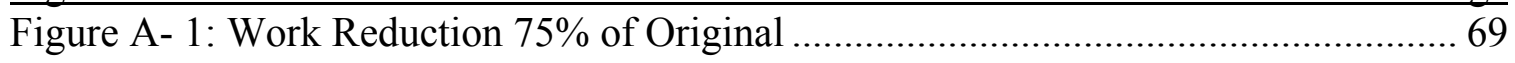

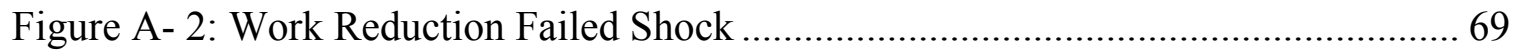

Figure A- 3: Work Reduction 50\% of Original ….............................................. 70

Figure A- 4: Work Reduction 25\% of Original ................................................... 70

Figure A- 5: Clinic Histogram for Front Axle OE................................................ 71

Figure A- 6: Clinic Histogram for Rear Axle OE ................................................... 72

Figure A- 7: Clinic Histogram for Front Axle New Shocks .................................... 72

Figure A- 8: Clinic Histogram for Rear Axle New Shocks ...................................... 73 
Table

Page

Table 2-1: System Parameters

Table 2-2: Poles and Zeros for the Two Models.......................................................... 23

Table 3-1: Damping Ratios and Statistics for the Adjustable Dampers .......................... 38

Table 3-2: Damping Ratio Statistics for the Adjustable Damper at Various Heights ...... 41

Table 3-3: Calculated Damping Ratios for the Adjustable Dampers ............................. 47

Table 3-4: Calculated Damping Ratios for the Worn Dampers.................................... 57

Table 3-5: Statistics for the Before and After Clinic .................................................. 58

Table 3-6 Descriptive Statistics for the Rear Axle Clinic Dynamometer Data ............... 60

Table 3-7 Descriptive Statistics for the Front Axle Clinic Dynamometer Data ............... 60

$\begin{array}{ll}\text { Equation } & \text { Page }\end{array}$

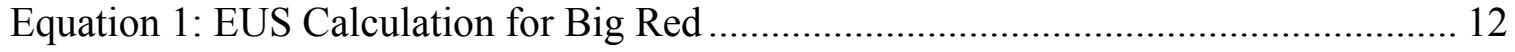

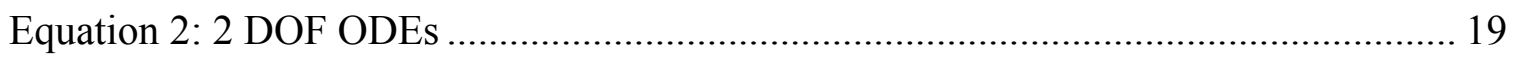

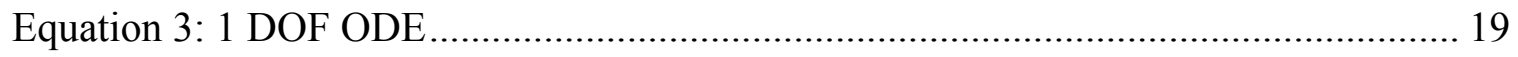

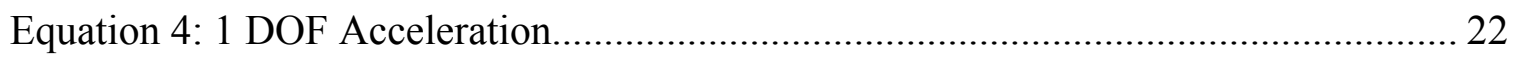

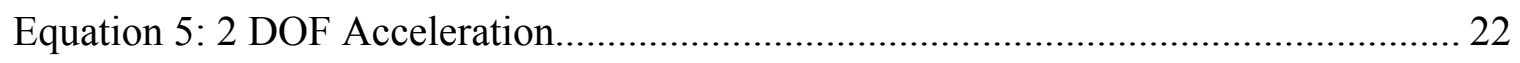

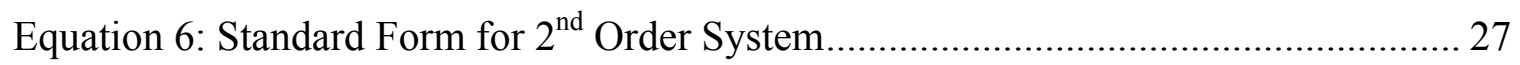

Equation 7: Exponentially Decaying Sinusoidal Acceleration for a $2^{\text {nd }}$ Order System.... 28

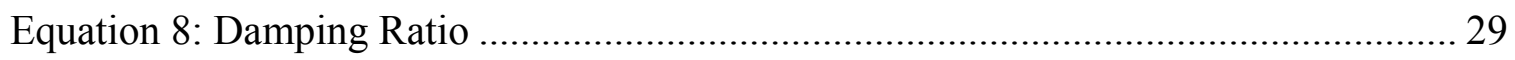

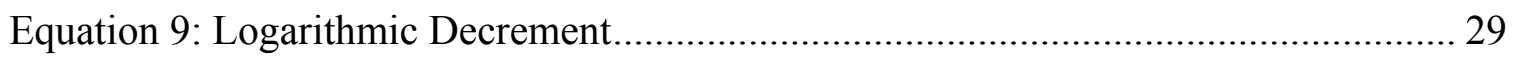

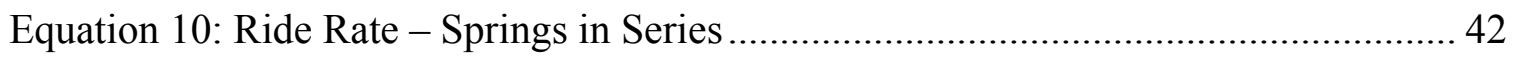




\section{CHAPTER 1}

\section{INTRODUCTION}

\subsection{Suspension Components}

To begin the discussion of automotive damper analysis, there must first be insight to the suspension system as a whole, and the role that the damper plays in the area of ride and handling. Once the desirable properties of a damper are understood, then the design of dampers may be explored. Understanding damper construction will help to understand the possible failure modes. A deteriorating or failed damper will respond to certain inputs in predictable manners. The type of response expected for a failed damper will assist in the development process for a new methodology to assess the wear of the automotive damper. The ambition is to create a method of suspension testing that can be used in a repair shop situation to detect worn automotive dampers.

Automobiles have many inputs that contribute to their performance and the comfort of the passengers. The first automobiles had merely a rigid frame which, coupled with the poor roads at the time, provided for a very rough ride. As the decades passed the linkages between the tires and the chassis became more and more complex. Today, every land vehicle incorporates components to smooth out the ride, and to improve handling at higher speeds [1]. 
The main components of a suspension that improve handling, noise, vibrations, and harshness (NVH), and passenger comfort are the tires, springs, and the damper. The main function of the tires is to maintain a frictional force at the road to prevent sliding and improve acceleration. The shocks and springs are present to further help the tire maintain contact with the ground. The springs can be used to control where the sprung mass resonance falls in the frequency spectrum. Generally, this is kept low, about $1 \mathrm{~Hz}$, so the resonance will occur at low speeds, which is dynamically a more stable situation [16].

The suspension damper is of great concern for maintaining a safe level of adhesion and reducing perception of road harshness. The damper works by dissipating the kinetic energy between the sprung and unsprung masses. This energy is converted to heat by the internal pressurized oil passing through the valves' orifices, which creates fluid shear, and thus friction. There are several main constructions for automotive dampers. Figure 1-1 shows the two dominant types, mono-tube and twin-tube. The former has only one chamber filled with oil, and a valve separating the oil and gas. The latter has a reserve chamber that contains the gas and permits the oil to flow through two valves. This is more work done, thus faster energy dissipation. Also, the extra surface of the twin-tube provides for improved thermal conductivity properties. It is universal for the dampers to use an inert gas to pressurize the fluid chambers. This gas serves two purposes. First and foremost, the gas acts to keep the oil from aerating. When the oil contains bubbles, it can be compressed. As the oil compresses, less is going to flow through the valves, which will reduce damper performance. A secondary function of the 
gas charge is to add a spring effect to the damper, which will improve, slightly, the overall spring rate [1].
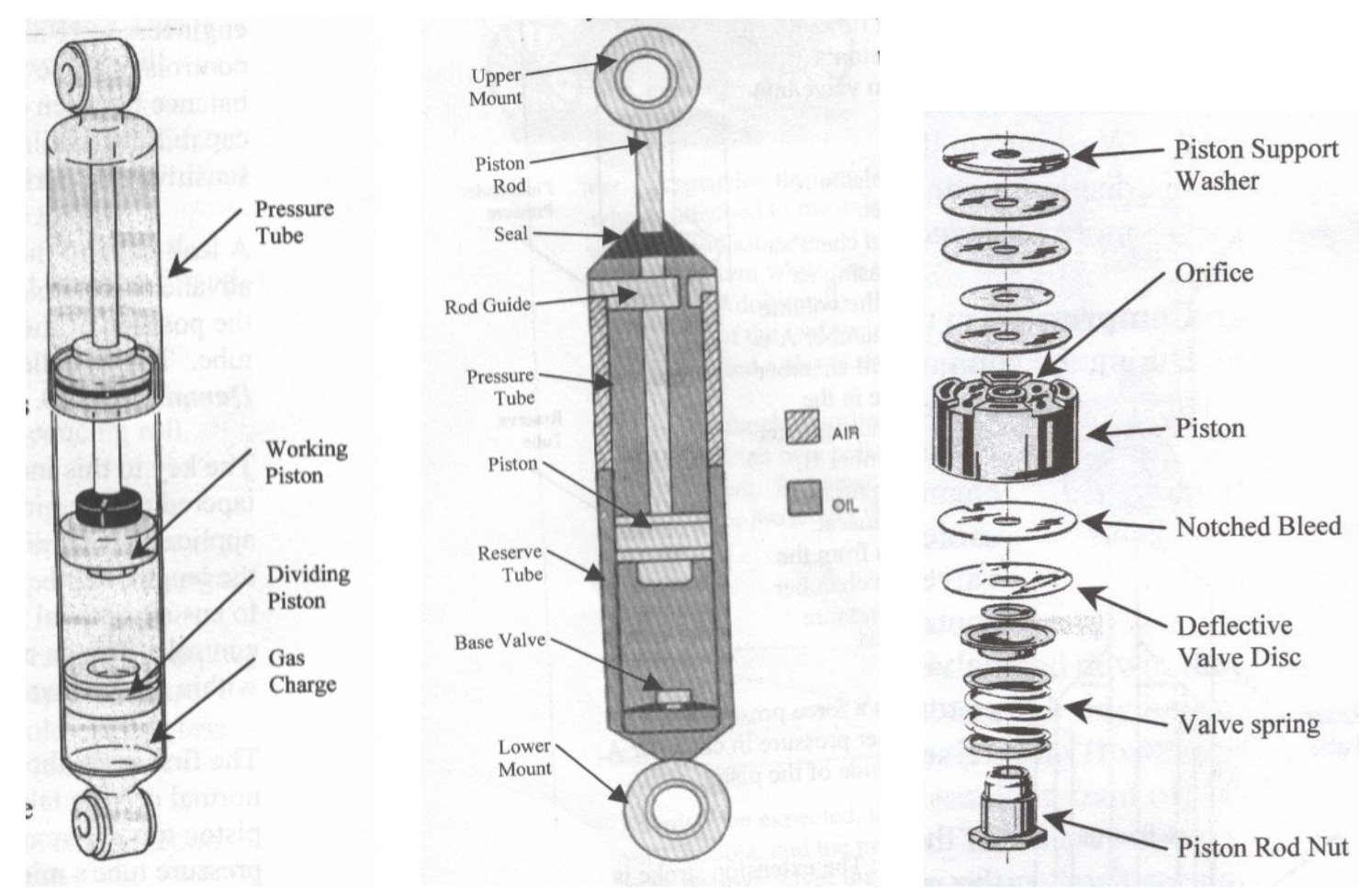

Figure 1-1: From Left to Right: Mono-tube, Twin-tube, and Typical Valve Construction

Figure 1-1 also shows an acceleration sensitive valve system. This valve will open a bypass to allow more fluid flow in response to harsh road conditions. The response is instant, giving greater control in severe situations, and maintains a good level of comfort in normal situations [1].

The lifespan of a damper will see heavy cyclic loading. The extreme conditions of most undercarriages provide numerous fatigue accelerating influences, such as water, salt, dirt, dust, and loose gravel. As a damper wears, its performance is jeopardized. Oil 
may leak out of the chamber causing a reduced ability to dampen vibrations. If contaminants enter the oil reservoir, the orifices can become blocked or worn which will alter the performance. Also, there is potential for mechanical failure. The valve systems can break down causing changes in the orifice flow. The piston can become detached from the rod causing the damper to be ineffective in extension or rebound.

If the damper is worn the suspension will not perform appropriately, thus the ride comfort will suffer, adhesion will be compromised, high speed maneuvers could be dangerous, and braking distances could be longer. With an idea of damper construction, function, and failure modes various test methods may be explored to pioneer a new suspension tester methodology.

\subsection{Suspension Parameter Testing}

Automotive design teams have long been using various mathematical models and computer simulations to aid the development of new vehicle models and to understand vehicle performance limitations. These models require accurate parameter characterization for the different suspension components in order to predict a vehicle's dynamics. This spawned a great deal of focus on systems to measure vehicle suspension parameters, which are necessary in mathematical models.

A common approach for these systems is to take the vehicle in static positions, and apply forces in specific ways to record the deflection of the component to be characterized, i.e. the tire, the springs, or the various linkages $[2,3,4]$. These quasi-static 
tests are great for further developing the models that have helped advance the automotive design process.

Once a vehicle is built, it faces the types of hazards that the vehicle dynamics simulators have predicted and quantified. There are simulators to predict fatigue life of suspension linkages [5]. However, these methods are for design purposes, and their theory doesn't carry over well to the area of vehicle diagnostics. To be useful in a repair shop, the test systems generally must be very quick and reliable. The static tests described thus far are time-consuming, and require much care to perform accurately. Furthermore, these static methods are ineffective to test the performance of automotive dampers. Dampers are velocity dependent; therefore any static test will not incorporate any forces affected by the damper.

\subsubsection{Dynamic Suspension Tests}

Dynamic tests must be used to assess the state of a vehicle's damping. There are a number of ways to test the vehicle and determine if the suspension is still performing as originally intended. The dampers act to isolate vibrations, and will generate a counteractive force proportional to a velocity input. Because of the response to a velocity input, dampers should be tested dynamically. There are simple dynamic tests when the shock absorber is removed from the suspension. The far reaching standard is a dynamometer test. This will run the damper through various sinusoidal frequencies, and measure the force seen at the peak velocity for the different frequencies [6, 7]. Figure 1-2 shows a results page for a dynamometer test. This particular test put the damper through 
four different excitation frequencies. From this, the main parameters of interest can be illustrated. The table at the top gives specific values for the force recorded at the peak cycle velocities. The work-done is also of importance, and gives an idea of the overall effort of the damper. The first plot of Figure 1-2 shows the force as a function of displacement as the test runs through its different frequencies. The other plot gives the force as a function of velocity. The force-velocity curves will be seen again in Chapter 3 to present some worn shocks. The force-velocity curve is often used to characterize the damper in simulation models by using either a gain proportional to velocity, or a spline method to interpolate the force for a given velocity.

Dynamometer tests are the standard in damper diagnostics. Their main drawback is the damper must be removed from the vehicle to run tests. This is time consuming, which generally leads to the method being shunned by repair shops who try to have a very high turnover rate. From the perspective of being able to ensure driver safety it is desirable to develop a quick and time efficient test to assess the performance of the suspension. 


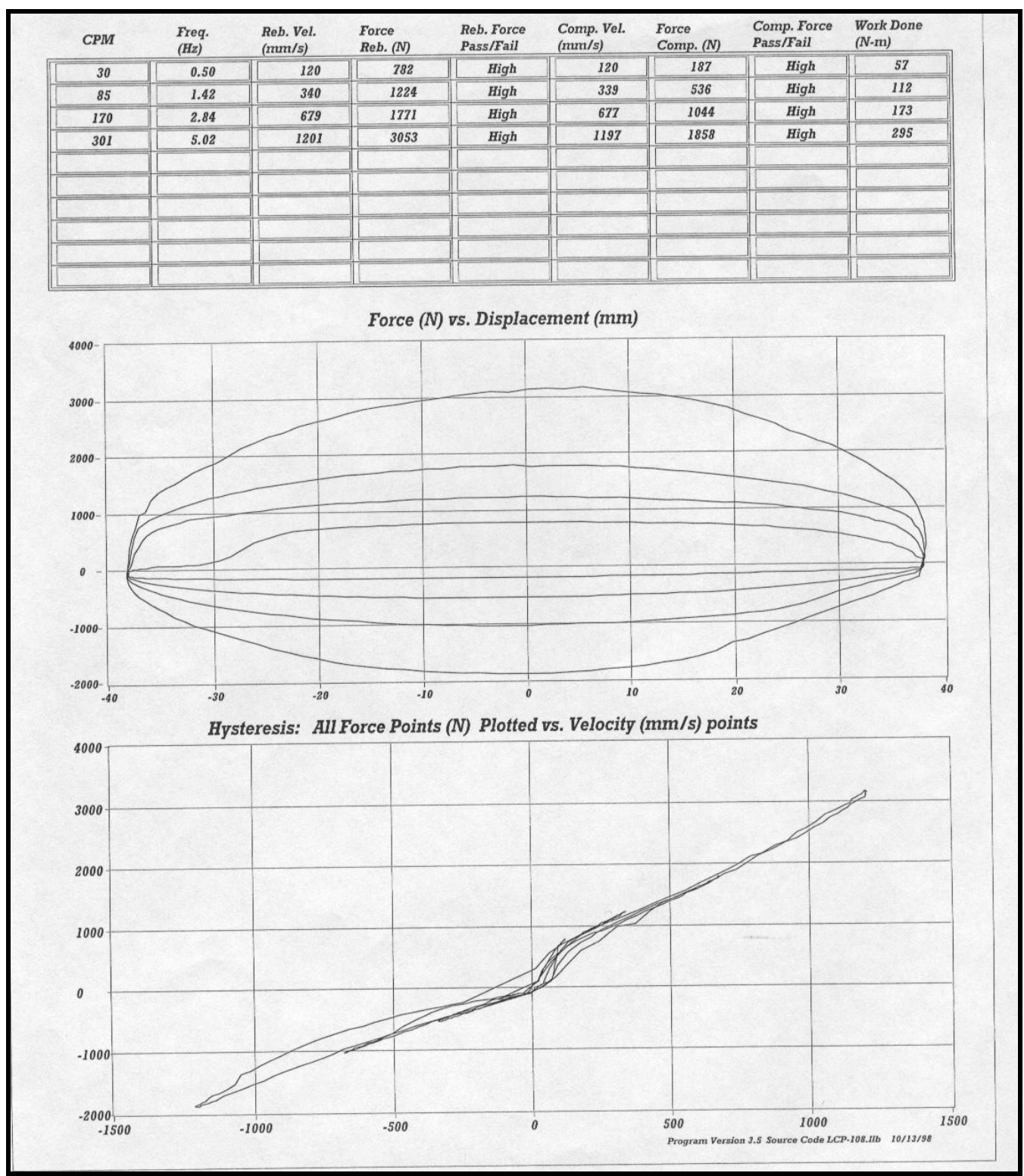

Figure 1-2: Results Page for Typical Dynamometer Test

There are several systems in use by repair shops to evaluate the condition of the suspension as a whole, and these infer the condition of the damper. One main method for suspension performance analysis is to excite the suspension through the tire via a shaking platform. The platform performs a sinusoidal sweep to observe the conditions for wheel 
hop resonance. Generally, they look for the resonance frequency, amplitude, and phase shift. There are two popular suspension testing systems that utilize the sine swept tire shaker. They each characterize the damper condition in slightly different manners $[8,9$, 10]:

1. The Hunter SA400 measures the force at the tire shaker interface, and measures the sinusoidal phase shift between the oscillating platform and the cyclic tire force at the tire. Figure 1-3 shows the output seen on the PC for this test method. The plot gives the frequency on the horizontal axis and the phase in degrees on the vertical axis. The phase is also shown on the tire schematic to give a user-friendly diagram of the side-to-side differences. A low phase represents poor adhesion, and worn shocks. 


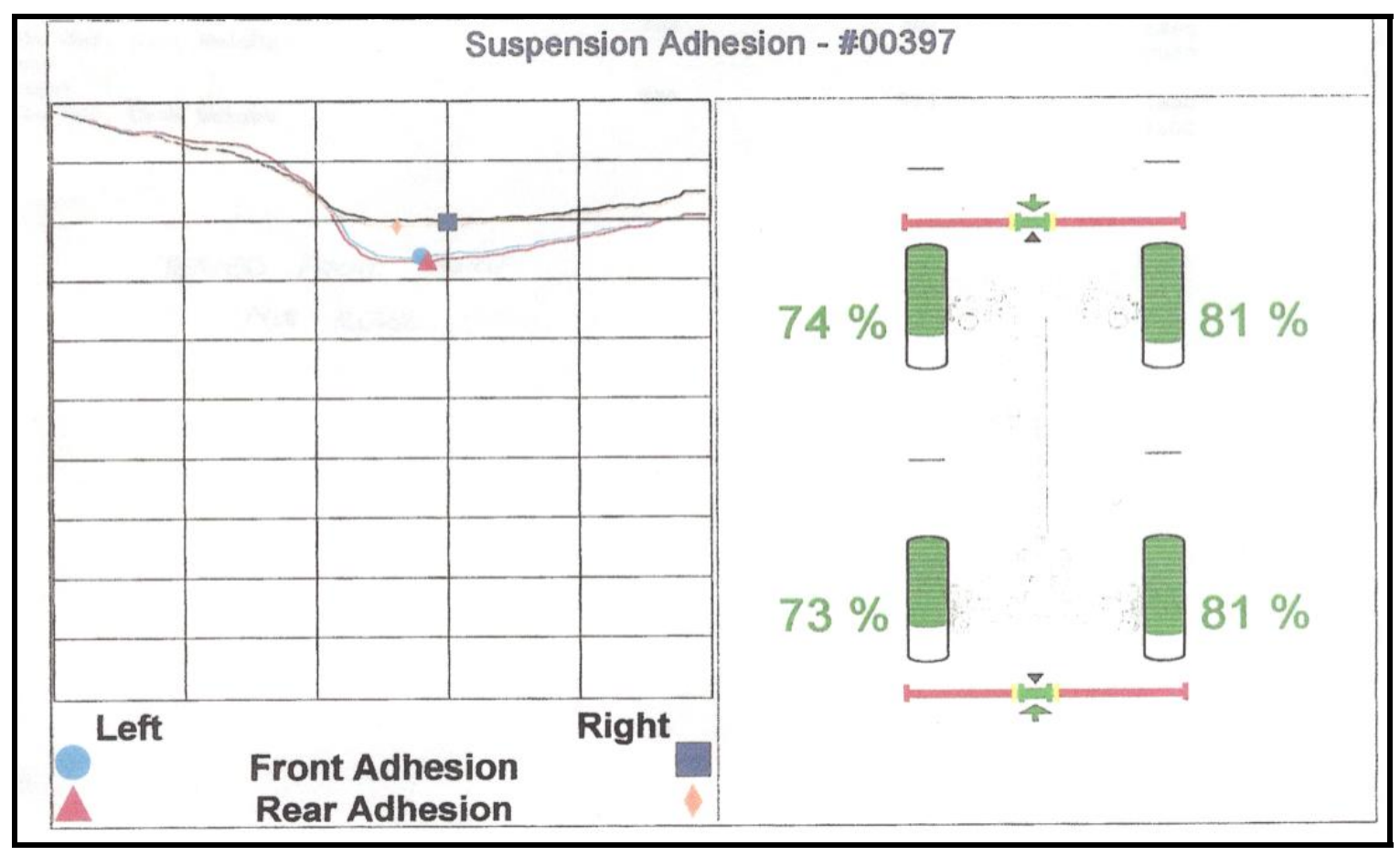

Figure 1-3: Output of the Hunter SA400

2. The Control Vehicular Argentino (CVA) excites the platform to $20 \mathrm{Hertz}$, and then shuts off. The ensuing platform vibrations decay at a rate that infers the performance of damper. The output is shown in Figure (1-4). The platform's displacement is also measured, as is the frequency of resonance. A large resonance amplitude and slow rate of decay are signs of poor damper performance. 


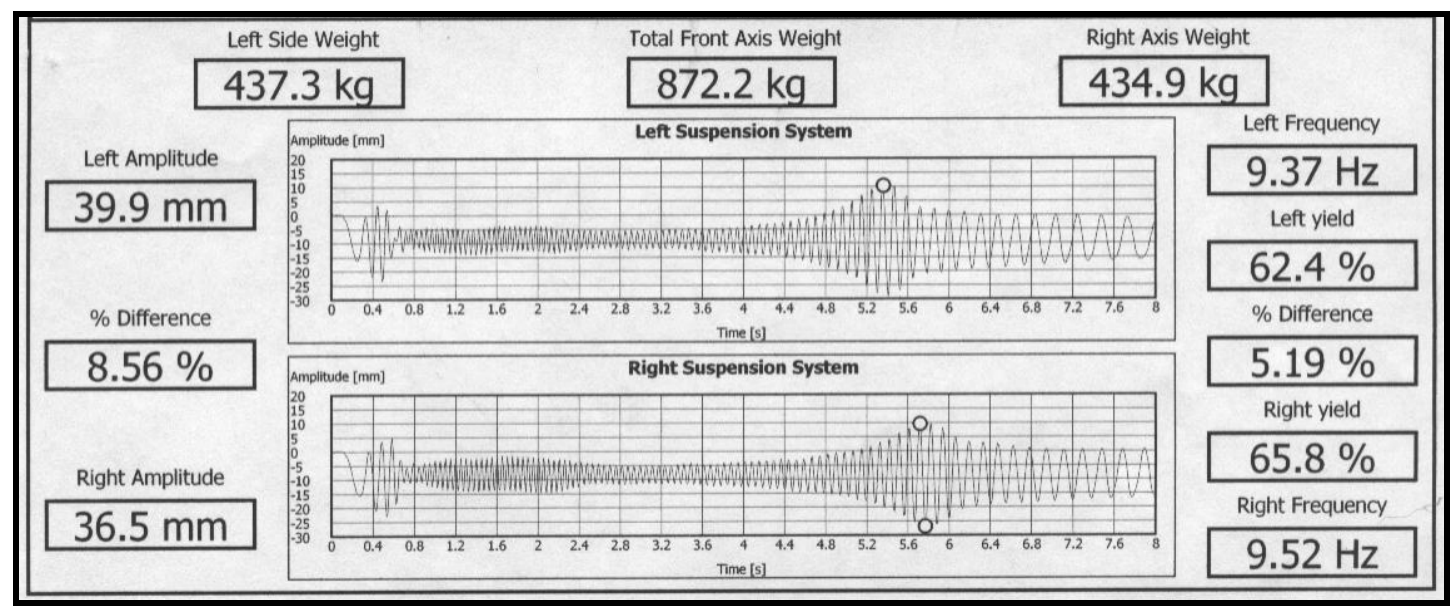

Figure 1-4: Output for the Control Vehicular Argentino (CVA)

Both these methods have been proven to be capable of detecting poor suspensions, and more specifically failed dampers. Since the automobile is such an integrated system, there are multiple shortcomings of each method. For instance temperature plays a vital role in damper performance by changing the damper fluid viscosity, thus altering the damping stiffness [8,9]. Another drawback is tire pressure adversely affects both systems, giving false indications of failure. Vehicles with solid axles will have coupled suspensions, and the poor condition of one damper will affect the performance at the axles other tire. Regardless of the shortcomings, if care is taken these methods can be effective. 


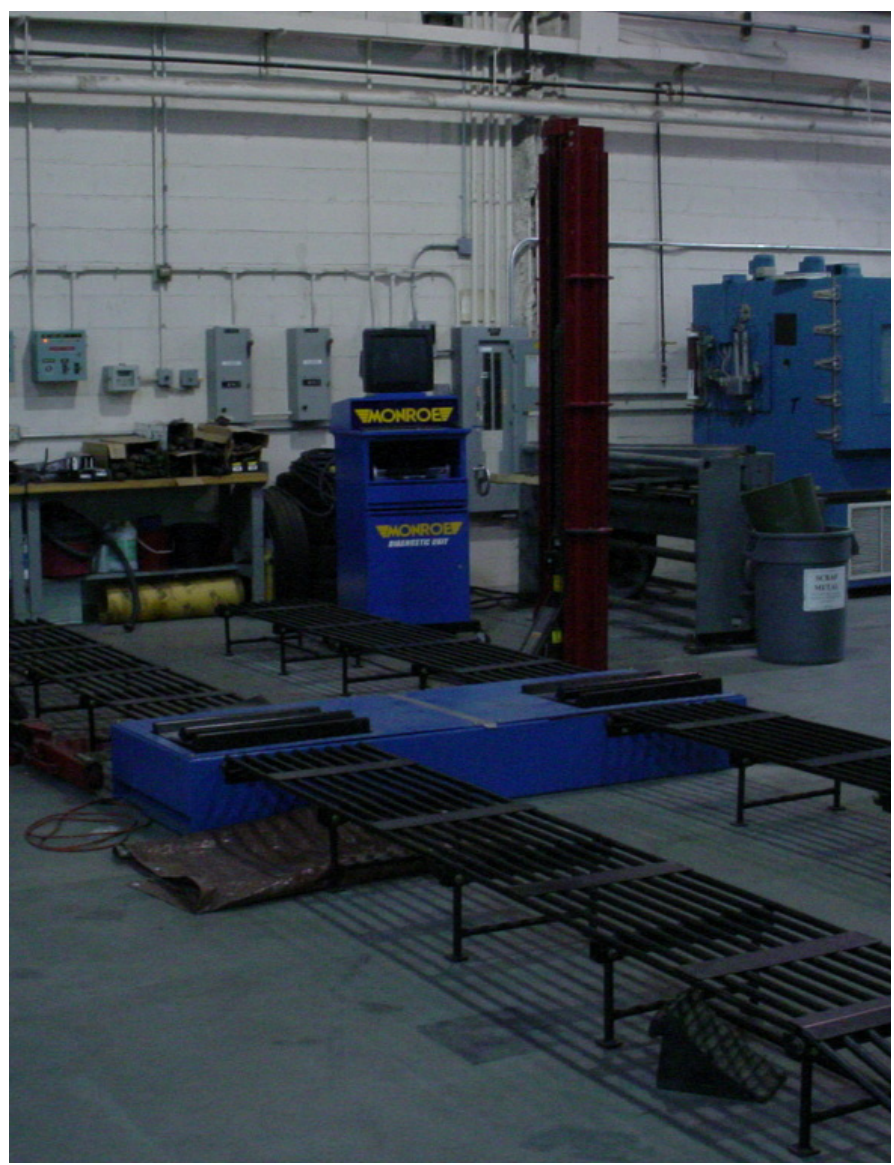

Figure 1-5 CVA Suspension Tester

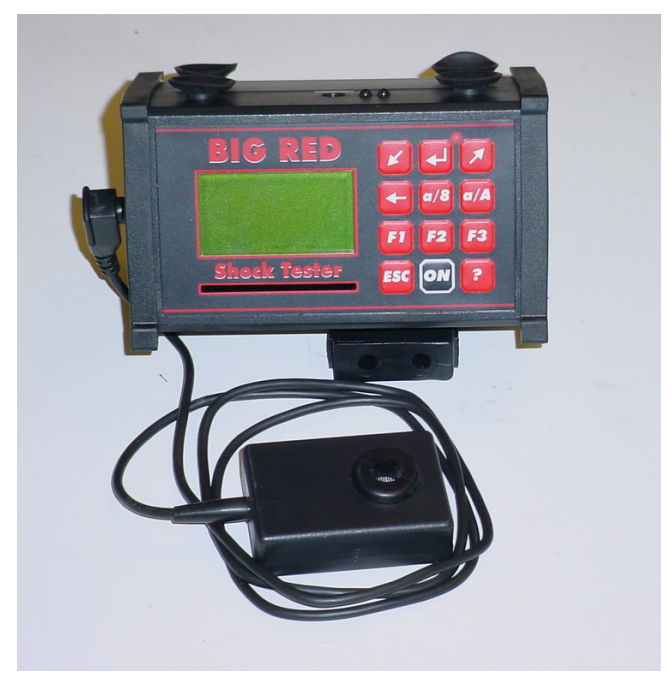

Figure 1-6: 'Big Red' Portable Suspension Tester

A much simpler method, which has been used in garages, is to push on the body of the vehicle and observe the oscillations of the sprung mass. Clearly, this is a much watered down concept. Initially, this was done while simply estimating if the oscillations seemed excessive $[11,12]$. However, with the proper instrumentation, this has proven to be very effective. A popular device in Europe, known as "Big Red", uses an ultrasonic transducer to measure the displacement of the sprung mass. It has an algorithm that 
calculates the damping ratio of the exponentially decaying sinusoid and then converts it to a percentage, which they call the Evaluated Ultrasonic Signal (EUS) [12]:

$$
E U S=100\left(1-\exp \left(\frac{-D \pi}{\sqrt{1-D^{2}}}\right)\right)
$$

\section{Equation 1: EUS Calculation for Big Red}

Here " $\mathrm{D}$ " is the damping ratio, which is a textbook calculation seen often in system dynamics for a second order linear time invariant system [12, 13, 14]. In this thesis, ' $D$ ' is referred to as ' $\zeta$ ' to uphold the nomenclature of the text theory studied. The damping ratio will be discussed in depth in Chapter 2 because it will be used in the experimental results of Chapter 3. The EUS value is compared to a reference value based on the suspension type. There are three generic suspension types programmed into the system: soft, normal, and sporting. These three settings each have an EUS value that is considered to be the normal value for that vehicle type. If the EUS value is $20 \%$ lower than the 'normal' value, then the shock is considered worn, and replacement is recommended.

Figure 1-7 shows the output for Big Red. The displacement recorded by the ultrasonic sensor is shown to give the user a feel for the oscillations of the vehicle. "E.eq\%" is the EUS value for this particular test. The output also gives the peak velocity measured ("Vel.") and the maximum displacement (“Ampl"). 


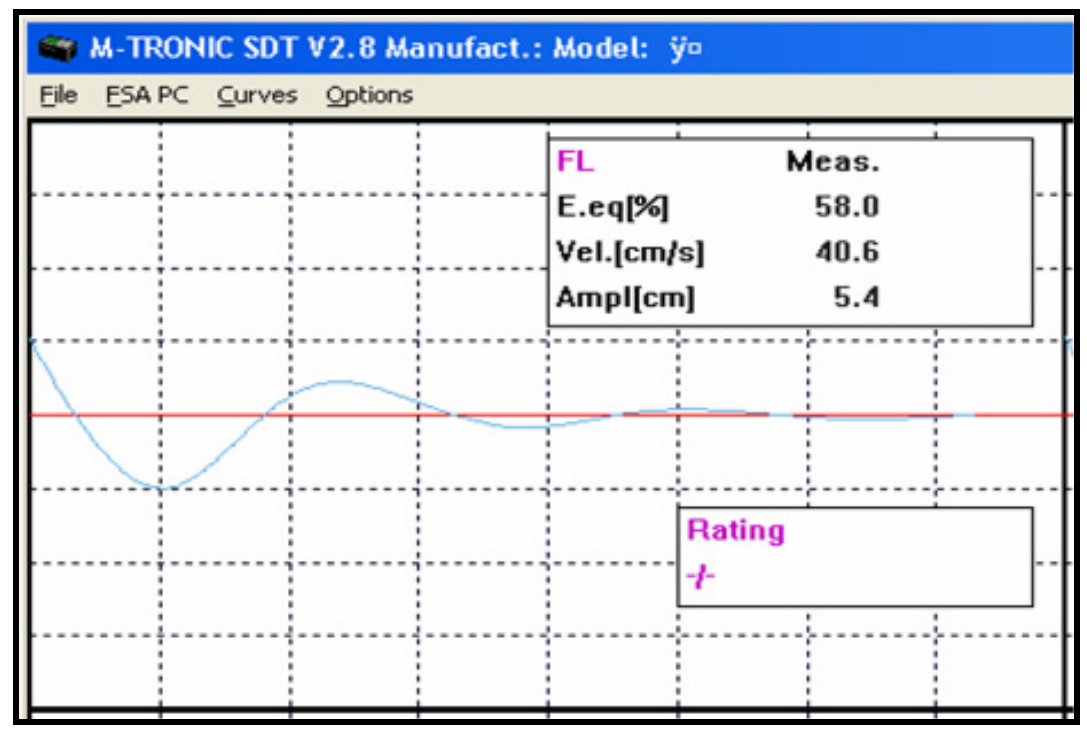

Figure 1-7: Output for the M-Tronic Big Red Shock Absorber Test Device

Figure 1-8 gives a representation of the responses that may be seen by varying the damping ratio [12]. As the damping ratio increases, i.e. a stiffer shock, the signal decays faster. The green region is considered safe. The yellow ban is a borderline area, and into the red is a defective shock in which replacement would be recommended. Notice the values for the damping ratio are between zero and one. Less than 0.25 for this model is considered dangerous. 


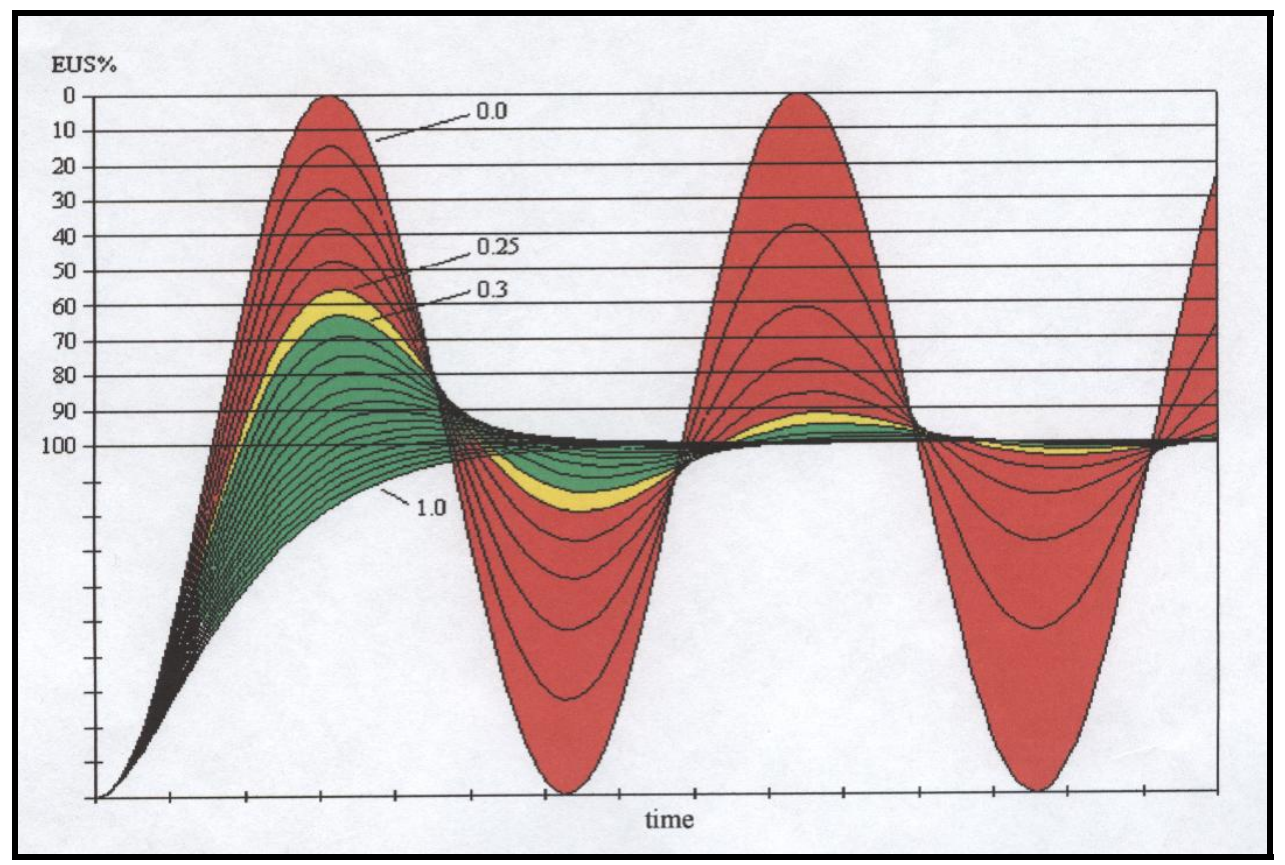

Figure 1-8: Display of Displacement Responses and Acceptable Damping Ratios for a Push Test

\subsection{Research Objectives}

The primary objective of this research is to develop new methodology for repair shop diagnosis of worn automotive dampers. This research will take what has been proven from the existing suspension testers, learn how and why they work, then develop a new methodology which will yield comparable reliability, at a much lower cost. The test method must be repeatable and consistent. Another desirable feature is to make the device portable and easy to use. The instrumentation is to be made with new technology that will be less expensive and more accurate then the technology used in the above noted suspension testers. 
Once the framework of the testing procedure is defined, tests will be run. The tests will need to evaluate the systems ability to:

1. Reliably collect data that is characteristic of the suspensions response.

2. Accurately describe the suspension response and correlate that data to worn dampers.

3. Find ranges for which the operator can say the dampers are good, fair, and unacceptable.

This will be accomplished by running tests on several different premises. A 2001 Jeep Grand Cherokee was provided for this research, from here on referred to as the "test vehicle". It will be the basis for the bulk of the testing. Additionally, a wide variety of shock absorbers were provided to give a variety of test data.

Three shocks with different degrees of damping were procured. The degree of damping was manipulated by draining the damping fluid, then welding the drain hole shut. The shock would then be run on a dynamometer. The percent of wear is determined by comparing the "Work Done" (see Figure 1-2) to that particular shock's original work done performance. Another shock provided has an internal failure of some kind. The exact mechanical failure can not be determined unless it is cut open. Based on experience of an industry expert, the failure could be a loose reserve tube, or the damper rod detached from the piston plunger. No matter what the failure, the dynamometer test clearly showed reduced performance (see Figure 3-21 and A-2). 
Additionally, a set of shock absorbers with a feature to adjust the degree of damping by simply turning a dial at the base of the damper was provided for analysis. This high performance shock, along with some other new aftermarket shock absorbers, provided a large amount of test opportunities.

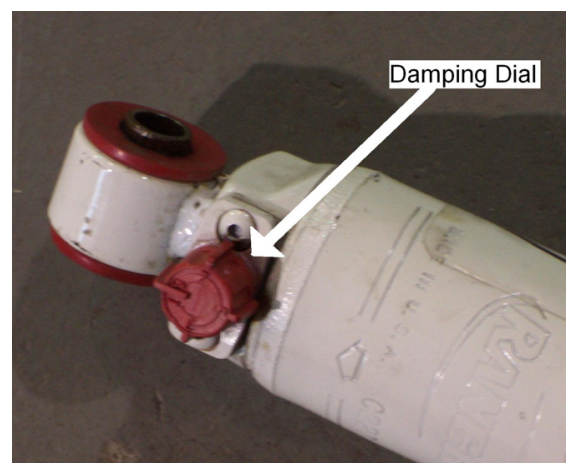

Figure 1-9: Adjustable Damper

With an understanding of the functionality of a suspension system, different testing methods can be developed to obtain useful parameters for the various suspension components. Due to shocks responding most noticeably to velocity, a dynamic test must be used to assess the damper's performance. The test procedure decided upon for this research uses accelerometers to measure the sprung mass motion in response to a drop test. Using a controlled drop method, a middle ground was found between the expensive and bulky floor shaking methods, and the inconsistent push test methods. Seismic accelerometers are highly sensitive to vibrations and can be outfitted in a system that requires no direct attachments at the time of testing. The test unit can be an independent box that is mounted on the wheel well, thus making it portable. This test procedure proved to be capable of reliably detecting worn shocks. The final test method is easy to administer and is only a fraction of the cost of existing testers. 


\section{CHAPTER 2}

\section{METHODOLOGY}

\subsection{Introduction}

From the introductory discussion, there were several methods to tests suspensions, without removing any components. These different methods all require a dynamic test procedure which involves energizing the suspension and performing an analysis of the dynamic response. Once an excitation method is decided upon, the dynamic response can be modeled to ascertain meaningful characteristics. The dynamic model will provide the groundwork for acquiring appropriate sensors to observe the pertinent states. An improved dynamic test method and new instrumentation will then be used to acquire data to statistically analyze the robustness and effectiveness of the system.

In an attempt to keep operating cost low and the use of time efficient, two main methods for input excitation were considered. First, the concept of the push test was analyzed. This method is extremely easy to perform on vehicles with soft suspensions, and there is no operating cost if no mechanical device is used. Unfortunately, this method is not reproducible, so from one test to the next there may be varying inputs, which will ultimately change the outputs. Also, for stiff suspensions, pushing on the bumper of a 
vehicle may be too difficult to induce enough of a vibration. This again could cause variation between tests.

The second obvious method, that could be simple and inexpensive, is a drop test. The basic idea is to raise the tire several inches off the ground, then quickly, and in a controlled manner, release the vehicle into freefall. After some debate the drop test was chosen for further analysis and development. This decision came from the premise of a reliable and repeatable method being mandatory. That being said, it would be easier to raise the vehicle and then drop it in a controlled fashion, then to push the vehicle down.

To expand on the concept, some guidelines were decided upon. First, the drop height must be high enough to give the system enough energy to produce several full cycles. Second, the height must be kept below some maximum value to avoid excessive roll oscillations that will transfer the energy to the other tire on the axle. The idea is to test one corner of the vehicle at a time. Thus, it is desirable to try to excite the test corner in only the vertical axis. If these conditions can be met, the normally complex vehicle dynamics models can be reduced to a very simple two degree of freedom (DOF) quartercar model.

Figure 2-1 depicts an approximate model for one quarter (corner) of an automobile. In this approximation, it is assumed that two lumped masses (sprung and unsprung) represent the inertial behavior of the vehicle in the vertical (z) coordinate. The sprung mass is typically assumed to be equal to one quarter of the total vehicle mass. The unsprung mass is predominantly that of the wheel. In the simplified model of Figure 2-1 
the stiffness parameter Ks and Cs represent the stiffness and damping coefficients of the suspension:

Equation 2: 2 DOF ODEs

$$
\begin{aligned}
& M_{s} \ddot{Z}_{s}+C_{s} \dot{Z}_{s}+K_{s} Z_{s}=C_{s} \dot{Z}_{u}+K_{s} Z_{u}+F \\
& M_{u} \ddot{Z}_{u}+C_{s} \dot{Z}_{u}+\left(K_{s}+K_{t}\right) Z_{u}=C_{s} \dot{Z}_{s}+K_{s} Z_{s}+K_{t} Z
\end{aligned}
$$

If the tire is properly inflated, the resonance corresponding to the unsprung mass oscillation (so-called hop frequency) is distinctly higher than the resonance that is characteristic of the vehicle body oscillating on the suspension. This behavior lead to the conclusion that at lower frequencies the system behaves like a single degree of freedom system such as the one shown in figure 2-2:

Equation 3: 1 DOF ODE

$$
M \ddot{Z}+C \dot{Z}+K Z=F
$$

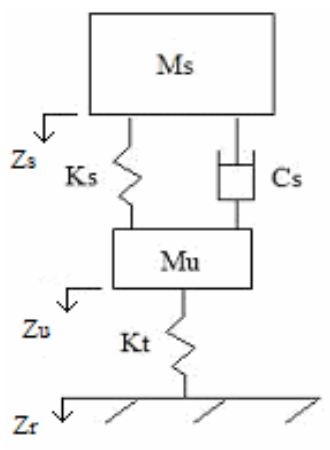

Figure 2-1: Two DOF Quarter-Car Model

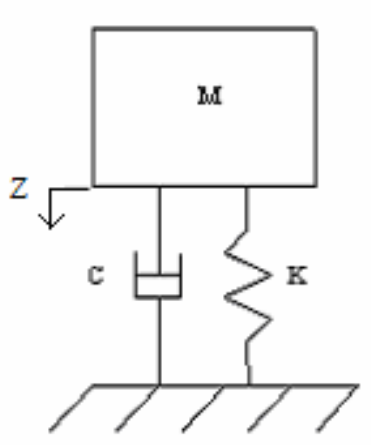

Figure 2-2: One DOF Model 
Figure 2-3 illustrates the frequency responses corresponding to the system of Figure 2.1. Here several input types are considered. For clarification, $\mathrm{Z}$ is the sprung mass displacement, $M$ is the sprung mass, $F_{b}$ is a force on the body, $Z_{r}$ is a road displacement input, and $\mathrm{F}_{\mathrm{w}}$ is a force on the wheel. A drop test is similar to a force on the body, i.e. $F_{b}$, if the system is looked at from the time of impact. At this point in time, the sprung mass has momentum, and the change in momentum is a force on the system [16].

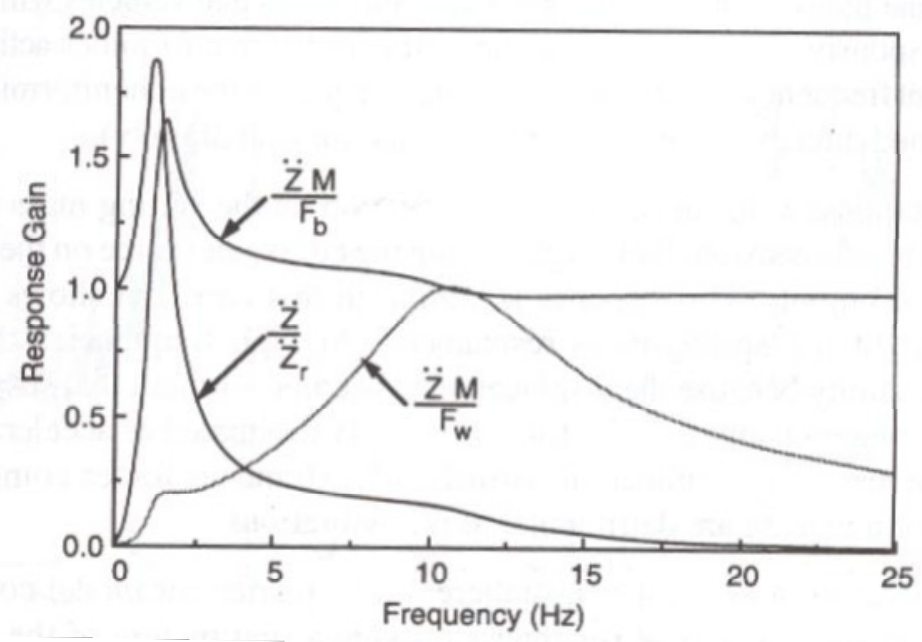

Figure 2-3: Quarter-car Response to Road, Tire, and Body Inputs [16]

The assumption of a 1 DOF approximation was explored to ensure model simplification is appropriate. Figure 2-4 shows just how comparable the 1 and 2 DOF systems are in the frequency domain. The difference in the two comes after the sprung mass resonance at $1.5 \mathrm{~Hz}$. Here, the $2 \mathrm{DOF}$ model has a slightly slower roll-off. By using a low pass filter, this higher frequency gain can be reduced to achieve the same acceleration response as the 1 DOF system. The transfer functions for these systems are 
given in Equations (4) and (5), along with the parameters used to obtain the associated frequency response (Table 2-1).

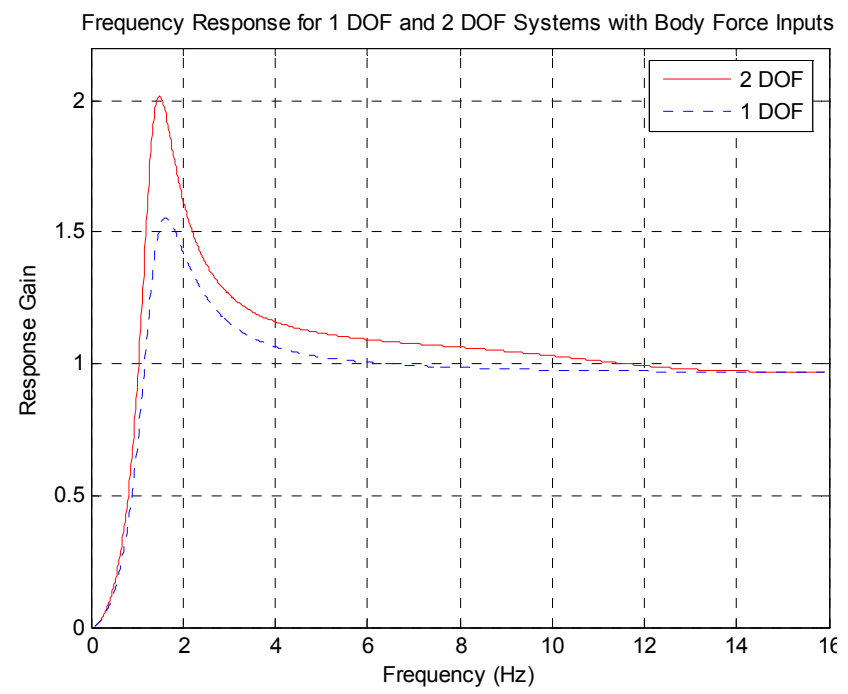

Figure 2-4: Sprung Mass Acceleration Response Gains to Body Force Inputs

To further expand on the plausibility of 1 DOF approximation, it is good practice to compare the system poles and zeros. This method is looking to see that the system behaves as a second order system would. For this type of mechanical system 1 degree of freedom will imply second order response, which is further described in Section 2-3. For a second order system, there exists theory to describe its degree of damping by log decrement analysis. In order to confidently use log decrement analysis on a response to a drop test the poles and zeros of the transfer functions must exhibit certain behavior. The poles and zeros for the transfer functions are given in Table 2-2. 
$\frac{\ddot{Z}}{F}=\frac{s^{2}}{M s^{2}+C s+K}$

Equation 4: 1 DOF Acceleration

$$
\frac{\ddot{Z}_{s}}{F}=\frac{s^{2}\left[M_{u} s^{2}+C_{s} s+\left(K_{s}+K_{t}\right)\right]}{M_{u} s^{4}+\left(M_{s}+M_{u}\right) C_{s} s^{3}+\left[M_{s}\left(K_{s}+K_{t}\right)+M_{u} K_{s}\right] s^{2}+C_{s} K_{t} s+K_{s} K_{t}}
$$

Equation 5: 2 DOF Acceleration

\begin{tabular}{|l|l|}
\hline Description & Value \\
\hline Sprung Mass & $\mathrm{Ms}=340 \mathrm{~kg}$ \\
\hline Unsprung Mass & $\mathrm{Mu}=80 \mathrm{~kg}$ \\
\hline Damping Constant & $\mathrm{Cs}=2.25 \mathrm{kN} /(\mathrm{m} / \mathrm{s})$ \\
\hline Spring Stiffness & $\mathrm{Ks}=31.2 \mathrm{kN} / \mathrm{m}$ \\
\hline Tire Stiffness & $\mathrm{Kt}=3120 \mathrm{kN} / \mathrm{m}$ \\
\hline
\end{tabular}

Table 2-1: System Parameters

The main concern is the 2 DOF model. Here the poles at $(-2.33 \pm 8.33 i)$ are dominant. These poles are almost identical to the poles for the 1 DOF model, which explains their similar behavior. The less influential poles at (-28.8 $\pm 70.7 \mathrm{i})$ are not only far enough away to be neglected, but are also lying almost on top of the zero at (28.1 $\pm 72.7 \mathrm{i}$ ). Both of these properties of the second pole pair render the effect of these poles nearly imperceptible [22]. Thus the 2 DOF representation can be approximated as second order. 


\begin{tabular}{|l|l|l|}
\hline & 1 DOF Acceleration & 2 DOF Acceleration \\
\hline Zeros & $\{0,0\}$ & $\{-28.1 \pm 72.7 \mathrm{i}, 0,0\}$ \\
\hline Poles & $\{-2.96 \pm 8.56 \mathrm{i}\}$ & $\{-2.33 \pm 8.33 \mathrm{i},-28.8 \pm 70.7 \mathrm{i}\}$ \\
\hline
\end{tabular}

Table 2-2: Poles and Zeros for the Two Models

The acceleration in response to an impulse was explored to see the differences between models in the time domain. Figure 2-4 shows the two outputs very nearly overlapping, except for the transients at the first peak for the 2 DOF model. These higher frequency vibrations are from the wheel hop mode. This could also be seen as the effect of the non-dominant pole pair. As stated before, these higher frequency vibrations can be eliminated by the use of a low-pass filter.

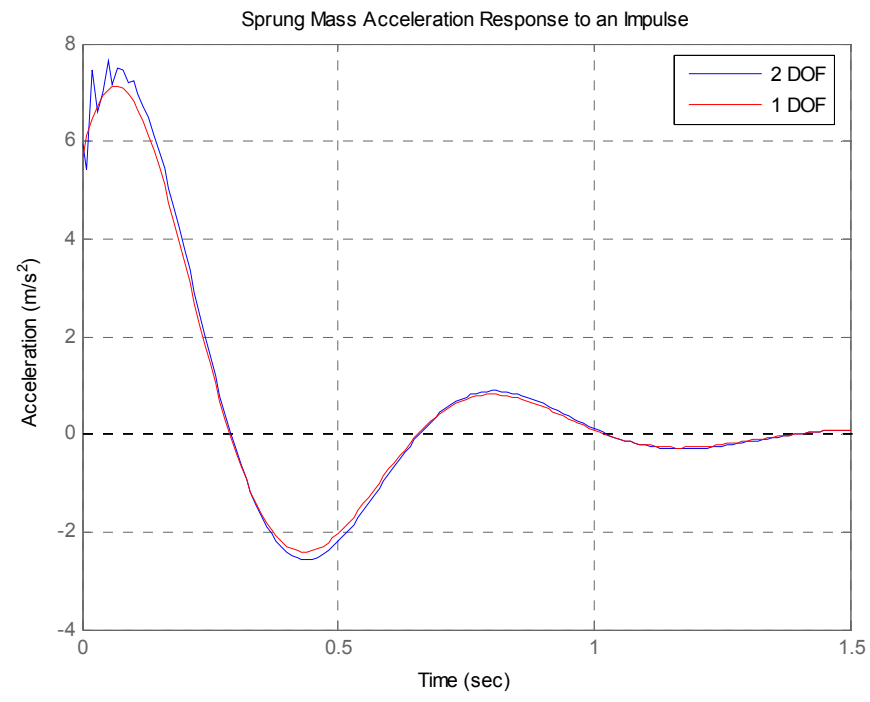

Figure 2-5: Acceleration Impulse Response

Based on these observations it is reasonable to consider a single damping parameter, Cs, to represent the damping effect of the entire suspension. Once the 
acceleration data is obtained, it will contain high frequency vibrations. We will implement a low-pass filter to attenuate the response above $4 \mathrm{~Hz}$. This will be discussed in more detail in Section 2-3. The data will then resemble a 1 DOF response, and it will be interpreted based on the results for a second order system.

With an idea of the response that should be seen, the instrumentation could be acquired. It should be noted that accelerometers were quickly of interest since the onset of micro electro-mechanical systems (MEMS) technology has greatly reduced their cost, and their accuracy is not compromised. Since the accelerometer is seismic, it does not need the type of attachments that most displacement sensors require. It could, in fact, be all contained in a small box if desired. MEMS accelerometers will thus be the transducer used in this analysis.

The next step was to develop a prototype for the dropping mechanism which could be used on the test vehicle. The idea was to develop something that raises one tire by the axle, which keeps the suspension essentially at its trim value. Once raised, the mechanism should be able to instantaneously drop the corner to give a free fall, which will help in test repeatability. The test vehicle has both front and rear solid axles, which provide a good surface to support the vehicle by a buckling member. This led to the fabrication of the "buckling knee" pictured in Figure 2-6. The buckling knee can support the weight of the vehicle. A cord at the hinge of the knee is pulled to cause the knee to buckle, thereby giving a freefall. 


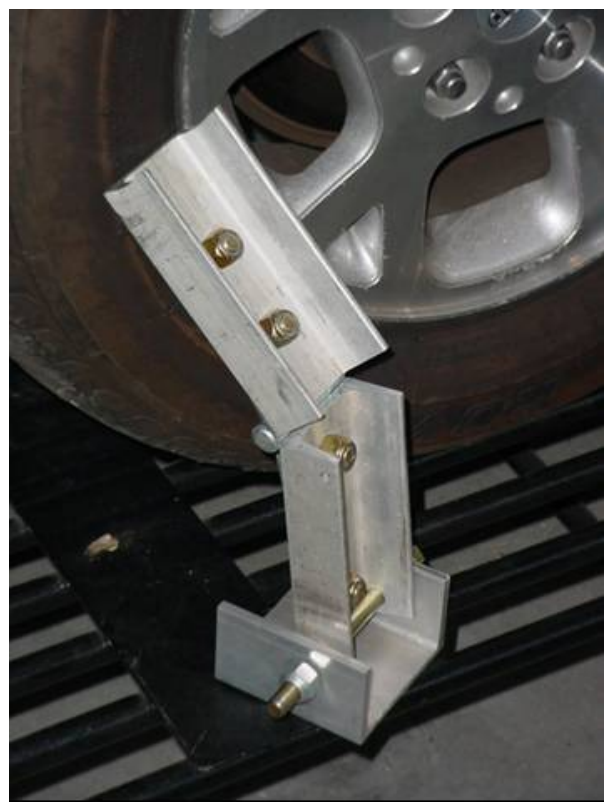

Figure 2-6: "Buckling Knee" - Instant Drop Mechanism

The final procedure is to raise the vehicle, by its axle, with a hydraulic floor jack. The knee is then placed underneath the axle, as near the test tire as possible. The floor jack is then slowly lowered until the axle rests solely on the knee. The drop height was adjusted with shims so the tire was approximately 2.5 inches off the ground. Once the vehicle was stable on the knee, the test is ready to be run.

\subsection{Data Acquisition}

With the suspension excitation method defined, the measurement instrumentation had to be procured. The models gave some background for the types of specifications required by the transducers to further refine the methodology. The data acquisition system used a laptop with LabVIEW ${ }^{\mathrm{TM}}$, connected to a National Instruments SC 2345 signal conditioning module carrier via a PCMCIA card. The three transducers used were a Space Age Instruments String Potentiometer with 12 inches of travel, an Analog 
Devices ADXL 202 AQC MEMS accelerometer, and a Sensotec Strain Gage Accelerometer. All required a 5 volt DC power supply. The MEMS accelerometer had a $\pm 2 \mathrm{~g}$ range, and its output was proportional to acceleration $(320 \mathrm{mV} / \mathrm{g})$. The strain gage accelerometer had a $\pm 5 \mathrm{~g}$ range and its output was also in proportion to the acceleration, however it had a much lower sensitivity $(6.986 \mathrm{mV} / \mathrm{g})$.

The main instrument of concern is the MEMS accelerometer. This is due to its cost being about $10 \%$ of the strain gage accelerometer, and $1 \%$ of the string pot. For the final system, the goal is to use the inexpensive MEMS accelerometer, to record the response of a quarter of the vehicle to a short, quick drop. The transducers are mounted on the wheel well with a bracket and suction cups like pictured in Figure 2-7. This record will then be post processed to see if a useable method of analysis is possible.

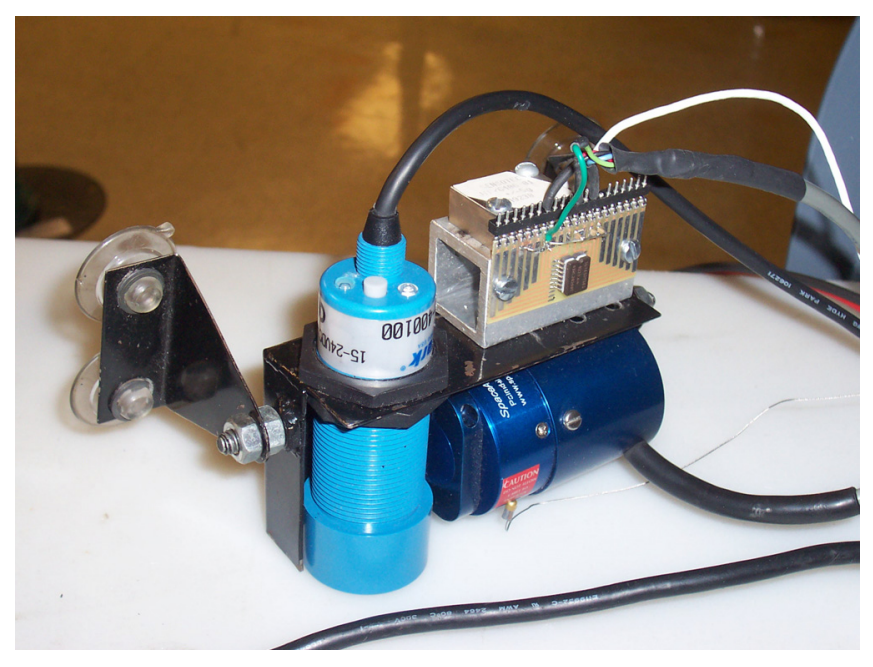

Figure 2-7: Test Instrumentation Affixed to Suction Bracket. 


\subsection{System Response}

The drop test provides a response that is comparable to the quarter-car model. The response yields essentially two frequency modes: one for the body motion resonance, and one for the wheel hop mode. Chapter 3 gives numerous FFTs that display these frequency modes. In order to characterize the damper, it would be beneficial to calculate some sort of parameter that is directly related to the damping capabilities. From theory, there is the well defined log decrement analysis which calculates the damping ratio for a transient that displays a decaying sinusoidal characteristic. For a second order system, the damping ratio is the parameter that incorporates the damping constant, seen below.

Rewriting Equation (4) in standard form gives:

$$
\frac{\ddot{Z}}{F}=\frac{K s^{2}}{\frac{s^{2}}{\omega_{n}}+\frac{2 \zeta}{\omega_{n}} s+1}
$$

Equation 6: Standard Form for $2^{\text {nd }}$ Order System

Where:

$$
\begin{aligned}
& \omega_{n}=\sqrt{\frac{K_{s}}{M_{s}}}=\text { Natural Frequency }(\mathrm{rad} / \mathrm{sec}) \\
& . \zeta=\frac{C_{s}}{2 \sqrt{K_{s} M_{s}}}=\text { Damping ratio (unitless) }-[12] \\
& \mathrm{K}=\text { system gain }
\end{aligned}
$$


Transforming the acceleration transfer function to the time domain gives [13]:

$$
\ddot{X}_{b-i m p u l s e}(t)=\frac{-K A \omega_{n}}{\sqrt{1-\zeta^{2}}} e^{-\sigma t}\left[\sigma^{2} \sin \left(\omega_{d} t\right)-\omega_{d}{ }^{2} \sin \left(\omega_{d} t\right)-2 \sigma \omega_{d} \cos \left(\omega_{d} t\right)\right]
$$

Equation 7: Exponentially Decaying Sinusoidal Acceleration for a $2^{\text {nd }}$ Order System

Where:

$$
\begin{aligned}
& \ddot{X}_{b-\text { impulse }}=\text { Sprung mass impulse response - acceleration }\left(\mathrm{m} / \mathrm{sec}^{2}\right) \\
& \omega_{n}=\text { Undamped natural frequency }(\mathrm{rad} / \mathrm{sec}) \\
& \zeta=\text { Damping ratio (unitless) } \\
& \omega_{d}=\omega_{n} \sqrt{1-\zeta^{2}}=\text { Damped natural frequency }(\mathrm{rad} / \mathrm{sec}) \\
& \sigma=\zeta \omega_{n}=
\end{aligned}
$$$$
\mathrm{KA}=\text { Gain Amplitude (m) }
$$

$\omega n$ can be approximated, and different $\zeta$ values can be inserted to view the response. It should be noted that $\zeta$ must fall between zero and one. Figure $2-8$ gives a plot of the splane which is useful in visualizing where the poles and zeros lie when only given the characteristic equation. 


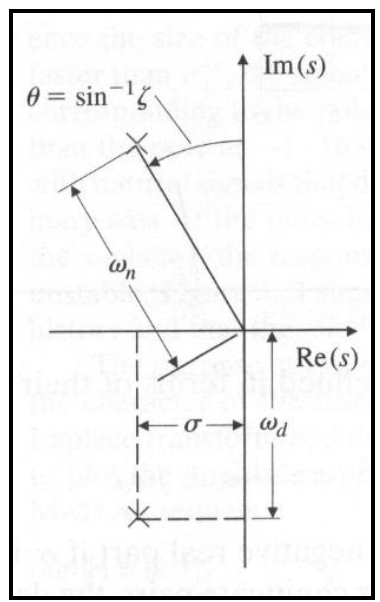

Figure 2-8: s-plane Plot of Imaginary Parameters [15]

The damping ratio, $\zeta$, in Equations (6) and (7) can be calculated from a plot, such as Figure 2-9, using Equations (10) and (11). This is known as the log decrement method [14]

$\zeta=\sqrt{\frac{\delta}{\left(4 \pi^{2}+\delta^{2}\right)}}$

Equation 8: Damping Ratio

Where $\delta$ is the Log Decrement defined as:

$\delta=\frac{1}{(n-1)} \ln \left(\frac{a_{i}}{a_{i+n}}\right)$

Equation 9: Logarithmic Decrement

$\underline{a}_{\mathrm{i}}=$ The magnitude of the peak with respect to the trim height

$n=$ Total number of peaks used in the log decrement calculation 
This calculation will yield a number that is descriptive of the rate of decay. Notice that the ratio used must be either a ratio of minima or maxima peaks to get a value that would yield a similar response if it were used in Equation (7). In the data post processing the damping ratio will be calculated for several different peak combinations to try to decipher the peak ratio that will give the most repeatable measurement of the dampers actual state. Looking at Figure 2-8, the ratio of peak a2 to a4 will be found. As will a3 to a5. Other variations of the ratio will be calculated as well, such as the ratio of peaks a2 to $\mathrm{a} 3$, and a3 to $\mathrm{a} 4$, but note these ratios will yield a value that does not produce a similar curve if used in Equation (7). Even though the log decrement calculation can use the ratio between one peak and a peak several cycles later, only subsequent peaks will be used because stiff suspensions will not realistically see more than two full cycles. So for all instances, 'n' from Equation (9) will equal two.

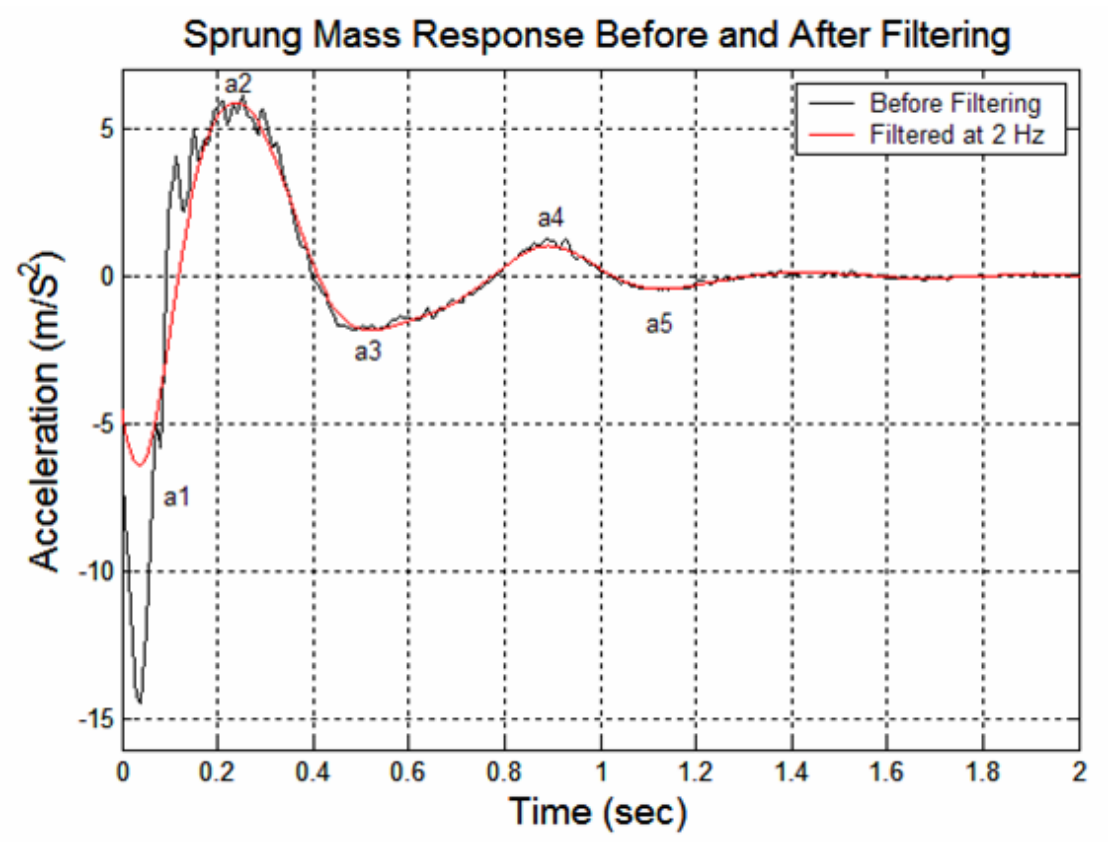

Figure 2-9: Labeled Peaks for the Typical Acceleration Response 


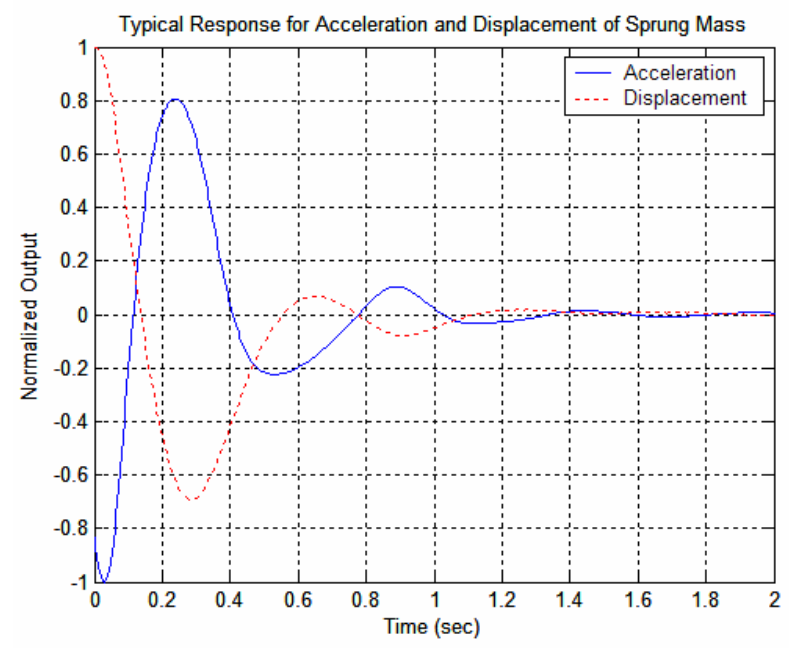

Figure 2-10: Relationship between Acceleration and Displacement from a Drop Test

Figures 2-9 and 2-10 are taken from actual drop tests. Figure 2-9 shows the response before and after filtering. The filtering takes place in MATLAB using a second order low-pass Butterworth filter with a $4 \mathrm{~Hz}$ cutoff frequency. It was then implemented using MATLAB's 'filtfilt' function. This is a function that filters forward and backward to achieve zero phase shift.

When the accelerometer signal is filtered, it essentially eliminates the wheel hop mode, leaving only the sprung mass mode which is well approximated as a 1 DOF system. Figure 2-10 shows the string potentiometer output as displacement and the filtered MEMS accelerometer output. This is given to illustrate the similarity in the two responses, and to give understanding of the position of the sprung mass for the acceleration cycles. In this figure a negative value is when the damper is in compression. 
When a corner of a vehicle is subjected to a drop test, its response is predominantly in the vertical axis. This one-dimensional motion allows for the suspension system to be simplified as a quarter-car model. Upon inspection, a quarter-car model's sprung mass acceleration will follow a response comparable to a 1 DOF system's inertial element. This allows second order approximation, and the use of well defined parameters to characterize the system performance. A system has been outlined to achieve an impulse response. The "buckling knee" will be placed under the axle, and then pulled to initiate a free-fall. The sprung mass acceleration will be measured by a MEMS accelerometer and recorded by LabVIEW onto a laptop. This record will then be post-processed in MATLAB to filter out the high frequency vibrations and then use logdecrement analysis to calculate the damping ratio. The damping ratio value will determine if the damper is performing as it should. 


\section{CHAPTER 3}

\section{EXPERIMENTAL RESULTS}

\subsection{Introduction}

In order to validate the measurement system and methodology prescribed in the previous chapter, the following tests were conducted. The number of tests runs for the situation being described is given in parentheses.

1. Test the vehicle with the adjustable dampers on high (x10) and low (x30) stiffness settings.

2. Run tests from various drop heights to see if there is an optimal range of heights. The drop height is defined as the distance between the tire and the ground. The heights were chosen after some observation to see what was simply too low of a height since the system would barely oscillate, and what was too high in that the system was rolling an excessive amount. The drop heights chosen were 1 in (x 10), 2.5 in (x 30), and 4 in (x 10).

3. Robustness tests:

a. Test the vehicle with low pressure in the tire of the test corner (x 30).

b. Test the vehicle with a failed damper on the same axle but on the opposite side from the test corner (x 30). 
4. Install new shocks all around, except the test corner will be equipped with the shocks of different degrees of damping from oil loss (3 drained dampers, 30 tests each). Also, the damper with the known mechanical failure will be included in this group (x 30).

5. A test clinic will be conducted with random Jeep Grand Cherokees from the model years 1999-2004. These vehicles will be first tested with there original suspension systems to see if any relation to mileage can be inferred. After the initial tests, they will all be outfitted with new shocks to see if the test system can detect any improvement, and to attempt to set a range of acceptable performance quantities (18 Jeeps were subjected to this before and after testing).

To eliminate as many variables from the test procedure as possible several precautions were taken prior to each test. The test vehicle was kept indoors at approximately $70^{\circ} \mathrm{F}$. The corner to be tested was oscillated for one minute to warm to damper. Finally, the tire pressure was set to manufacturer specifications of 33 psi, except, of course, during the low tire pressure tests.

For all the drop tests discussed in this chapter there are three plots of interest. In post processing, an average waveform of the filtered and unfiltered signals were calculated. This was done by aligning the signals at their drop point, then averaging each point to get one characteristic signal for the thirty drops. For illustration, Figure 3-1 has the 30 unfiltered test responses and the mean waveform all lined up using their drop time. Notice they are all very similar and resemble essentially one curve. This plot also has the 
filtered waveform to see its effect. The filtered waveform has essentially all the same features, except the initial spike is smoother, and the ripples due to wheel hop are eliminated.

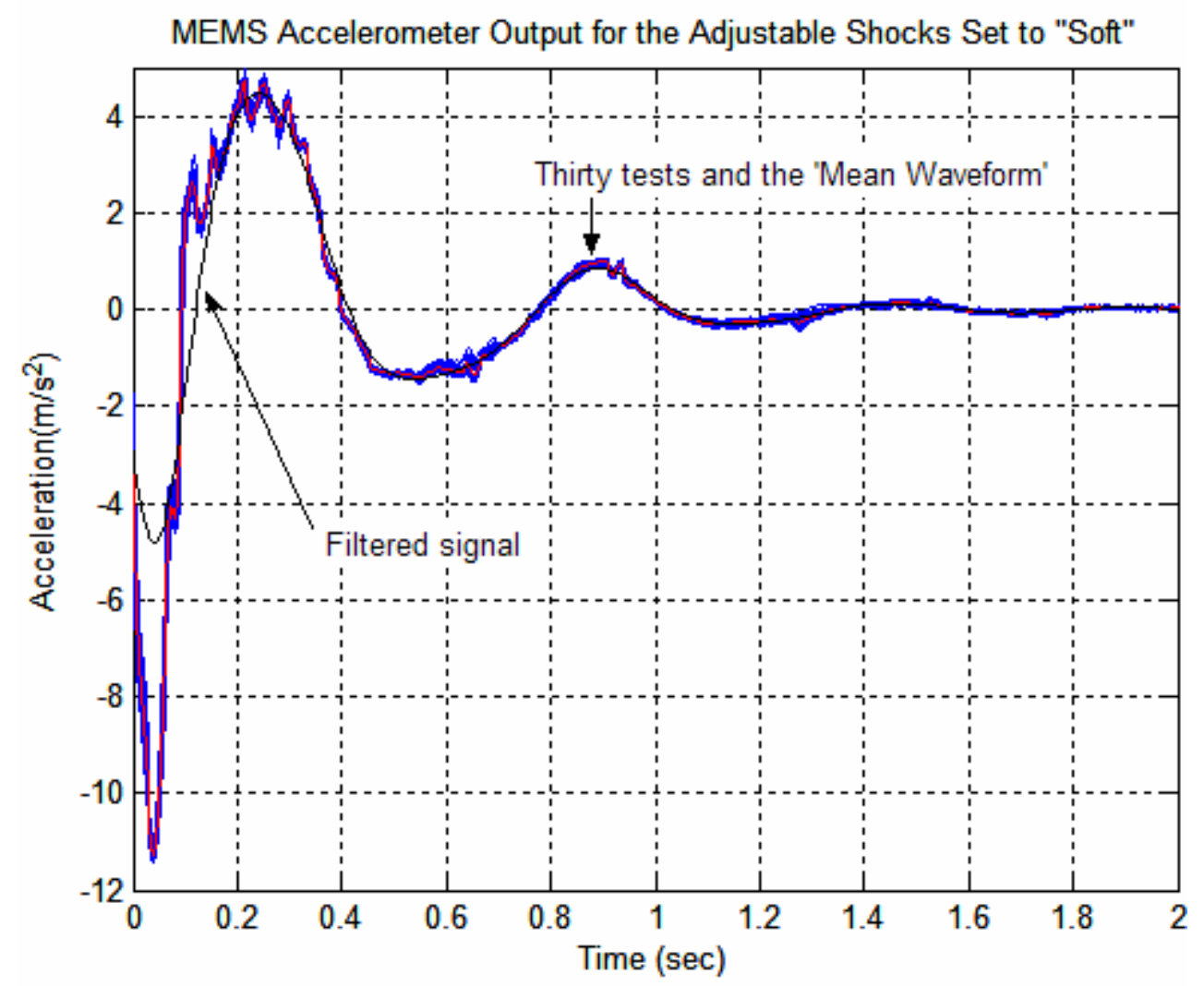

Figure 3-1: Demonstrating the Predictability of the Drop Test Vibrations

The third plot is a Fast Fourier Transform (FFT) of the unfiltered acceleration. This plot is used to demonstrate the resonant peaks seen in the frequency domain. They all will generally have a large spike at the sprung mass resonance frequency, which is nominally $1.5 \mathrm{~Hz}$. The next spike is at approximately $10 \mathrm{~Hz}$ for the wheel hop mode. 
After the plots, a table of statistics is given. The table compiles the damping ratios which are calculated for the filtered signals. They list four zeta (damping ratio) values. "Zeta 1" is from the log decrement between peaks a1 and a3, "Zeta 2" is between a2 and a4, "Zeta 3" is for a3 and a5, etc. This table gives the average and standard deviation for the sample. It also gives the coefficient of variation, $\mathrm{Cv}$, which is the standard deviation divided by the mean to get a percent of variation [18]. The table also lists the minimum and maximum values to show the spread of the data.

\subsubsection{Adjustable Damper Results}

With the adjustable dampers installed, multiple tests were run. The difference between the soft and stiff settings, variation of the drop height, and the system robustness tests were all performed with the adjustable dampers. They will be assessed one at a time.

\subsubsection{High and Low Stiffness}

These tests were run with the adjustable damper set to its stiffest setting, then to its softest setting (for a picture of the damper see Figure 1-9). By turning the knob on the base of the damper, the base valve orifices are adjusted to change the degree of flow constriction. Thirty runs were made at each setting, and Figure 3-2 shows all the test runs superimposed. Notice how the soft setting attenuates the wheel hop vibrations more than the stiff setting. Clearly, the soft setting oscillates longer as well. This will be seen in the damping ratio calculations, which are compiled in Table 3-1. From this table, Zeta 2 is the most repeatable, based from its low coefficient of variation. These values show a $35 \%$ decrease in damping ratio between the stiff and soft setting. 
Figure 3-3 shows after the signal was filtered, which makes it easier to see the difference in decay rates. The FFT (Figure 3-4) shows similar properties between the two settings' resonances.

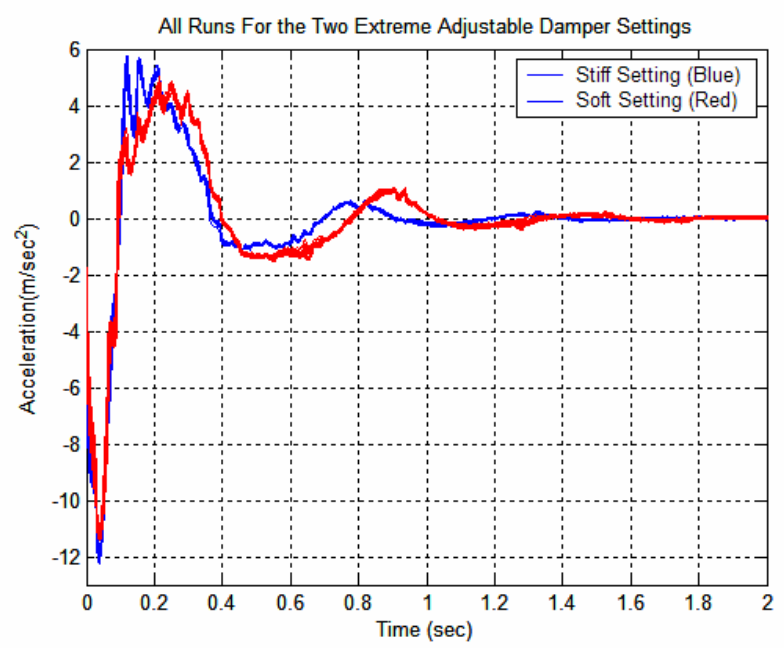

Figure 3-2 Unfiltered Adjustable Damper Response

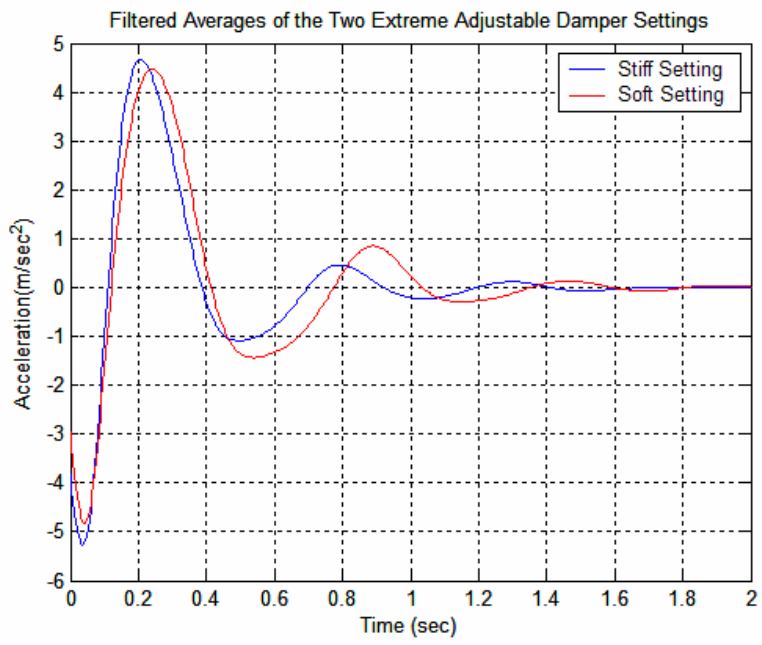

Figure 3-3 Filtered Adjustable Damper Response 


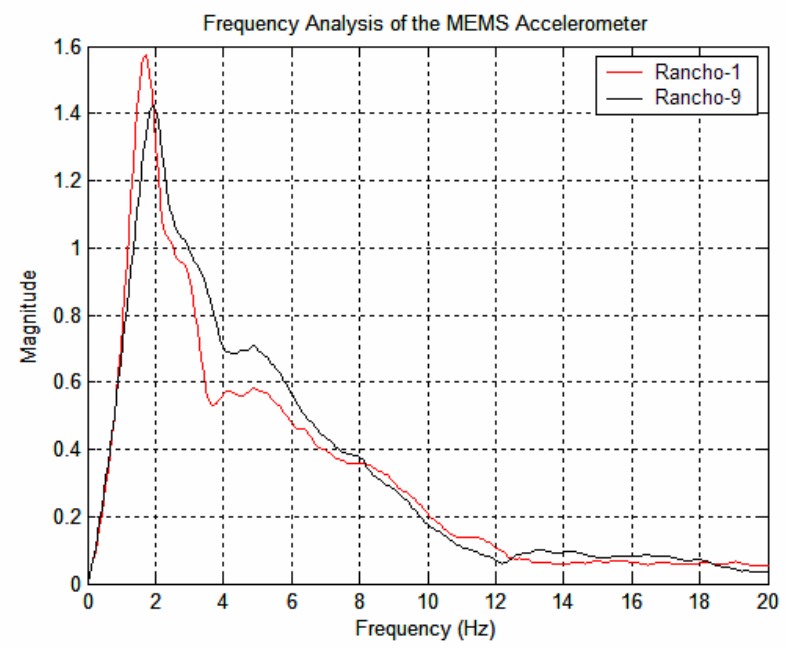

Figure 3-4 FFT of the Adjustable Damper

\begin{tabular}{|c|c|c|c|c|c|}
\hline & & Zeta 1 & Zeta 2 & Zeta 3 & Zeta 4 \\
\hline \multirow{5}{*}{$\begin{array}{l}\frac{\hbar}{0} \\
\text { ம }\end{array}$} & AVG & 0.189 & 0.255 & 0.243 & 0.292 \\
\hline & STDEV & 3.98E-03 & 7.37E-03 & 1.48E-02 & 2.19E-02 \\
\hline & $\mathrm{Cv}$ & 2.099 & 2.885 & 6.093 & 7.514 \\
\hline & MIN & 0.182 & 0.243 & 0.215 & 0.258 \\
\hline & MAX & 0.197 & 0.271 & 0.265 & 0.343 \\
\hline \multirow{5}{*}{ 豊 } & AVG & 0.244 & 0.346 & 0.240 & 0.217 \\
\hline & STDEV & 6.68E-03 & $5.49 \mathrm{E}-03$ & 1.91E-02 & $2.37 \mathrm{E}-02$ \\
\hline & $\mathrm{Cv}$ & 2.742 & 1.588 & 7.955 & 10.924 \\
\hline & MIN & 0.234 & 0.338 & 0.214 & 0.176 \\
\hline & MAX & 0.257 & 0.357 & 0.267 & 0.242 \\
\hline
\end{tabular}

Table 3-1: Damping Ratios and Statistics for the Adjustable Dampers

\subsubsection{Varying Drop Height}

Figure 3-5 shows the mean waveforms for the three different drop heights. They all appear similar in nature. The main difference is the amount of energy imposed into the system, thus the magnitudes are different. This can be seen in all three plots. However, the damping ratio remains relatively unchanged. Table 3-2 gives the statistics, and again Zeta 2 is showing the most repeatable values. Zeta 1 is repeatable, but the value given is small and not characteristic of the type of response 
decay rate that theory predicts. If the Zeta 1 value were put into Equation (7), the response would not die out as quickly as is seen in the actual system. Zeta 2, on the other hand, would produce a response very similar to Figure 3-6. The Zeta 1 value is not a good representation of the systems true decay rate. This is because Zeta 1 uses peaks a1 and a3. The peak al is actually the impact when the tire hits the ground, thus the suspension has not begun to respond, and the peak should not give a value meaningful to the suspension performance. Also, it is known from literature that the values should fall between 0.20 and 0.40 [16].

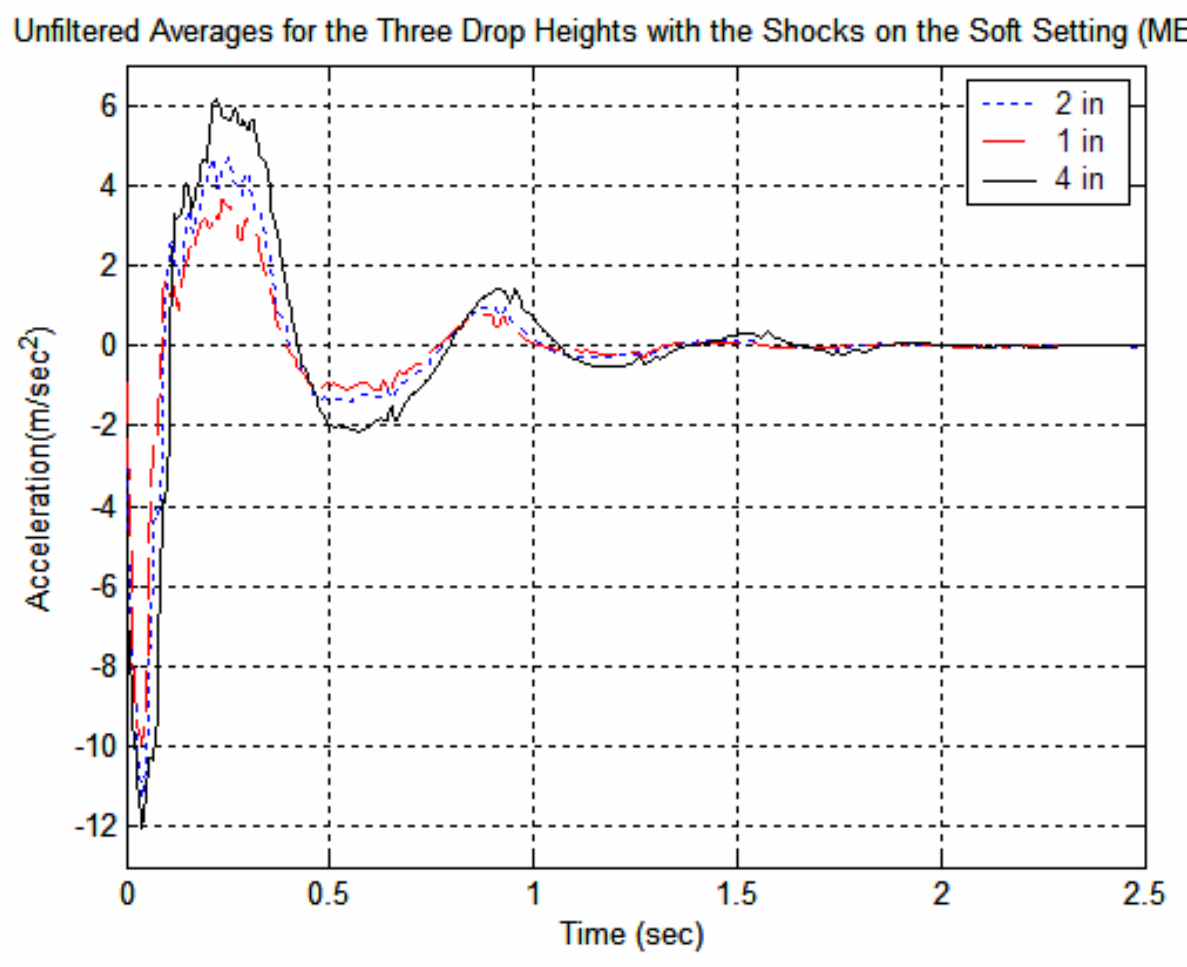

Figure 3-5 Unfiltered Response from Three Drop Heights 


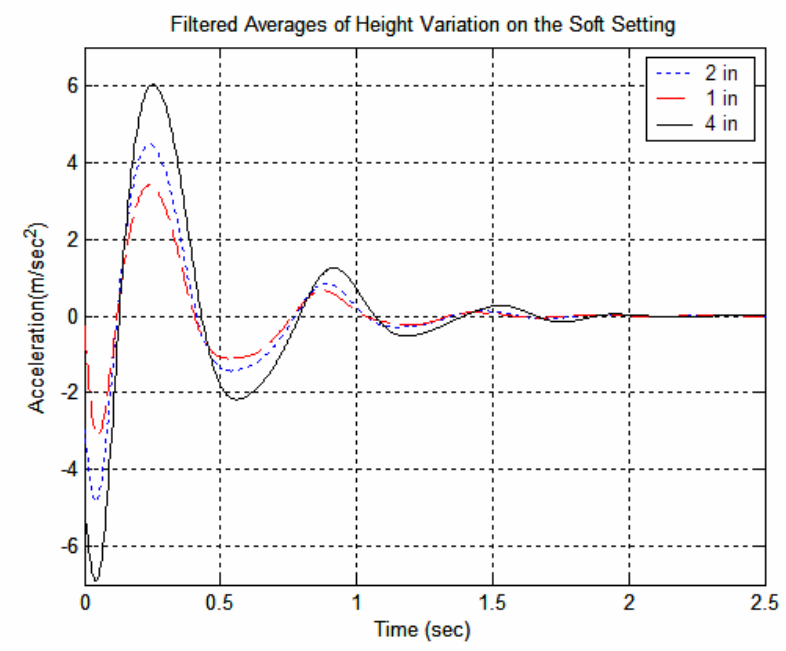

Figure 3-6 Filtered Response from Three Drop Heights

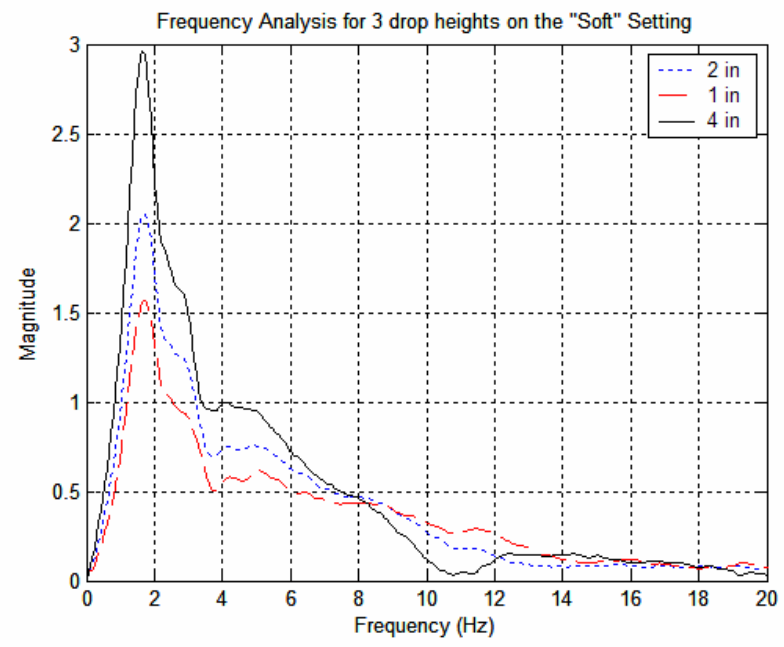

Figure 3-7 FFT of Responses from Three Drop Height 


\begin{tabular}{|c|c|c|c|c|c|}
\hline & & Zeta 1 & Zeta 2 & Zeta 3 & Zeta 4 \\
\cline { 2 - 6 } & AVG & 0.163 & 0.253 & 0.241 & 0.318 \\
\cline { 2 - 6 }$\Xi$ & STDEV & $2.78 \mathrm{E}-03$ & $5.33 \mathrm{E}-03$ & $1.69 \mathrm{E}-02$ & $3.81 \mathrm{E}-02$ \\
\cline { 2 - 6 } & CV & 1.704 & 2.107 & 7.004 & 11.988 \\
\cline { 2 - 6 } & MIN & 0.158 & 0.244 & 0.211 & 0.272 \\
\cline { 2 - 6 } & MAX & 0.167 & 0.260 & 0.261 & 0.387 \\
\hline \multirow{4}{*}{$\Xi$} & AVG & 0.181 & 0.243 & 0.220 & 0.240 \\
\cline { 2 - 6 } & STDEV & $2.03 \mathrm{E}-03$ & $4.38 \mathrm{E}-03$ & $9.44 \mathrm{E}-03$ & $1.31 \mathrm{E}-02$ \\
\cline { 2 - 6 } & Cv & 1.124 & 1.807 & 4.281 & 5.455 \\
\cline { 2 - 6 } & MIN & 0.176 & 0.236 & 0.205 & 0.225 \\
\cline { 2 - 6 } & MAX & 0.184 & 0.250 & 0.239 & 0.270 \\
\hline
\end{tabular}

Table 3-2: Damping Ratio Statistics for the Adjustable Damper at Various Heights

\subsubsection{System Robustness}

First, the situation with low tire pressure in the test corner will be examined. The tire pressure was set to $10 \mathrm{psi}$, approximately one-third of the manufacture's specification. Both corners of the axle had the adjustable shocks set to the stiffest setting. Immediately, the difference is obvious. The low tire pressure has affected the sprung mass response, giving larger wheel hop oscillations in the initial descent. Also noticeable from Figure 3-8, peak a3 has a perturbation in it. This is most likely due to the low tire pressure changing the ride rate of the test corner. The filtering process was not able to eliminate this disturbance which is shown in Figure 3-9. Also, using the definition of ride rate (Equation 10), the low tire stiffness will lower the overall stiffness [16]. And using the basic definition for natural frequency (Equations 6 and 7) a lower stiffness will lower the frequency, as can be seen.

The FFTs in Figure 3-10, 3-13 and 3-16 all show two resonances near the sprung mass mode. This could be from the decreased spring constant of the tire. The natural frequency is given under Equation (7) as the square root of the ratio between the spring constant and the sprung mass [16]. Using the values from Table2-1 this would give 
$\omega_{n}=9.58(\mathrm{rad} / \mathrm{sec})$ or $1.5 \mathrm{~Hz}$, which is about where the first resonant peak is seen. The second peak is at roughly $3 \mathrm{~Hz}$. All three of the robustness tests see this second resonant peak at $3 \mathrm{~Hz}$. This could be from the test side responding differently than the opposite side of the axle, so now there are two sprung mass resonances.

$$
R R=\frac{K_{s} K_{t}}{K_{s}+K_{t}}
$$

Equation 10: Ride Rate - Springs in Series

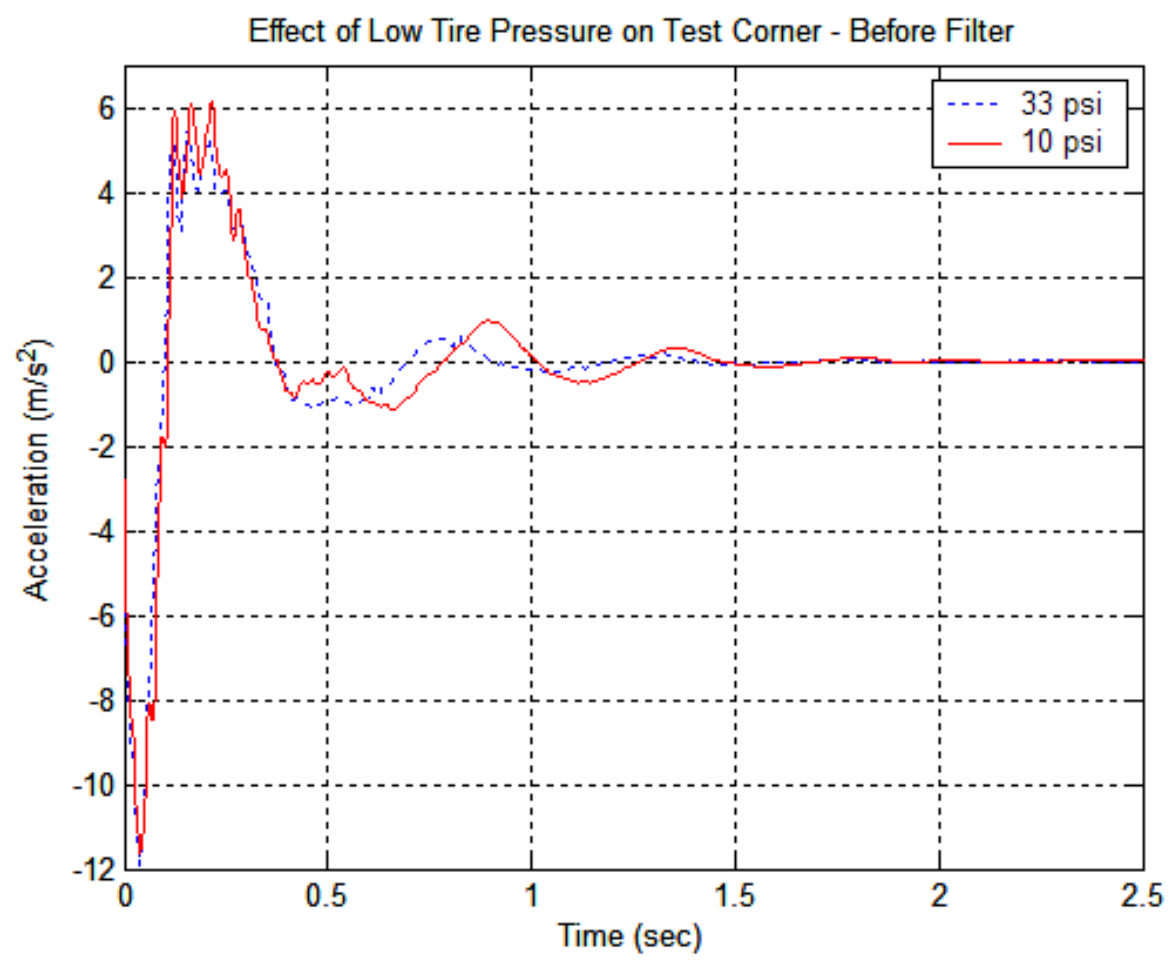

Figure 3-8: Test Corner Set to Low Tire Pressure - Before Filter 


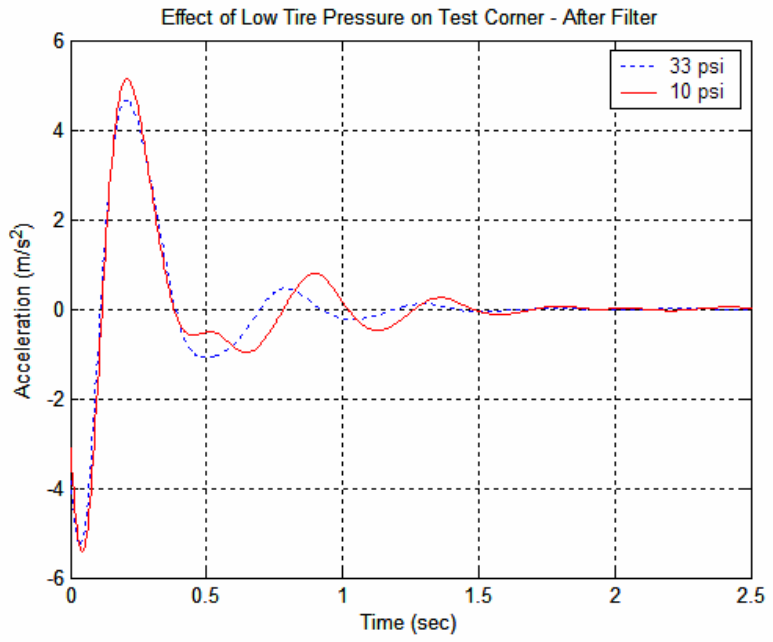

Figure 3-9 Test Corner Set to Low Tire Pressure - After Filter

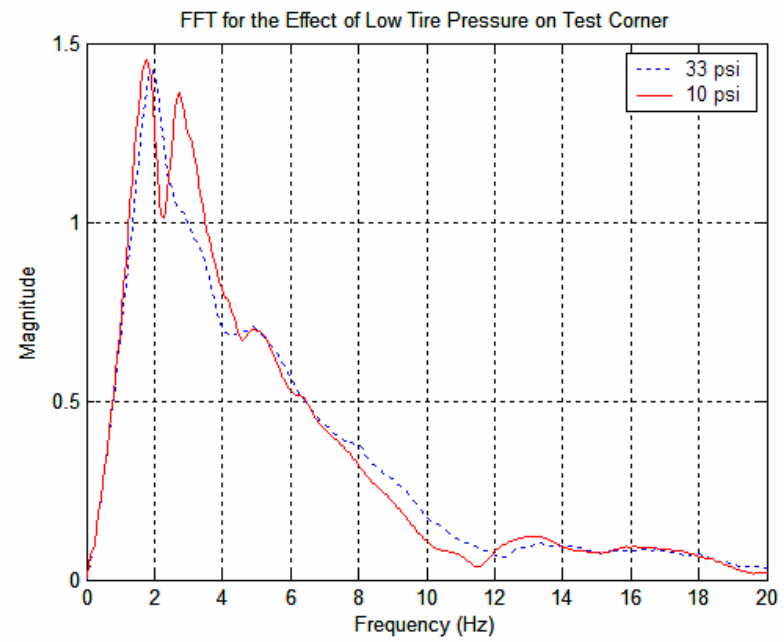

Figure 3-10 FFT of Test Corner Set to Low Tire Pressure 


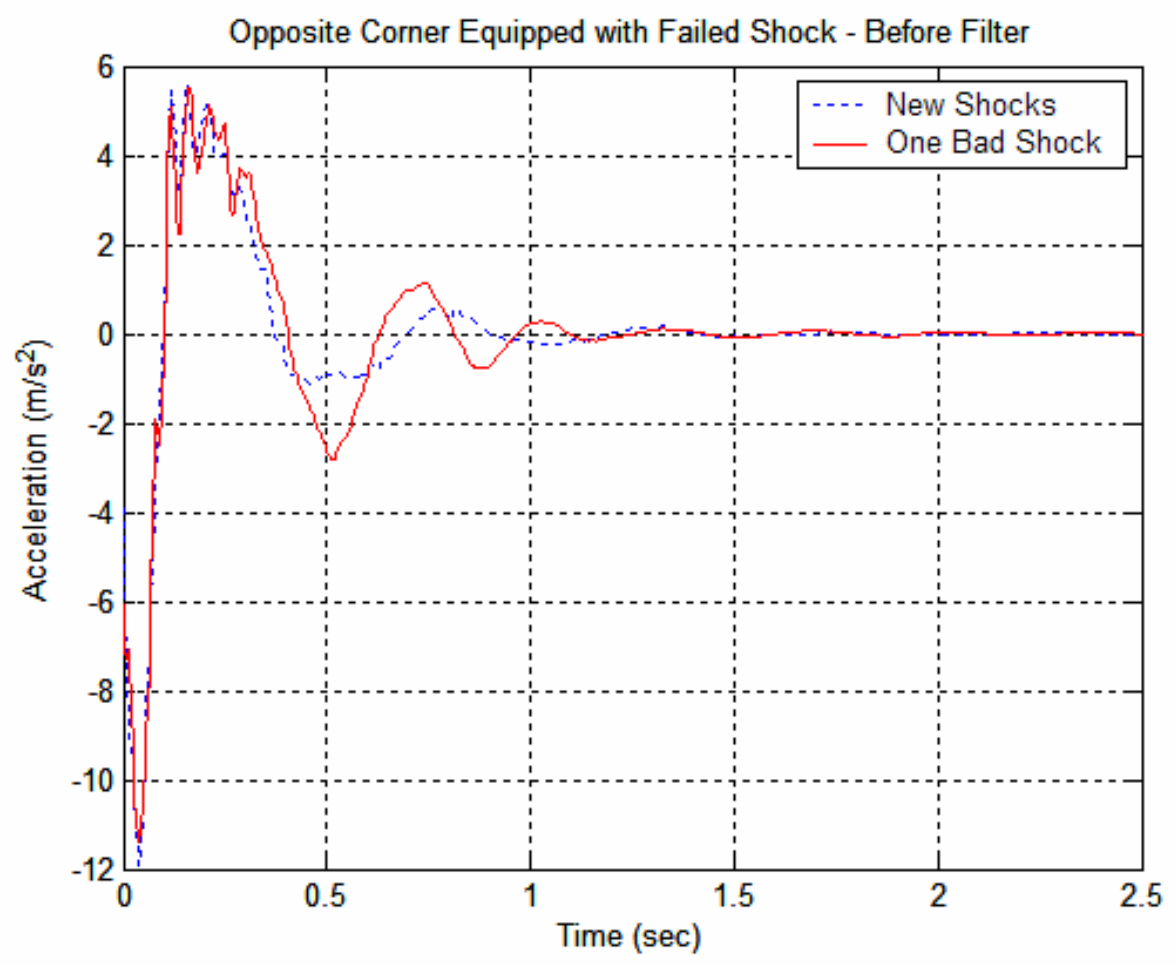

Figure 3-11 Failed Shock on Opposite Corner

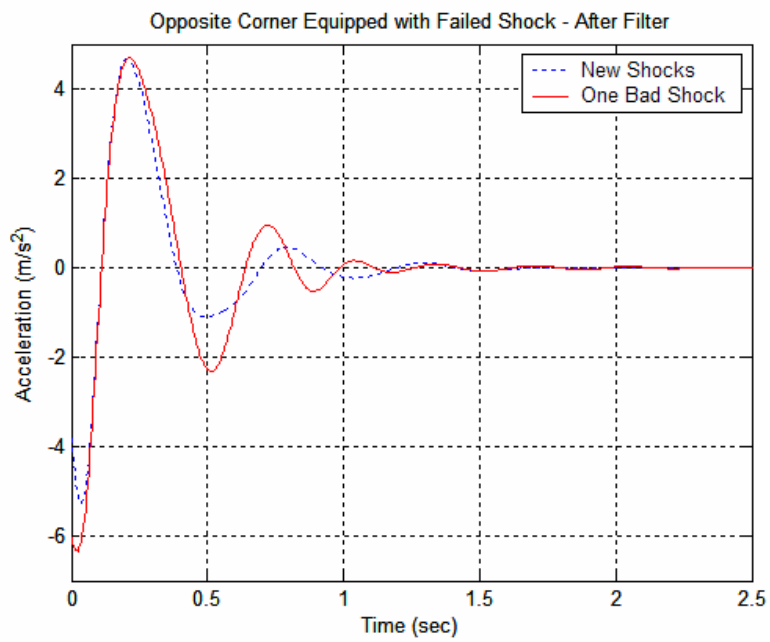

Figure 3-12 Failed Shock on Opposite Corner -Filtered 


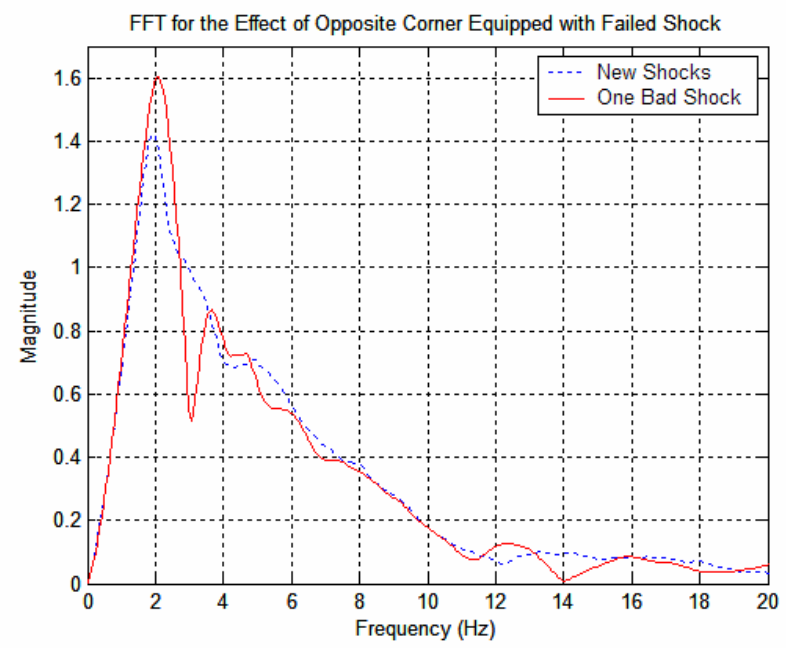

Figure 3-13 FFT of Failed Shock on Opposite Corner

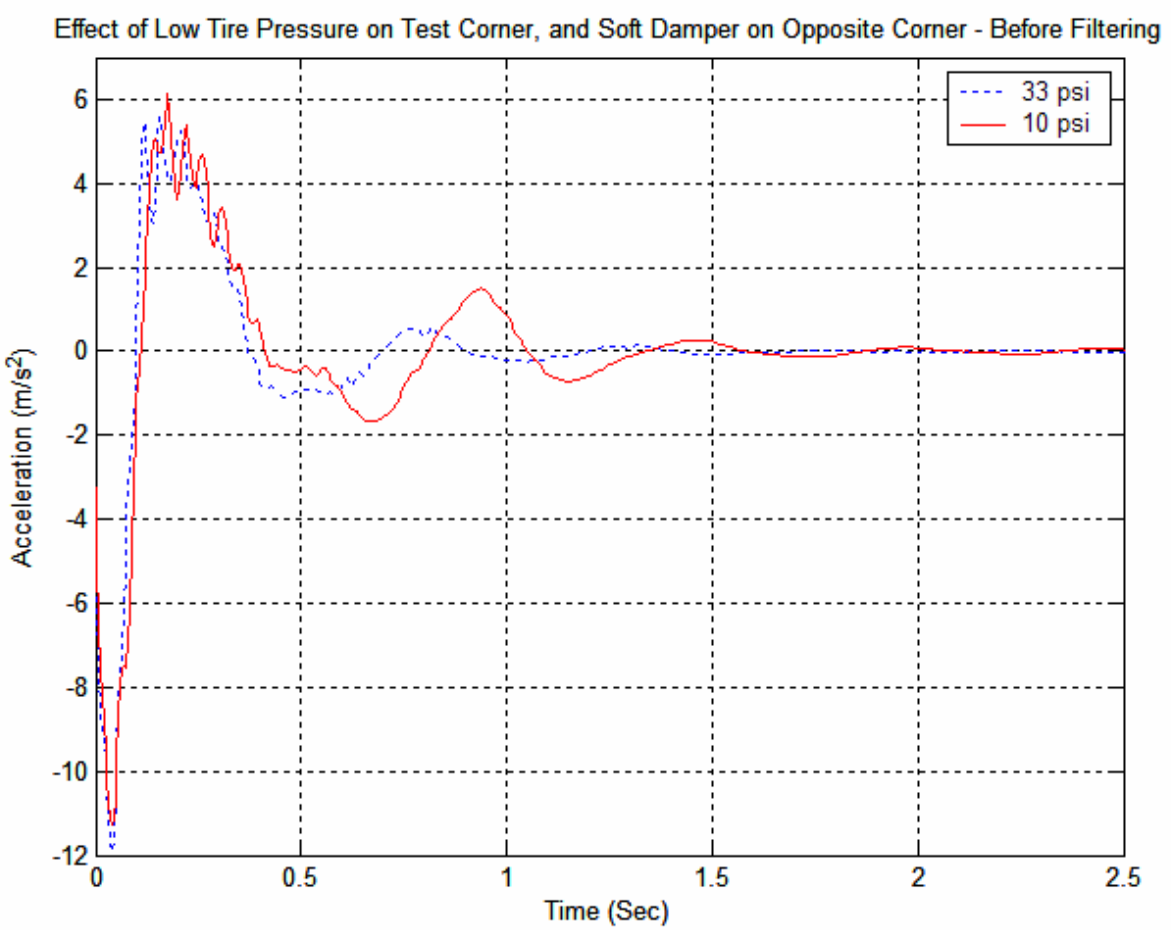

Figure 3-14: Low Tire Pressure and One Soft Damper 


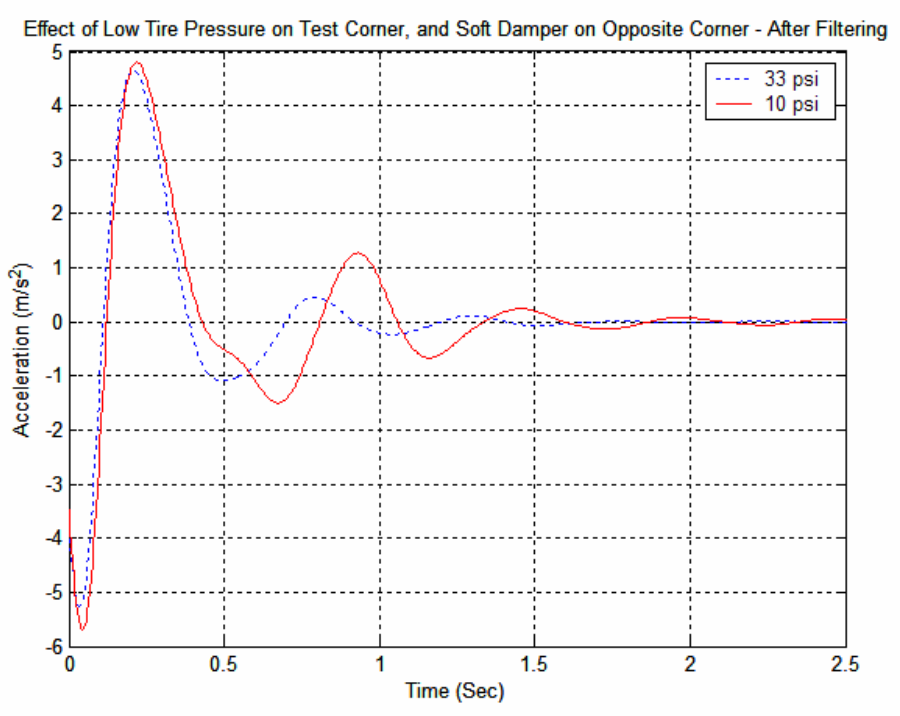

Figure 3-15: Low Tire Pressure and One Soft Damper- Filtered

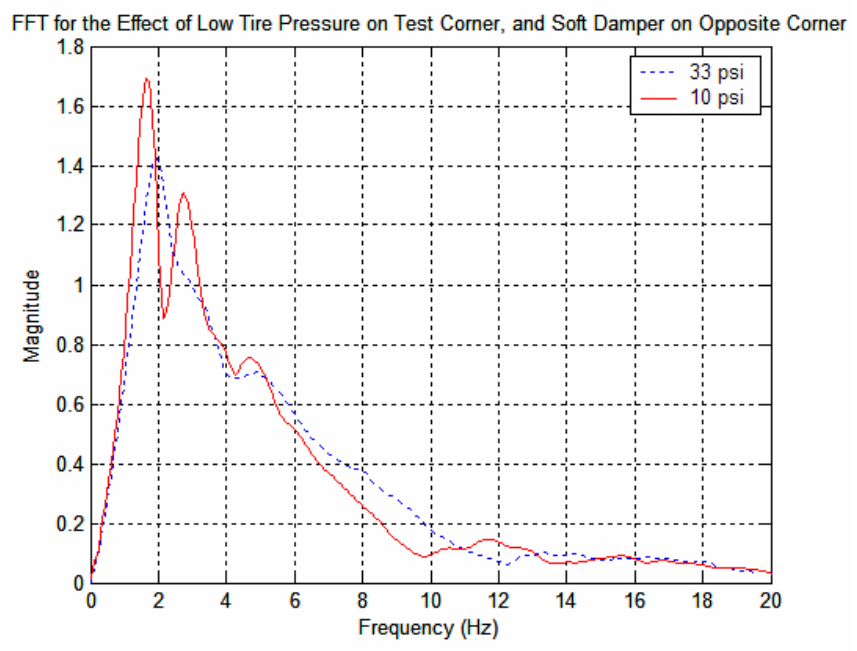

Figure 3-16: FFT of Low Tire Pressure and One Soft Damper

Figures 3-11 through 3-16 show the outputs when a bad shock is installed on the opposite corner of the axle. For this solid axle vehicle, there is a considerable affect from roll motions spreading the kinetic energy to each end of the axle. Table 3-3 tabulates the statistical data for the robustness tests. Using the "All Good" setting as the standard, the 
other three tests clearly show some drop in the damping ratio. Zeta 2 is again chosen as the most reliable value. From this table, low pressure gives the smallest change in Zeta 2, yielding a $17 \%$ drop. There is a $29 \%$ drop when the opposite corner is a much softer damper. Note that the damper used on the opposite corner is the shock drained to $25 \%$ of its original work performance. As will be seen in the next section, this is a very poor damper that recorded a 0.179 damping ratio, which is $50 \%$ lower value than the stiff setting used for the "All Good" scenario. As could be expected, the situation with low tire pressure on the test corner and a failed shock on the opposite corner saw the worst performance.

\begin{tabular}{|c|c|c|c|c|c|}
\hline & & Zeta 1 & Zeta 2 & Zeta 3 & Zeta 4 \\
\hline \multirow{5}{*}{$\begin{array}{l}8 \\
8 \\
0 \\
\overline{8}\end{array}$} & Average & 0.244 & 0.346 & 0.240 & 0.217 \\
\hline & St Dev & 6.684E-03 & 5.490E-03 & 1.907E-02 & $2.369 \mathrm{E}-02$ \\
\hline & Cv & 2.742 & 1.588 & 7.955 & 10.924 \\
\hline & Min & 0.234 & 0.338 & 0.214 & 0.176 \\
\hline & Max & 0.257 & 0.357 & 0.267 & 0.242 \\
\hline \multirow{5}{*}{ 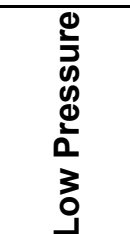 } & Average & 0.263 & 0.286 & 0.112 & 0.182 \\
\hline & St Dev & 8.965E-03 & 8.989E-03 & 9.732E-03 & $2.441 \mathrm{E}-02$ \\
\hline & Cv & 3.412 & 3.140 & 8.721 & 13.381 \\
\hline & Min & 0.237 & 0.266 & 0.087 & 0.134 \\
\hline & Max & 0.276 & 0.314 & 0.127 & 0.263 \\
\hline \multirow{5}{*}{ 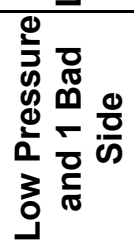 } & Average & 0.208 & 0.207 & 0.127 & 0.261 \\
\hline & St Dev & 7.903E-03 & $6.345 \mathrm{E}-03$ & 1.190E-02 & $2.706 \mathrm{E}-02$ \\
\hline & Cv & 3.805 & 3.070 & 9.374 & 10.357 \\
\hline & Min & 0.199 & 0.200 & 0.092 & 0.235 \\
\hline & Max & 0.231 & 0.222 & 0.146 & 0.348 \\
\hline \multirow{5}{*}{ 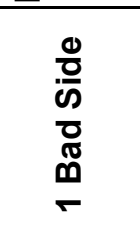 } & Average & 0.158 & 0.247 & 0.230 & 0.270 \\
\hline & St Dev & 7.593E-03 & 9.999E-03 & 1.908E-02 & $2.684 \mathrm{E}-02$ \\
\hline & Cv & 4.806 & 4.056 & 8.287 & 9.955 \\
\hline & Min & 0.144 & 0.230 & 0.149 & 0.186 \\
\hline & Max & 0.187 & 0.272 & 0.257 & 0.358 \\
\hline
\end{tabular}

Table 3-3: Calculated Damping Ratios for the Adjustable Dampers 


\subsubsection{Worn Damper Results}

For all of the worn damper test results, the force velocity curves for the dampers are given (Figures 3-17, 3-21, 3-25, 3-29). These curves come from the dynamometer test results, and show the curve for the original damper, then the curve for the damper once the oil was drained.

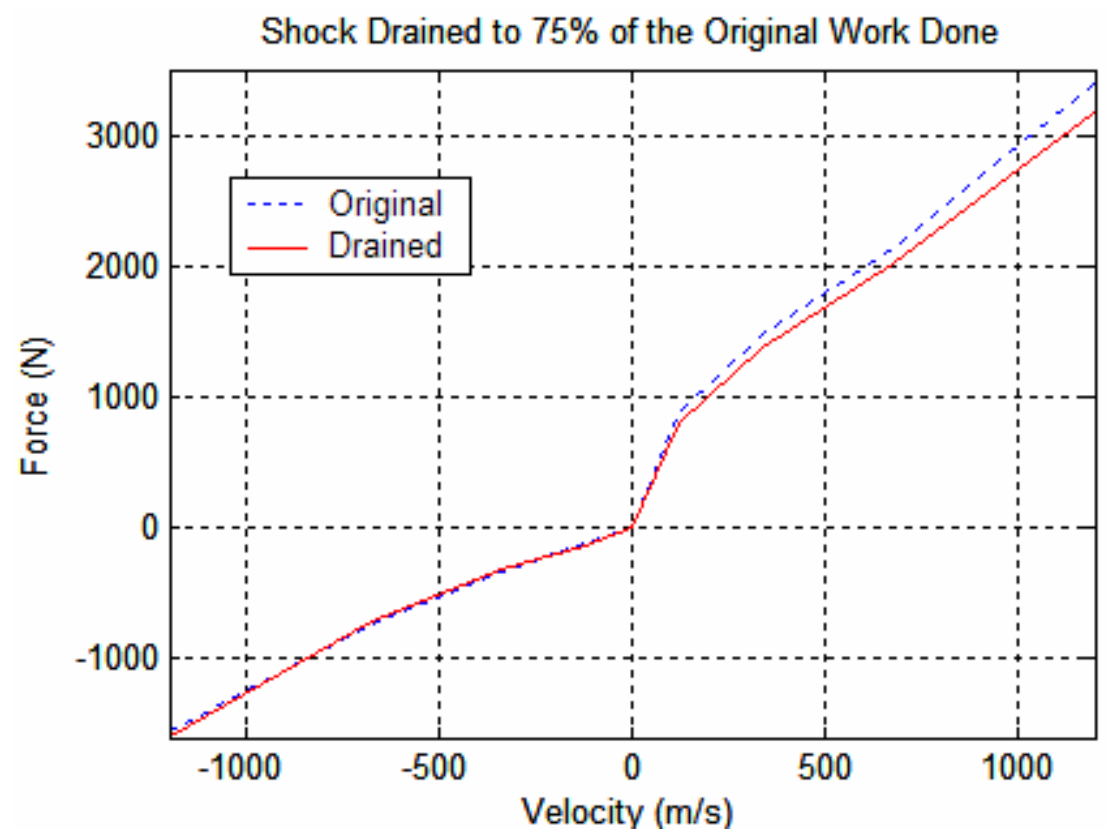

Figure 3-17: Force Velocity Data for the 75\% Damper 


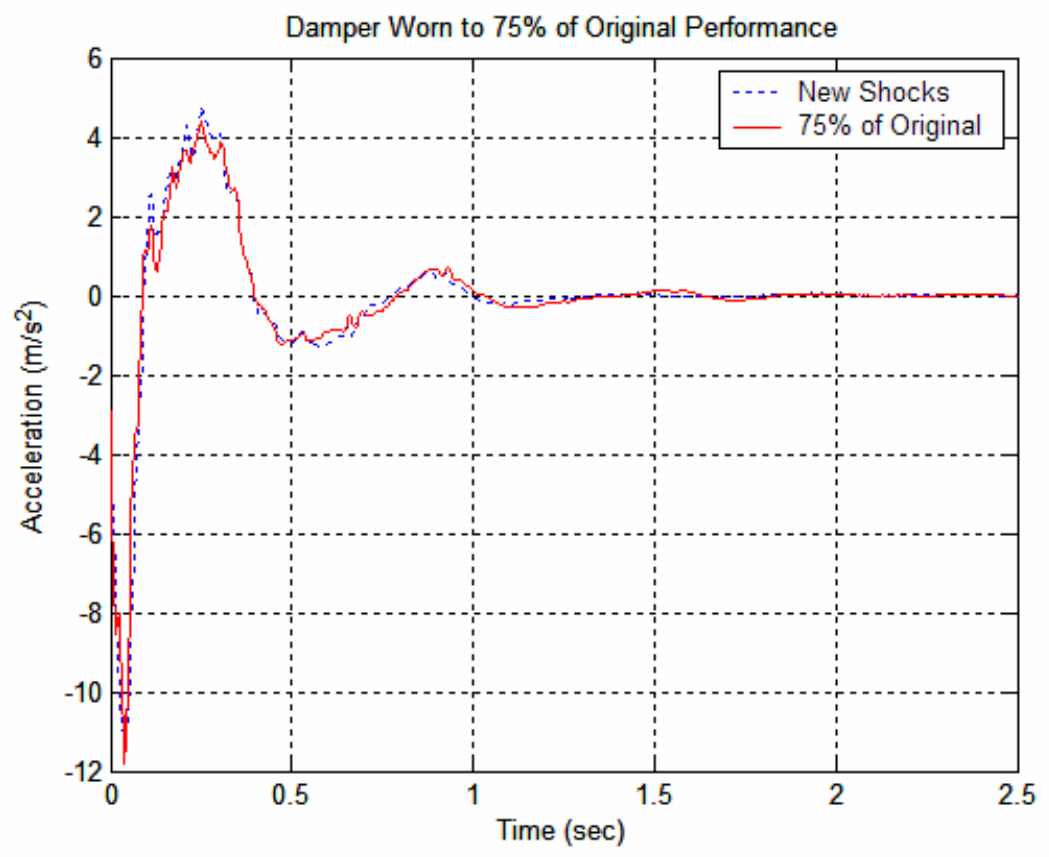

Figure 3-18 Damper Worn to 75\% of Original Damping

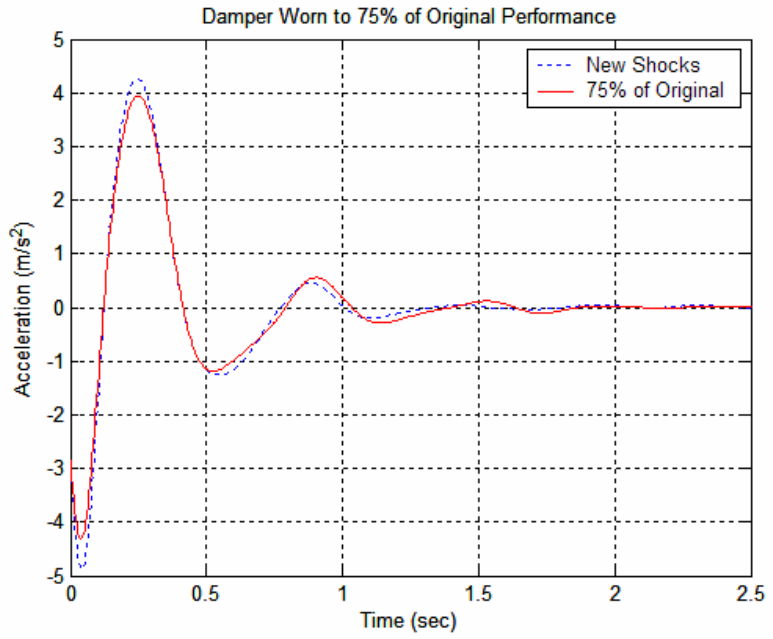

Figure 3-19 Damper Worn to 75\% of Original Damping - Filtered 


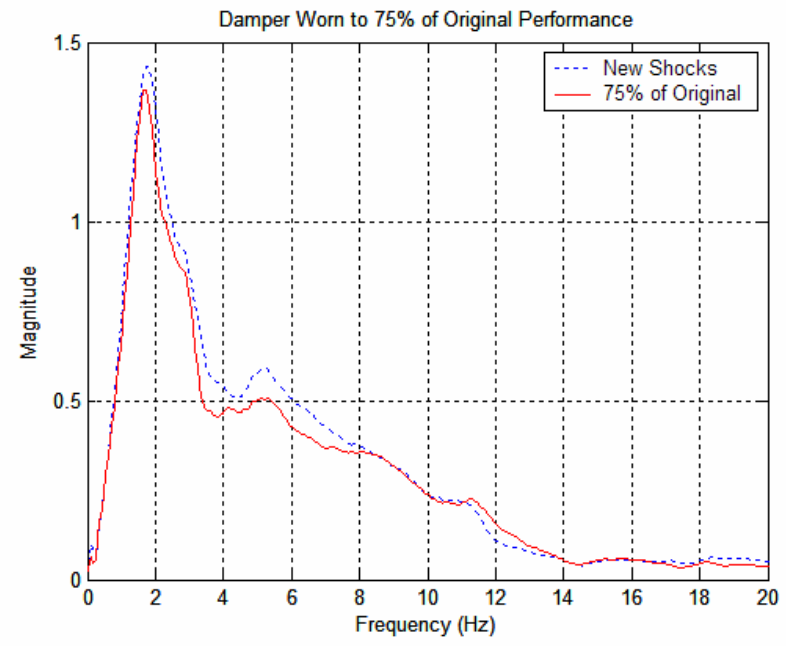

Figure 3-20 FFT of Damper Worn to 75\% of Original Damping

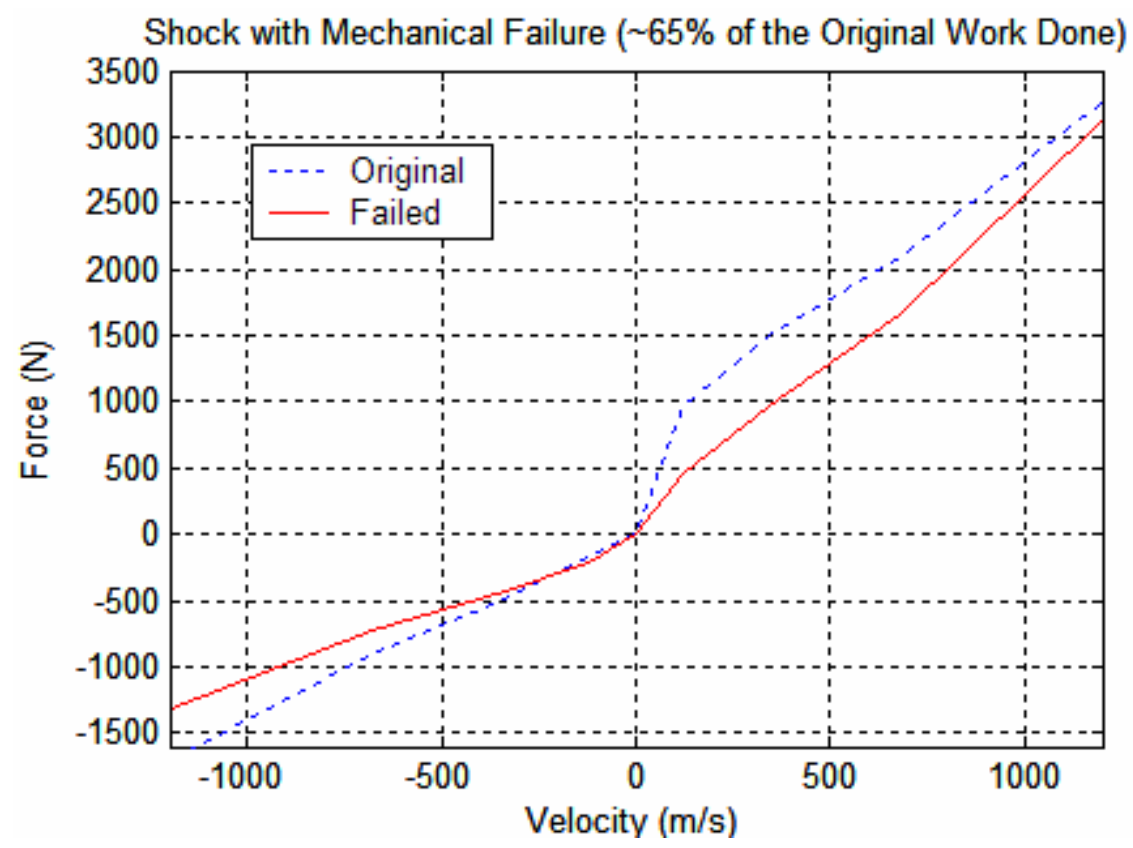

Figure 3-21: Force Velocity Data for New, but Defective Shocks 


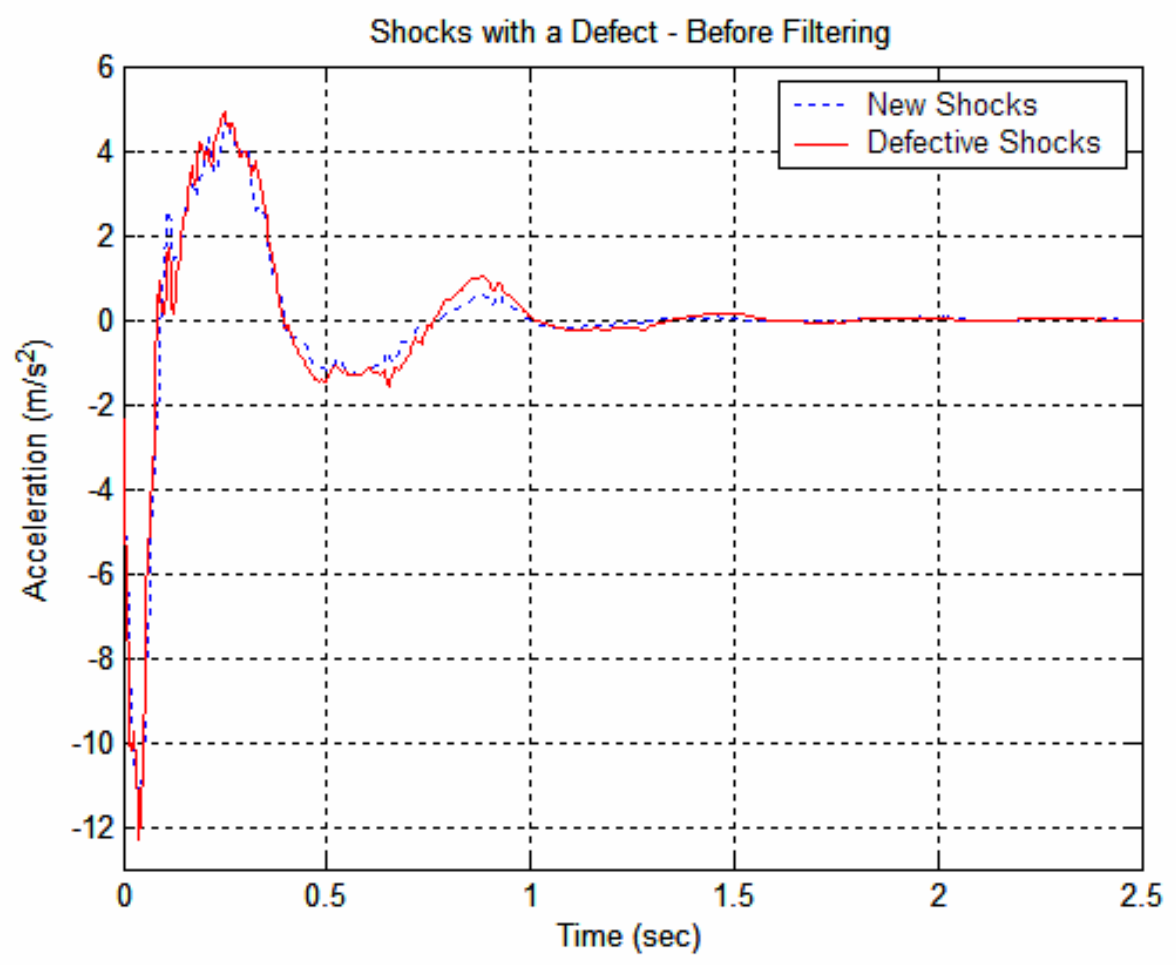

Figure 3-22 Response of New, but Defective Shocks

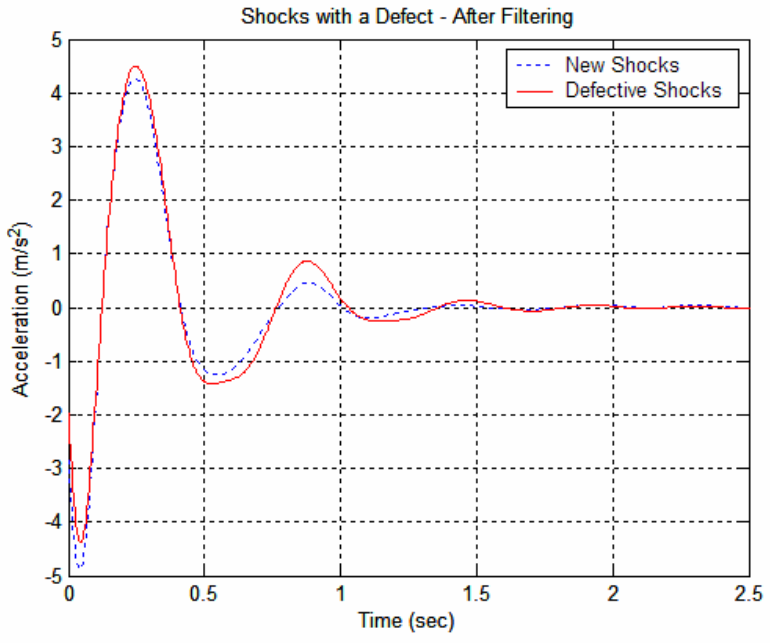

Figure 3-23 Response of New, but Defective Shocks - Filtered 


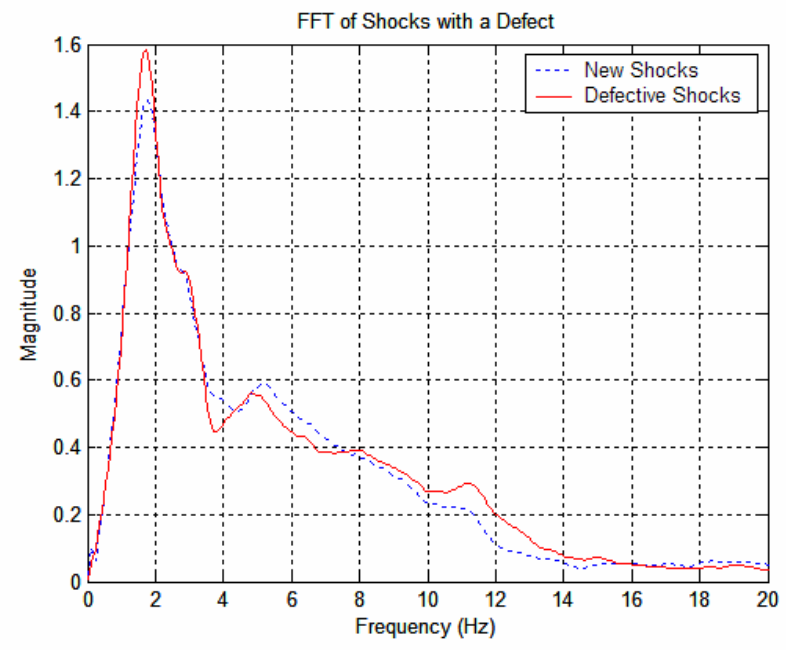

Figure 3-24 FFT of Response of New, but Defective Shocks

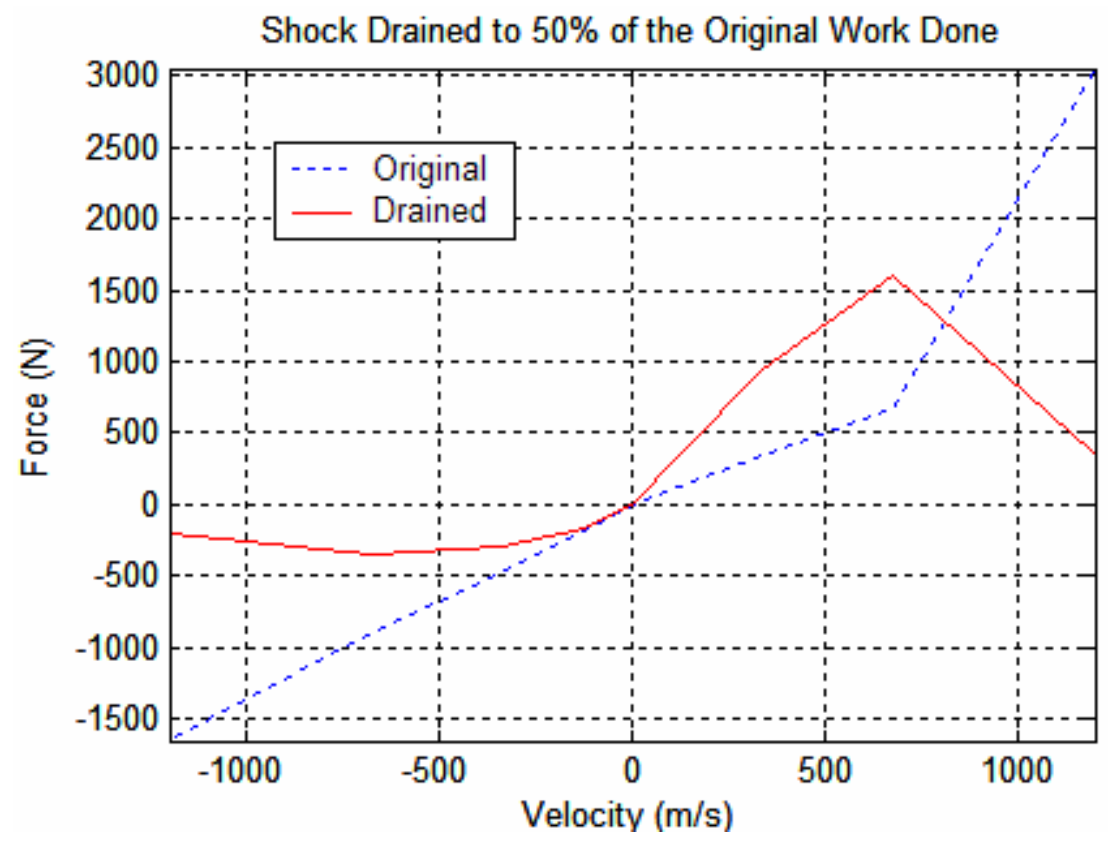

Figure 3-25: Force Velocity Data for the 50\% Damper 


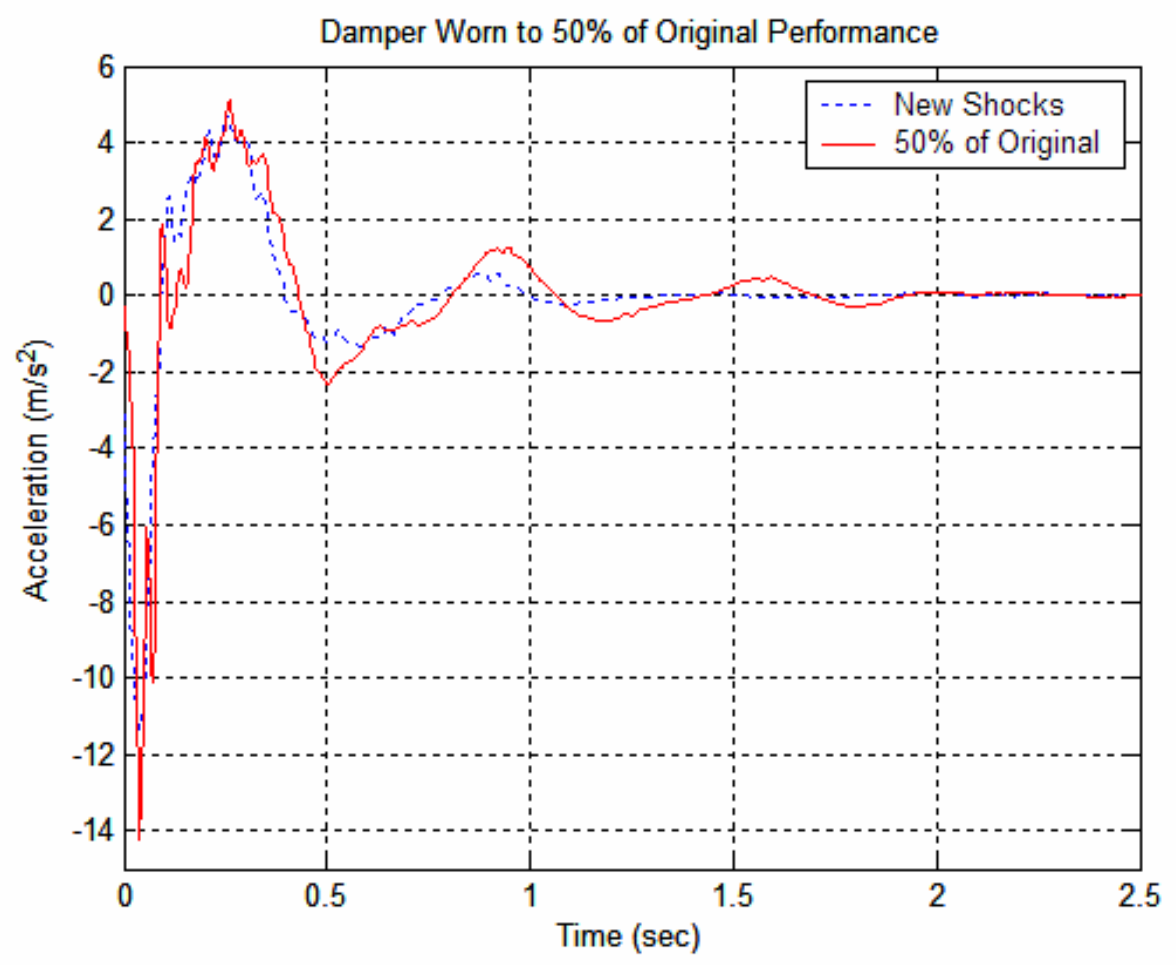

Figure 3-26 Damper Worn to 50\% of Original Damping

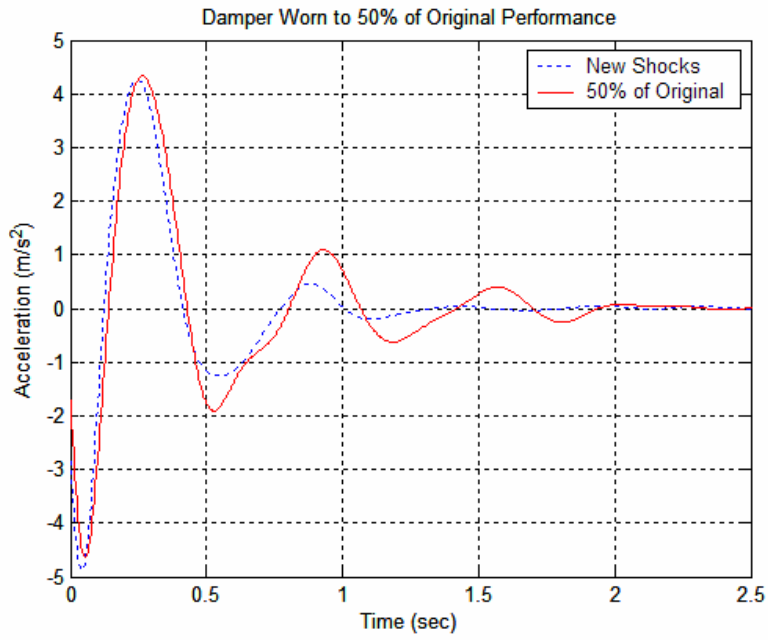

Figure 3-27 Damper Worn to 50\% of Original Damping - Filtered 


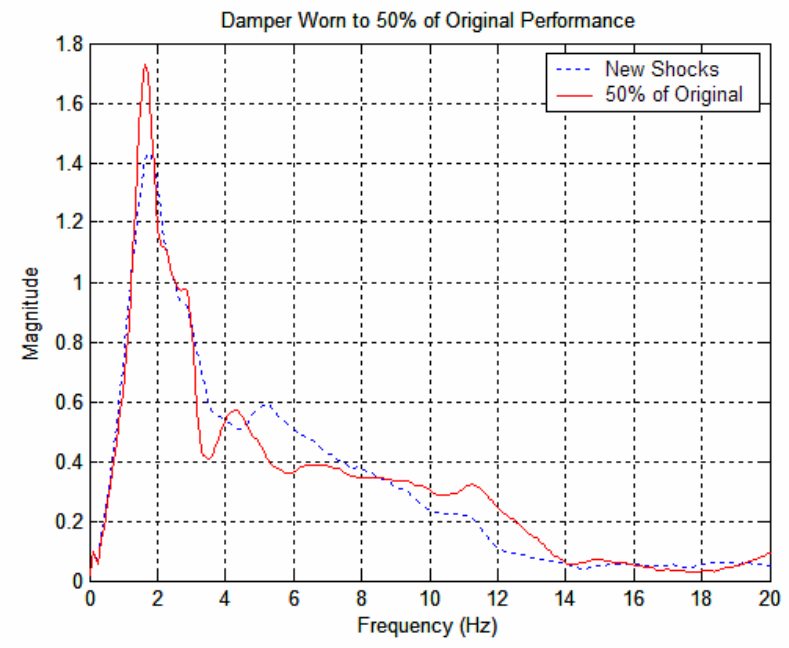

Figure 3-28 FFT of Damper Worn to 50\% of Original Damping

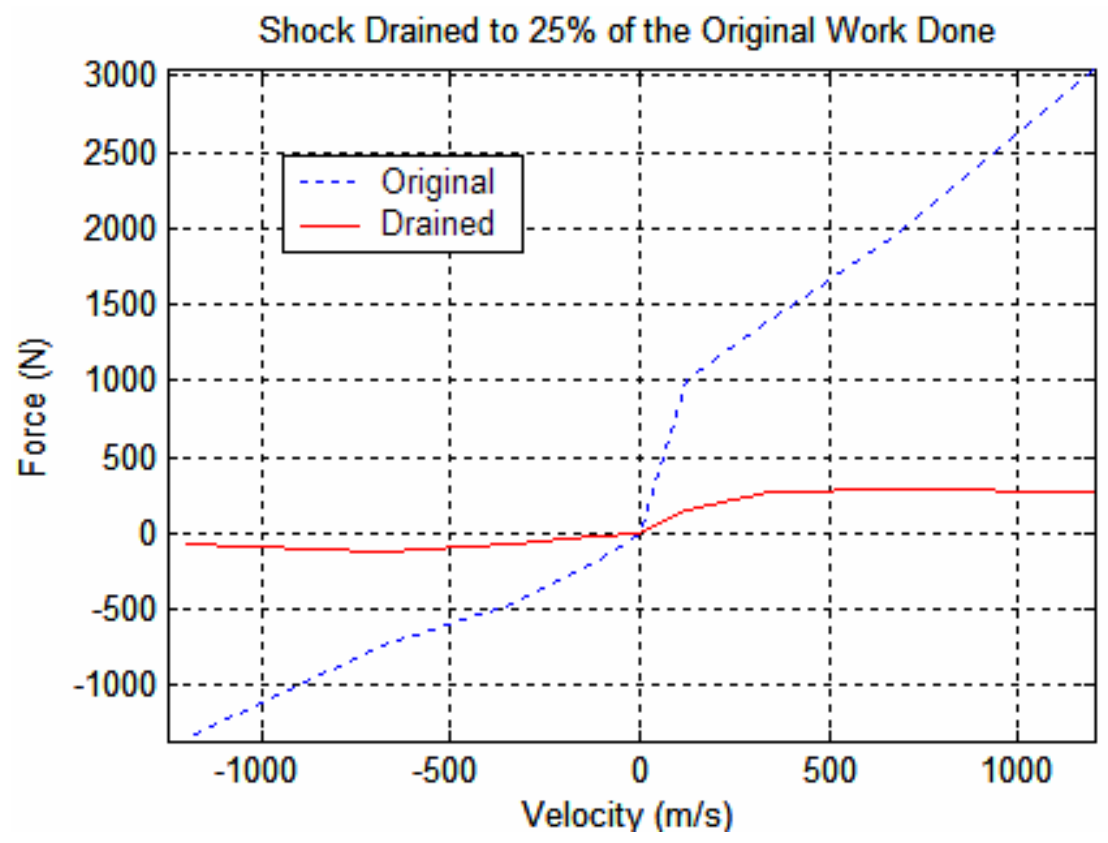

Figure 3-29 Force Velocity Data For the 25\% Damper 


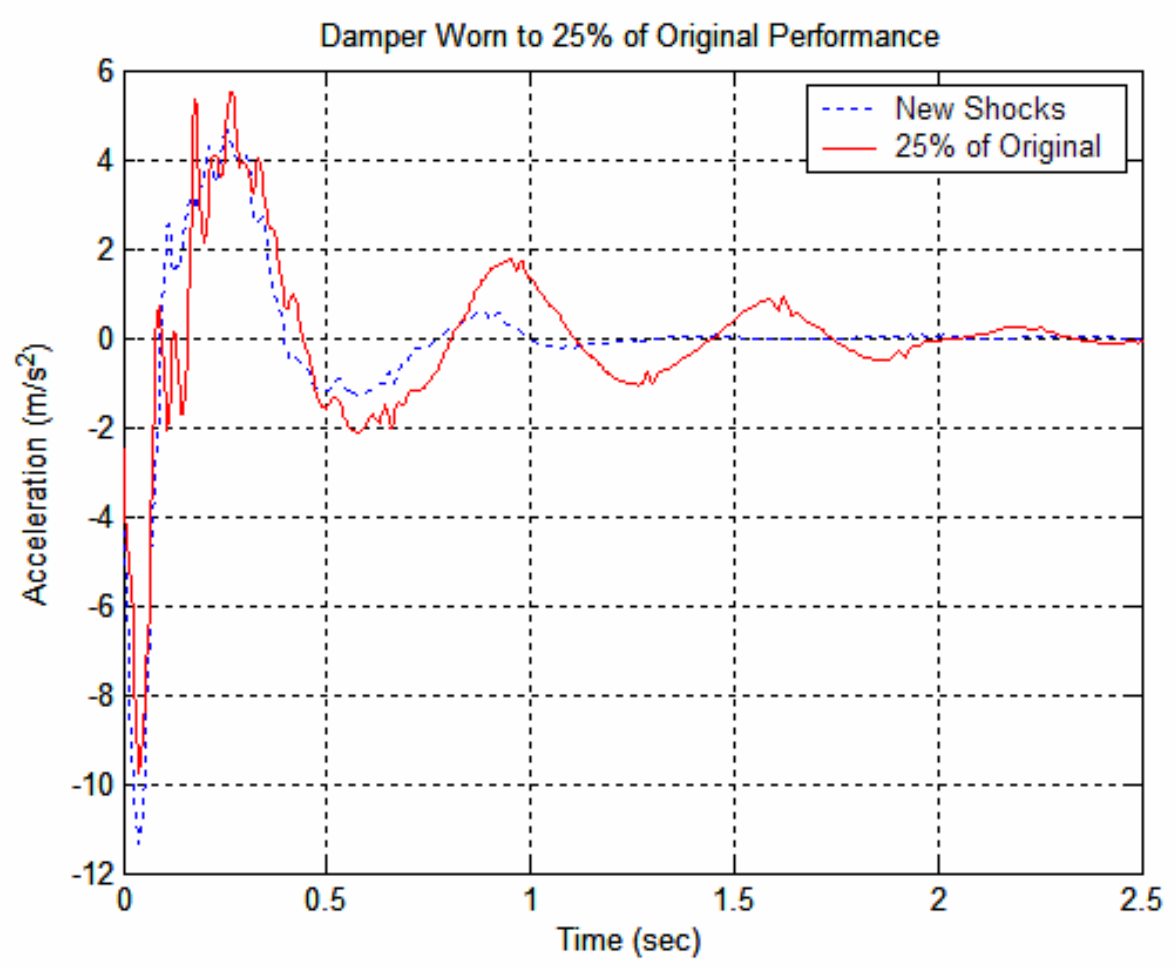

Figure 3-30 Damper Worn to 25\% of Original Damping

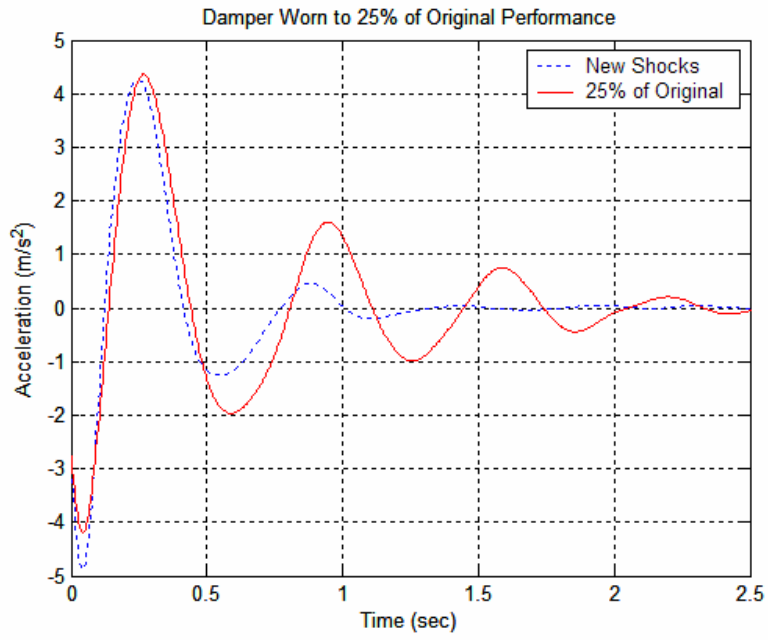

Figure 3-31 Damper Worn to 25\% of Original Damping - Filtered 


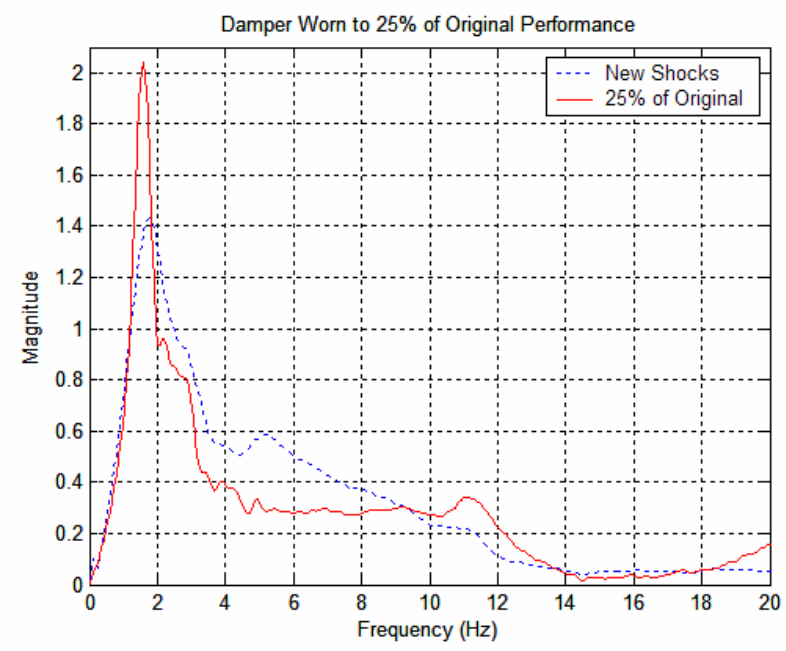

Figure 3-32 FFT of Damper Worn to 25\% of Original Damping

The worn dampers showed a significant drop in damping ratio values as the condition of the dampers worsened. Notice the Zeta 4 calculations for the new dampers have a real and imaginary part. This is because the signal has essentially died out, and the algorithm used to calculate these values will continue to try to calculate the damping ratio, even though there are no discernable peaks. This is proof that the earlier peaks must be used since stiffer shocks simply won't have oscillations that last more than two cycles.

Looking at all the plots for this section, the most dramatic difference is between the new shocks and the shocks that are $25 \%$ of the original. There are clearly more oscillations. Also, the FFTs show more of a wheel hop resonance as the dampers degrade.

The Appendix also has some plots to show the drained dampers degradation of "work-done" from the dynamometer tests. Figure 3-12 gives the F-V curve for the damper with a mechanical failure. This damper is given an approximate value of $65 \%$ of the original shock. This was calculated by taking a new shocks work-done data and 
calculating the percent of reduction from the new damper to the failed damper's work done. The reduction was roughly $65 \%$.

\begin{tabular}{|c|c|c|c|c|c|}
\hline & & Zeta 1 & Zeta 2 & Zeta 3 & Zeta 4 \\
\hline \multirow{5}{*}{$\stackrel{\circ}{\stackrel{0}{i n}}$} & Average & 0.235 & 0.179 & 0.108 & 0.103 \\
\hline & St Dev & $4.264 \mathrm{E}-03$ & $4.534 \mathrm{E}-03$ & $4.203 \mathrm{E}-03$ & $5.067 \mathrm{E}-03$ \\
\hline & Cv & $1.815 \mathrm{E}+00$ & $2.535 \mathrm{E}+00$ & $3.883 \mathrm{E}+00$ & $4.932 \mathrm{E}+00$ \\
\hline & Min & 0.227 & 0.171 & 0.095 & 0.095 \\
\hline & Max & 0.243 & 0.198 & 0.115 & 0.116 \\
\hline \multirow{5}{*}{$\stackrel{\circ}{\stackrel{0}{\circ}}$} & Average & 0.270 & 0.213 & 0.190 & 0.141 \\
\hline & St Dev & $1.041 \mathrm{E}-02$ & $1.095 \mathrm{E}-02$ & $2.346 \mathrm{E}-02$ & $2.150 \mathrm{E}-02$ \\
\hline & Cv & $3.853 \mathrm{E}+00$ & $5.138 \mathrm{E}+00$ & $1.233 \mathrm{E}+01$ & $1.530 \mathrm{E}+01$ \\
\hline & Min & 0.250 & 0.195 & 0.112 & 0.108 \\
\hline & Max & 0.303 & 0.246 & 0.218 & 0.190 \\
\hline \multirow{5}{*}{ in } & Average & 0.330 & 0.271 & 0.197 & 0.228 \\
\hline & St Dev & $2.529 \mathrm{E}-02$ & $4.845 \mathrm{E}-02$ & $3.255 \mathrm{E}-02$ & $6.612 \mathrm{E}-02$ \\
\hline & $C_{v}$ & $7.671 \mathrm{E}+00$ & $1.787 \mathrm{E}+01$ & $1.649 \mathrm{E}+01$ & $2.898 \mathrm{E}+01$ \\
\hline & Min & 0.204 & 0.024 & 0.081 & 0.141 \\
\hline & Max & 0.358 & 0.317 & 0.246 & 0.384 \\
\hline \multirow{5}{*}{$\sum_{0}^{2}$} & Average & 0.320 & 0.315 & 0.258 & $0.31797-0.071294 i$ \\
\hline & St Dev & $9.798 \mathrm{E}-03$ & $2.456 \mathrm{E}-02$ & $4.257 \mathrm{E}-02$ & $1.839 \mathrm{E}-01$ \\
\hline & Cv & $3.062 \mathrm{E}+00$ & $7.788 \mathrm{E}+00$ & $1.648 \mathrm{E}+01$ & $55.056+12.345 \mathrm{i}$ \\
\hline & Min & 0.305 & 0.272 & 0.187 & 0.170 \\
\hline & Max & 0.340 & 0.355 & 0.365 & $0.57947-0.34264 i$ \\
\hline \multirow{5}{*}{$\frac{\widetilde{d}}{\widetilde{D}}$} & Average & 0.306 & 0.242 & 0.247 & 0.273 \\
\hline & St Dev & $4.678 \mathrm{E}-03$ & $5.489 \mathrm{E}-03$ & $1.265 \mathrm{E}-02$ & $1.842 \mathrm{E}-02$ \\
\hline & Cv & $1.527 \mathrm{E}+00$ & $2.271 \mathrm{E}+00$ & $5.120 \mathrm{E}+00$ & $6.753 \mathrm{E}+00$ \\
\hline & Min & 0.292 & 0.232 & 0.212 & 0.246 \\
\hline & Max & 0.320 & 0.251 & 0.267 & 0.322 \\
\hline
\end{tabular}

Table 3-4: Calculated Damping Ratios for the Worn Dampers

\subsubsection{Test Clinic Results}

The data below is for the 18 Jeep Grand Cherokees that were tested before and after new shocks were installed. Figures 3-32 and 3-33 show the Force Velocity data after the original equipment $(\mathrm{OE})$ shocks were removed and put through a dynamometer test. 
Tables 3-6 and 3-7 show some statistical values for the dynamometer tests for this sample of vehicles. Q1 is the first quartile, meaning $25 \%$ or less of the data is below this value. Q3 is the third quartile, so $75 \%$ or less of the data is below the third quartile. The median is the second quartile.

Since the Zeta 2 value was time and again the most repeatable value in the earlier tests, and Zeta 2 most resembled the type of value that vehicle dynamics theory and system dynamics theory in general would predict, the clinic results focus on this parameter. The statistics for the 18 Jeeps tested are in Table 3-5. The upper and lower bound values give the "six sigma" spread of the data. That is to say that $99.7 \%$ of the data for a complete population should fall between these values if the data is normally distributed. This is more telling for the new shocks, since it gives an acceptable range for this make and model of vehicle with new shocks installed. The $95 \%$ confidence interval is also given (C.I.). Using the Front axle with $\mathrm{OE}$ as an example, this is interpreted as: with $95 \%$ confidence the mean is between $0.2835 \pm 0.00854$ [18].

\begin{tabular}{|c|c|c|c|c|c|c|}
\hline & Mean & St Dev & Cv (\%) & $\begin{array}{c}\text { Upper } \\
\text { Bound }\end{array}$ & $\begin{array}{c}\text { Lower } \\
\text { Bound }\end{array}$ & C.I. \\
\hline Front OE & 0.2835 & 0.02506 & 8.84 & 0.35868 & 0.20832 & .00854 \\
\hline Rear OE & 0.3553 & 0.02587 & 7.28 & 0.43291 & 0.27769 & .00882 \\
\hline Front New & 0.2785 & 0.03318 & 11.9 & 0.37804 & 0.17896 & .01131 \\
\hline Rear New & 0.3445 & 0.04503 & 13.1 & 0.47959 & .020941 & .01535 \\
\hline
\end{tabular}

Table 3-5: Statistics for the Before and After Clinic 


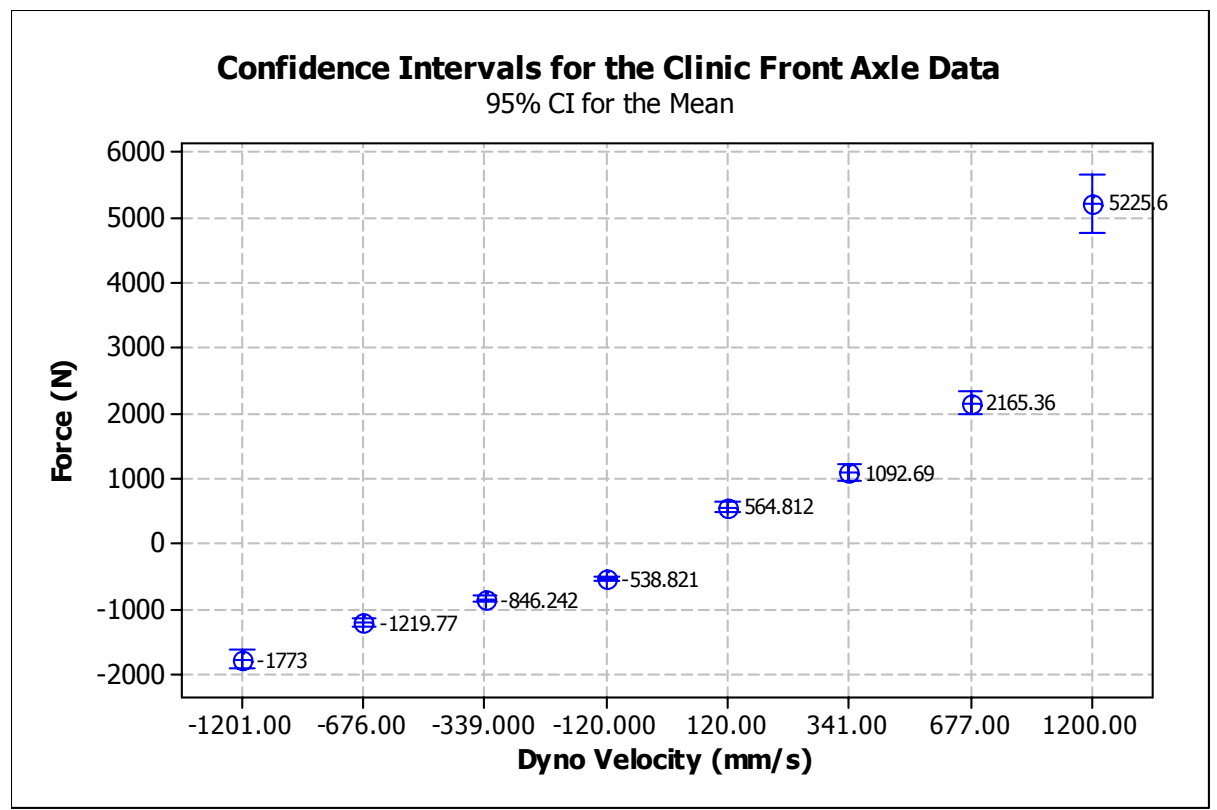

Figure 3-33

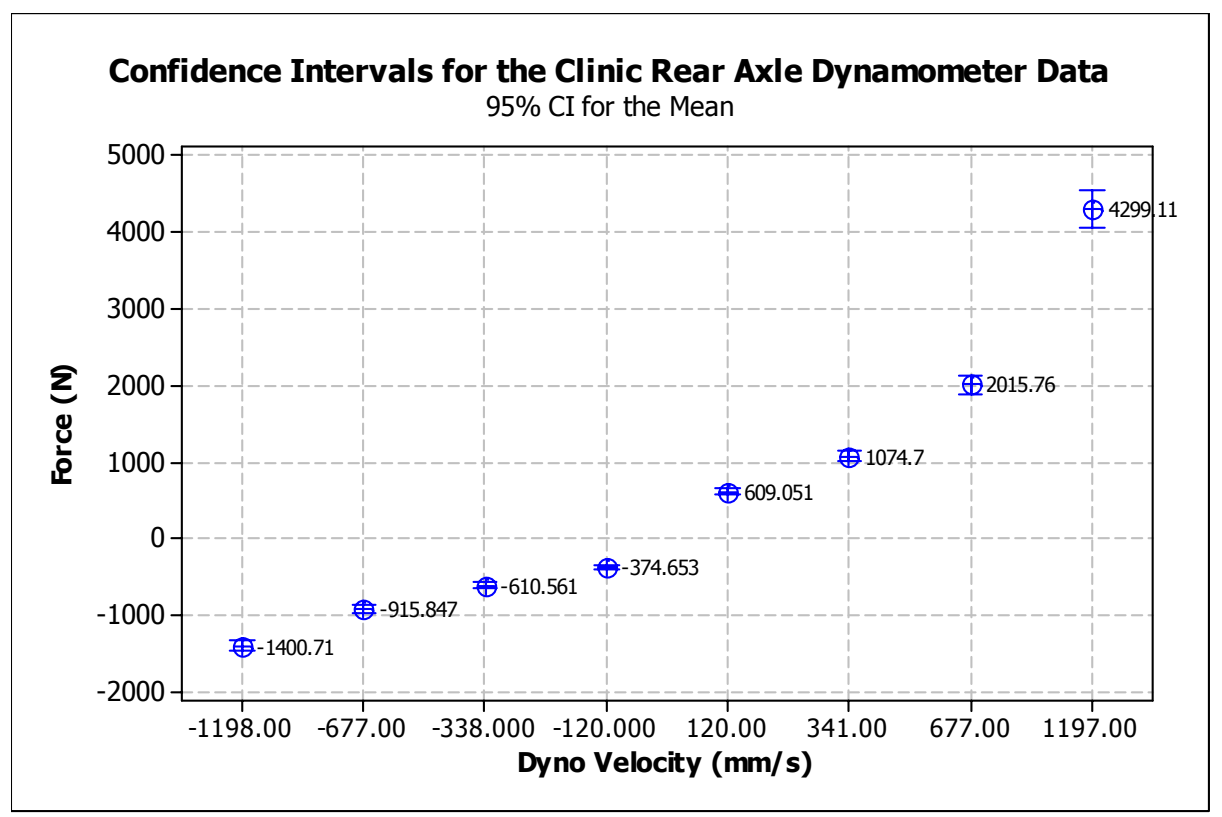

Figure 3-34 


\begin{tabular}{|c|c|c|c|c|c|c|c|}
\hline $\begin{array}{c}\text { Velocity } \\
(\mathrm{mm} / \mathrm{s})\end{array}$ & $\begin{array}{c}\text { Mean } \\
\text { Force }(\mathrm{N})\end{array}$ & $\begin{array}{c}\text { St. } \\
\text { Dev }\end{array}$ & Minimum & Q1 & Median & Q3 & Maximum \\
\hline-1198 & -1400.7 & 248.9 & -1892.0 & -1442.5 & -1403.5 & -1367.0 & -117.2 \\
\hline-677 & -915.8 & 170.5 & -1278.0 & -933.8 & -918.0 & -888.8 & -91.8 \\
\hline-338 & -610.6 & 100.2 & -869.0 & -630.8 & -606.0 & -582.3 & -219.0 \\
\hline-120 & -374.7 & 94.1 & -681.0 & -393.8 & -368.0 & -343.8 & -65.1 \\
\hline 120 & 609.1 & 148.7 & 106.5 & 560.3 & 592.0 & 616.3 & 1063.0 \\
\hline 341 & 1074.7 & 234.8 & 149.9 & 1020.0 & 1061.5 & 1083.8 & 1774.0 \\
\hline 677 & 2015.8 & 383.4 & 218.1 & 1956.8 & 2055.7 & 2116.0 & 2754.0 \\
\hline 1197 & 4299.0 & 769.0 & 363.0 & 4241.0 & 4383.0 & 4432.0 & 5818.0 \\
\hline
\end{tabular}

Table 3-6 Descriptive Statistics for the Rear Axle Clinic Dynamometer Data

\begin{tabular}{|c|c|c|c|c|c|c|c|}
\hline $\begin{array}{c}\text { Velocity } \\
(\mathrm{mm} / \mathrm{s})\end{array}$ & $\begin{array}{c}\text { Mean } \\
\text { Force }(\mathrm{N})\end{array}$ & St. Dev & Minimum & Q1 & Median & Q3 & Maximum \\
\hline-1201 & -1773.0 & 422.8 & -2072.0 & -1940.0 & -1874.5 & -1821.3 & -268.2 \\
\hline-676 & -1219.8 & 204.5 & -1397.0 & -1301.0 & -1249.4 & -1214.5 & -82.1 \\
\hline-339 & -846.2 & 141.4 & -977.0 & -900.3 & -862.5 & -827.3 & -54.1 \\
\hline-120 & -538.8 & 90.9 & -624.0 & -584.3 & -555.4 & -511.0 & -40.1 \\
\hline 120 & 564.8 & 247.4 & 204.0 & 435.5 & 555.3 & 580.5 & 1441.0 \\
\hline 341 & 1092.7 & 365.2 & 297.2 & 951.0 & 1092.1 & 1158.0 & 2143.0 \\
\hline 677 & 2165.4 & 584.4 & 264.0 & 2096.3 & 2331.0 & 2514.0 & 2610.0 \\
\hline 1200 & 5226.0 & 1436.0 & 370.0 & 5308.0 & 5720.0 & 5956.0 & 6382.0 \\
\hline
\end{tabular}

Table 3-7 Descriptive Statistics for the Front Axle Clinic Dynamometer Data

Generally, the clinic data was fairly confined to small variances. However, the population was not adequately represented, and more testing should be done to get a more complete sample size. From the dynamometer data collected, it was apparent that 
most of the vehicles had shock absorbers that were functioning properly. This was not a desired finding, since we had hoped to be able to acquire some failed shocks. The problem was the vehicles tested were all relatively new and generally driven on city roads. To find more shocks that are degraded, it would be advisable to find older vehicles, and vehicles that tend to drive off the beaten path.

The series of tests conducted and discussed in this chapter were very enlightening. The most telling test group was the shocks with oil drained. This group had very low variability and a clear gradient in the damping ratio value from the good damper to failure. The robustness tests also proved what was expected. They did see variability due to the spurious inputs, but that simply means the temperature and tire pressure must be watched. All the other suspension testers have stated that the temperature of the shock, and low tire pressure will play a role in not only the measured values, but also in ride and handling. The test clinic produced a lot of good data, but just not enough to adequately relate mileage to suspension performance. Especially since each vehicle will see so many different road inputs that will influence the life of the various components. 


\section{CHAPTER 4}

\section{CONCLUSIONS}

\subsection{Interpreting Test Results}

Various dynamic suspension testing systems do exist, however they all have several drawbacks. They all are influenced by tire pressure, vehicle roll, load shift, vibrations across solid axles, and temperature. These are factors that are difficult to omit in a non-intrusive test, but if care is taken they won't devastate results. The largest drawback for all these testers is really their cost. This research sought to achieve comparable results, with the types of spurious inputs already known, and dramatically reduce the system price so the test methodology may be used in any repair shop. This can be achieved by using MEMS accelerometers for data acquisition along with a simple mechanical dropping device. The acceleration in response to the drop test can be assessed as if it were a second order one degree of freedom system. Using a second order approximation, system parameters can be calculated, and the damping ratio will provide adequate information about the effectiveness of the vehicle's damper.

From the various tests conducted there was a wealth of data obtained and knowledge gained. The main conclusion is that the damping ratio found from an acceleration signal for a vehicle's sprung mass response to a drop test can give 
meaningful information about the condition of the shock absorbers. This is a straightforward calculation that should be simple to implement into some software package; high powered mathematical tools such as MATLAB are not necessary. Also, the filtering used in MATLAB could easily be done with an analogue low pass filter. The algorithm to find the signals' peaks is less complicated when the wheel hop vibrations are attenuated. For the MATLAB m-file a cutoff of $4 \mathrm{~Hz}$ was used; this is recommend for future prototypes. The basic m-file is provided in the Appendix.

Since there are performance limitations, several steps need to be taken to ensure the data acquired will be most descriptive of the suspensions condition.

1. The tire pressure needs to be set to manufacturer specifications, on all tires prior to beginning testing.

2. The dampers should be warm. All the tests in this research were conducted at nominally $70^{\circ} \mathrm{F}$. Also, the test corner should be oscillated for roughly one minute to ensure the damper is at an operating temperature and internal condition.

3. The accelerometer needs to be placed above the centerline of the tire at the rim of the wheel well. The accelerometer needs to be placed such that its vertical axis is orthogonal to the ground.

Even though the tests with one bad shock on the opposite side showed false readings for the tested dampers condition, this is not a major problem. For instance, consider a vehicle being tested with a solid axle, and this particular make has an acceptable damping ratio range of $0.25-0.35$. If corner $\mathrm{A}$ is tested and a damping ratio of 
0.25 is calculated, which is borderline for replacement, and corner B, of the same axle, is tested and receives a reading of 0.17 , then the recommendation is to replace the shock in corner $\mathrm{B}$, it is clearly failed. Once replaced, retest the entire axle to see if the measurement at corner A improves. So, false readings are given when a worn shock is installed on the axle. Being able to compare the four tire readings will help pinpoint which corners truly have a worn damper.

\subsection{Future Work}

The immediate future will see the enlistment of a replacement for the buckling knee. The buckling knee worked well for this research because the test vehicle had a front and rear solid axle. Not all vehicles have an axle that is parallel to the ground. The new apparatus will be designed such that any vehicle may be subjected to a repeatable and controlled drop. The main design focus will be on an instrument that lifts the vehicle by its tire then quickly releases to try to achieve the same level of rapid acceleration that the buckling knee saw. Once this is developed, it will have to undergo tests, similar to those discussed in this thesis, to ensure its dropping repeatability. Once a system is fully repeatable, it will be ready for use on all vehicles.

While the results here are promising for bringing a comparable product at a fraction of the price, there is still an abundance of field tests required to further validate the concept. Once a new dropping mechanism is fully functional, large amounts of data need to be collected for the full spectrum of vehicle suspension types on different makes and models. A possible method of obtaining more data is to enlist several repair shops to begin using the system. The data could be collected in a large database which groups the 
vehicles by make and model. This database could then be analyzed to set the damping ratio tolerances for safe handling.

Another interesting area of research is an onboard diagnostics system incorporating these inexpensive MEMS accelerometers. A possibility is to have the transducer attached permanently to the body, and have the vehicles contain the microprocessor to continuously monitor the vehicles oscillations. This could even be coupled with some tire pressure transducer so the road input force will be known. With a known force input and output acceleration, a continual frequency response can be produced and compared to the original performance of the vehicle to track degradation.

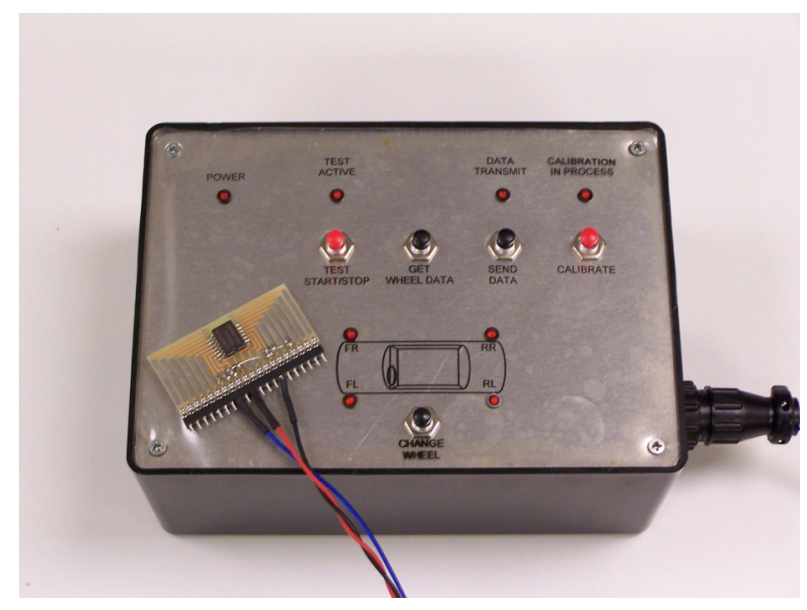

The methodology for the automotive damper diagnostic system outlined in this thesis will dramatically cut down the price of suspension testers. If the price is more reasonable, then more repair shops will use it in an effort to eliminate the number of vehicles riding on dysfunctional suspension systems. Hopefully, this research will help to reduce the number of accidents that may be linked to worn shock absorbers. 
1. Tenneco Automotive, "Fundamentals of Ride Control" Training and Study Guide.

2. Ellis, John R. et al. "The Design of Suspension a Parameter Measurement Device". SAE \#870576, 1987.

3. Coovert, Sr., David A. et al. "Design and Operation of a New-Type Suspension Measurement Device”. SAE \#920048. 1992

4. Christos, Jeffrey P. "A Simplified Method for the Measurement of Composite Suspension Parameters”. SAE \#910232, 1991.

5. Baek, W.K. and Stephens, R.I., "Fatigue Life Prediction and Experimental Verification for an Automotive Suspension Component Using Dynamic Simulation and Finite Element Analysis," Advances in Fatigue Life Predictive Techniques, ASTM STP 1122, Philadelphia, 1992.

6. Kowalski, Darin, et al. "The Effects of Different Input Excitation on the Dynamic Characterization of an Automotive Shock Absorber”. SAE \#2001-01-1442, 2001.

7. Jeong, Seung-Kab and Suh, Jin-Kawn. "Prediction of Fundamental Mode Frequency with Extraction of Dynamic Properties of Automotive Shock Absorbers and Tire". SAE \#2001-01-0498, 2001.

8. Tsymberov, Anatoly, “An Improved Non-Intrusive Automotive Suspension Testing Apparatus with Means to Determine the Condition of the Dampers,”_SAE \#960735, 1996. 
9. Balsarotti, Steve and Bradley, Wayne. "Experimental Evaluation of a Non-Intrusive Automotive Suspension Testing Apparatus”. SAE \#2000-01-1329, 2000.

10. Haedo, Martin J., "Suspension Tester CVA 2003: User Manual,” Buenos Aires, Argentina, 2003.

11. Oberheide, et al. "Hand-Portable Shock Absorber Tester," U.S. Patent 4,062,221, December 13, 1977.

12. "Technical Documentation for the M-Tronic Shock Absorber Test Device Big Red" http://www.m-tronic.de/downloads/etd.pdf Last Accessed January 7, 2005.

13. Doebelin, Ernest O., Measurement Systems: Application and Design. $5^{\text {th }}$ ed. New York, NY. MCGraw-Hill, Inc. 2004.

14. William J. Palm III, Modeling, Analysis, and Control of Dynamic Systems. $2^{\text {nd }}$ ed. New York, NY. Wiley, 1998.

15. Franklin, Gene F., et al., Feedback Control of Dynamic Systems. $4^{\text {th }}$ ed. Upper Saddle River, New Jersey. Prentice Hall, 2002.

16. Gillespie, Thomas D., Fundamentals of Vehicle Dynamics. Society of Automotive Engineers, Warrendale, PA, 1992.

17. Milliken, William F., and Douglas L. Milliken, Race Car Vehicle Dynamics. Society of Automotive Engineers, Warrendale, PA, 1995.

18. Doebelin, Ernest O., Engineering Experimentation: Planning, Executing, and Reporting. New York, NY. MCGraw-Hill, Inc. 1995. 


\section{Appendix A}

Work vs. Frequency for the shock absorbers that had oil drained, and for the shock with a mechanical failure. 


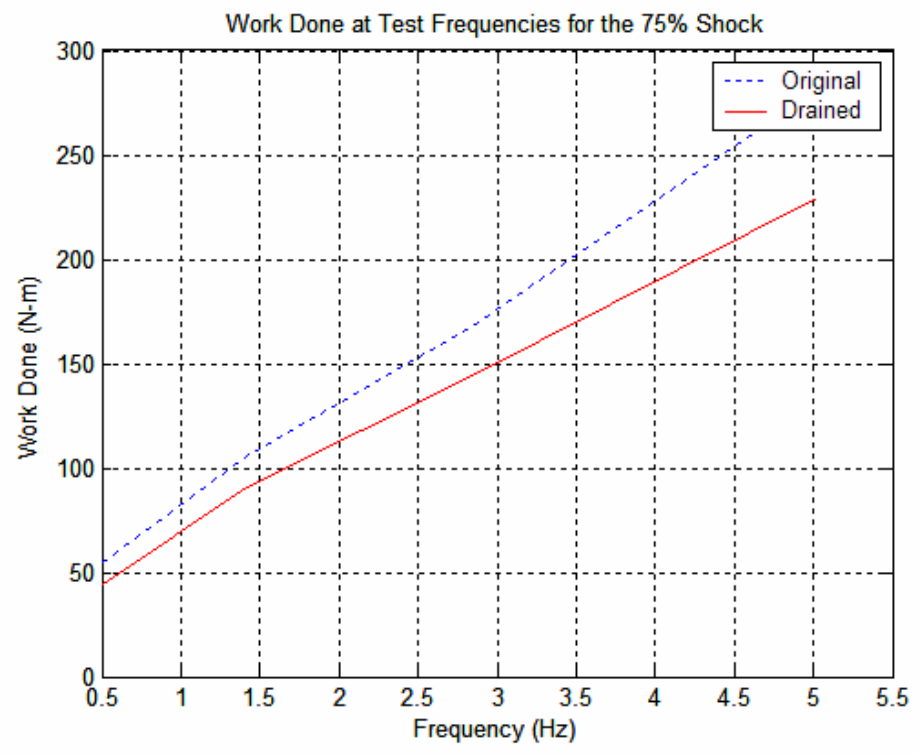

Figure A- 1: Work Reduction $75 \%$ of Original

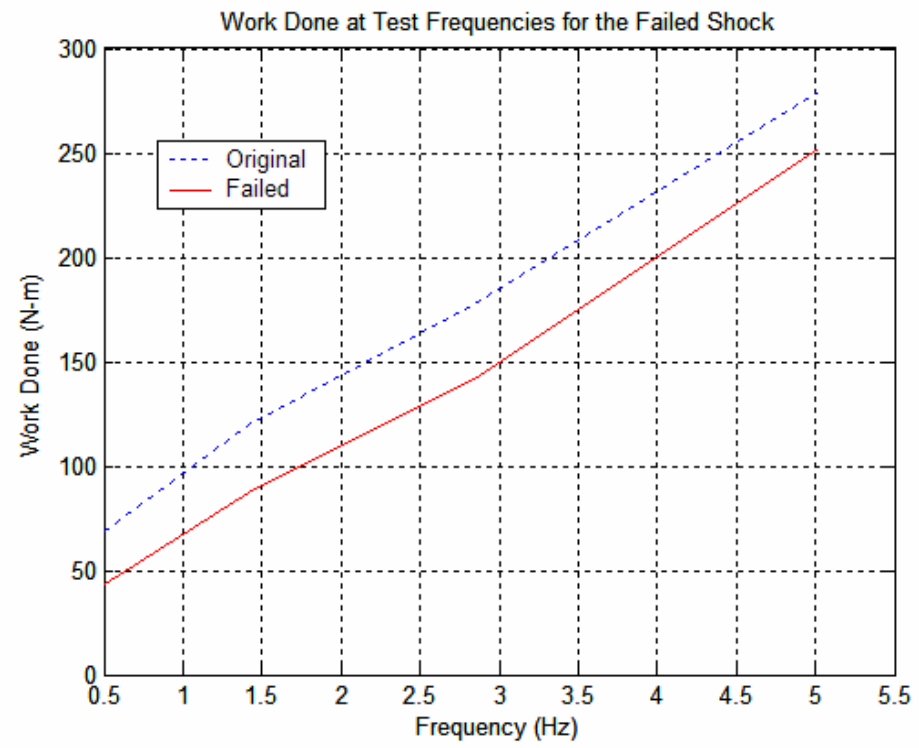

Figure A- 2: Work Reduction Failed Shock 


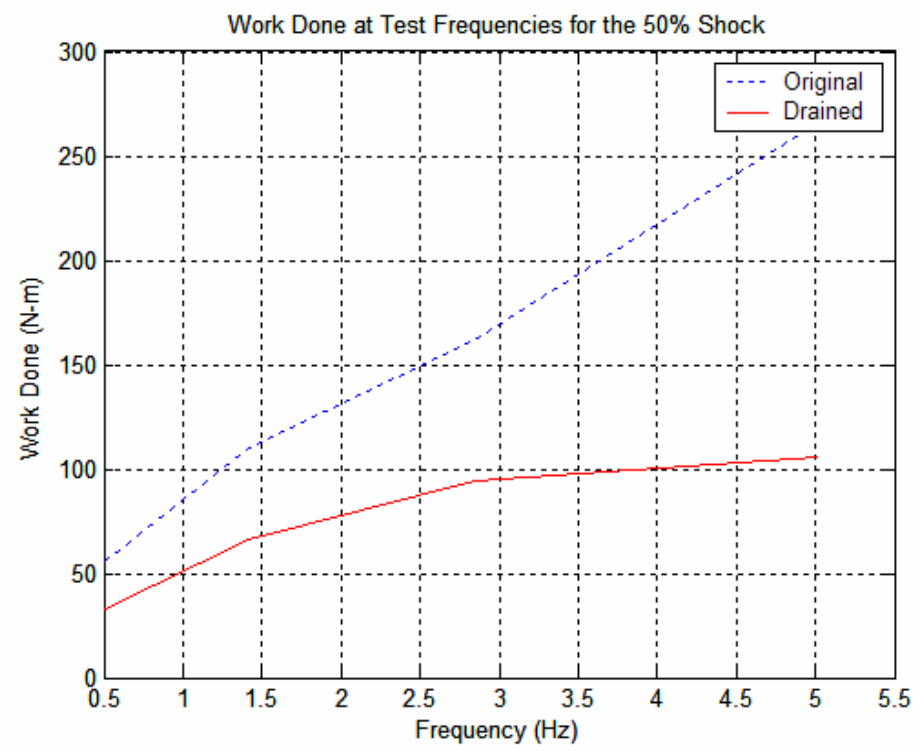

Figure A- 3: Work Reduction 50\% of Original

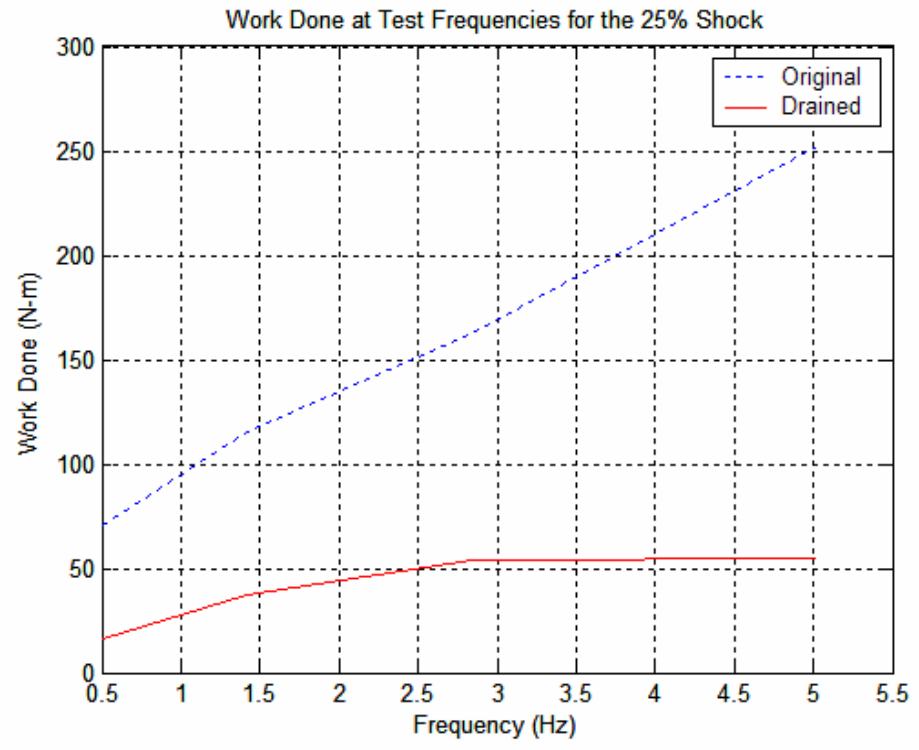

Figure A- 4: Work Reduction $25 \%$ of Original 


\section{Appendix B}

Histograms from the clinic results for each axle, before and after the shocks were replaced.

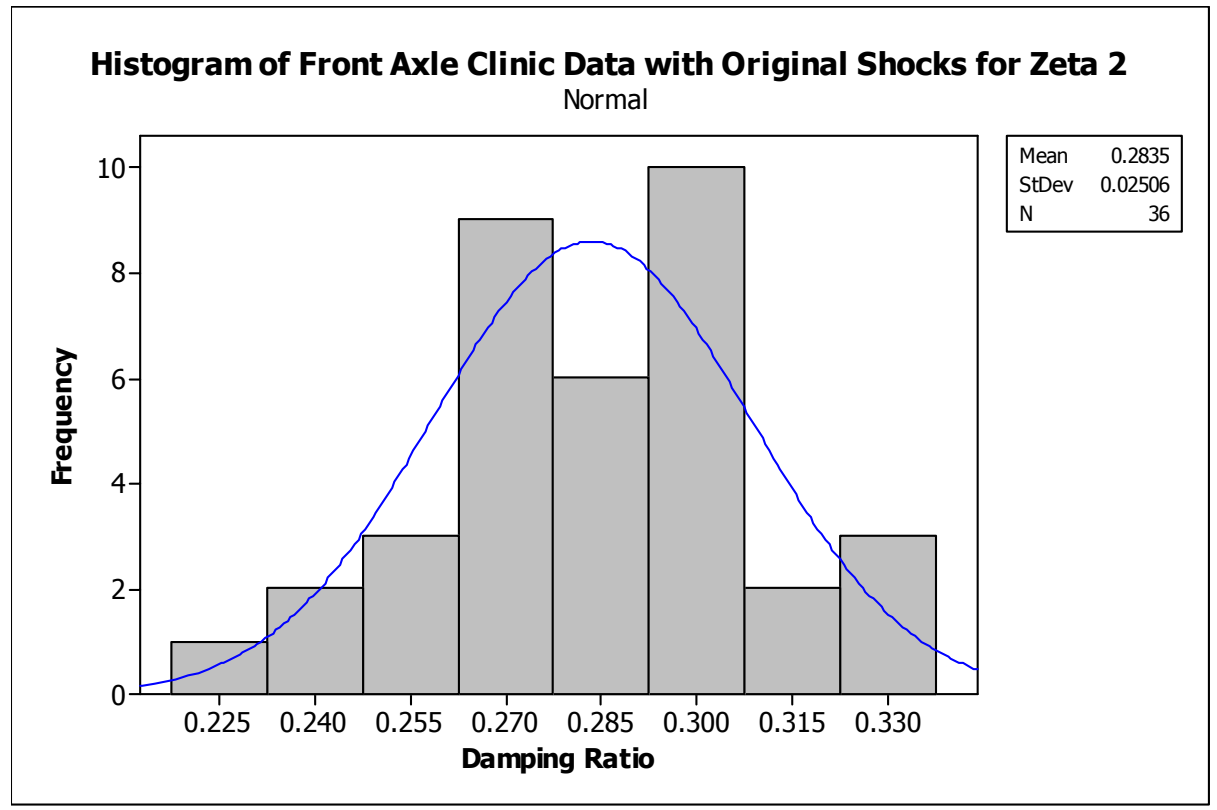

Figure A- 5: Clinic Histogram for Front Axle OE 


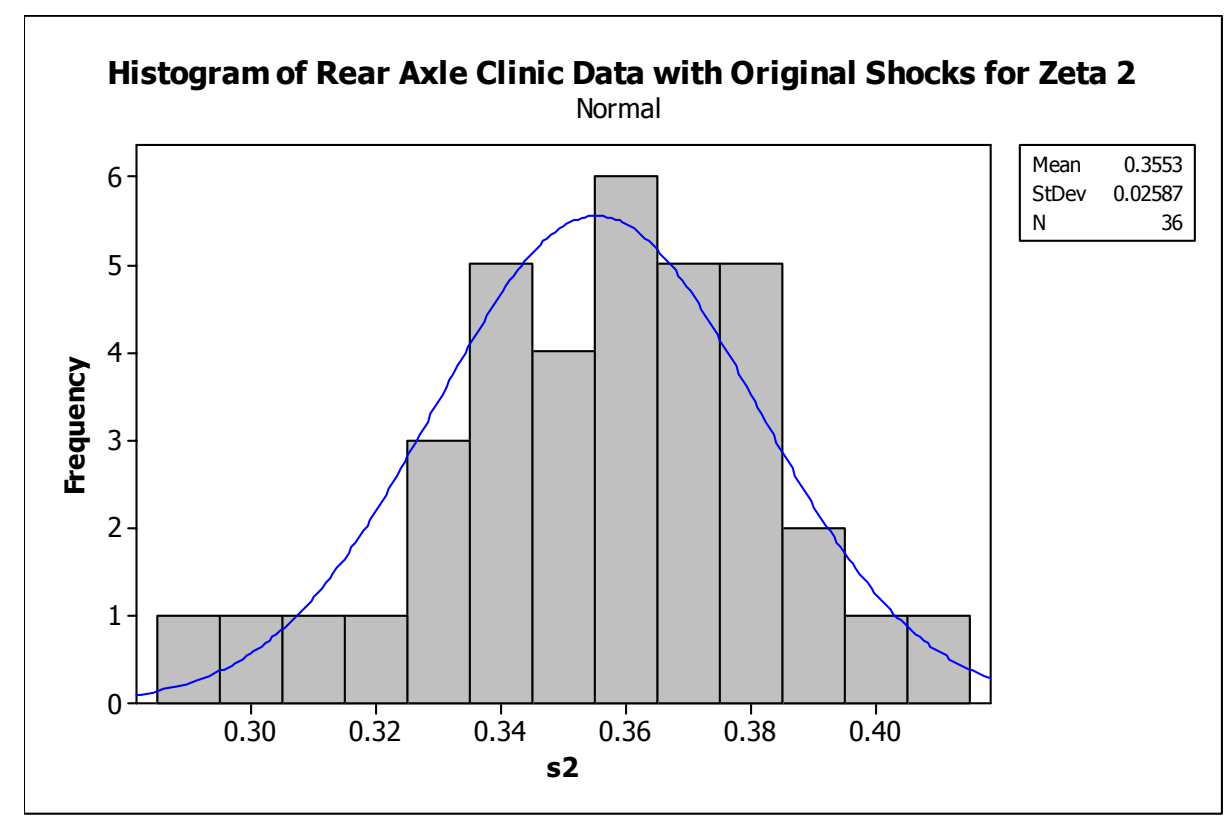

Figure A- 6: Clinic Histogram for Rear Axle OE

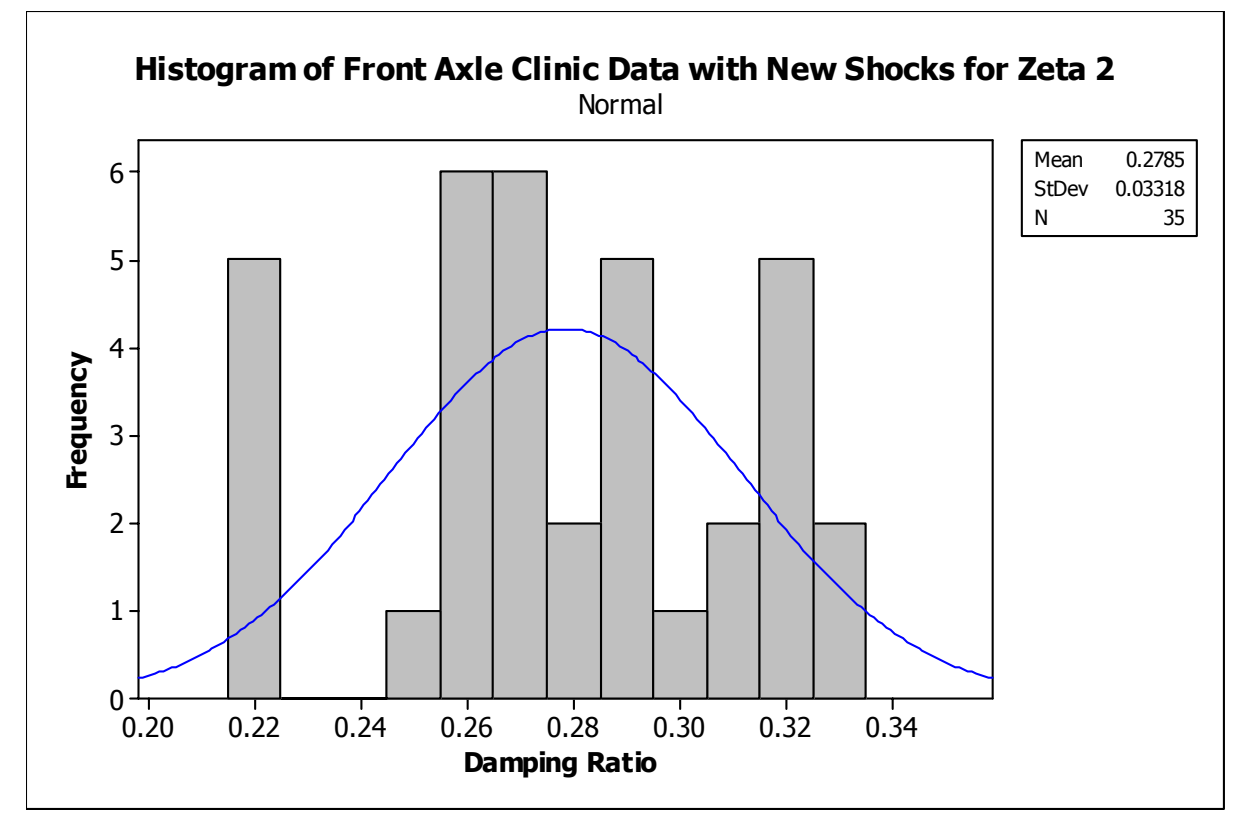

Figure A- 7: Clinic Histogram for Front Axle New Shocks 


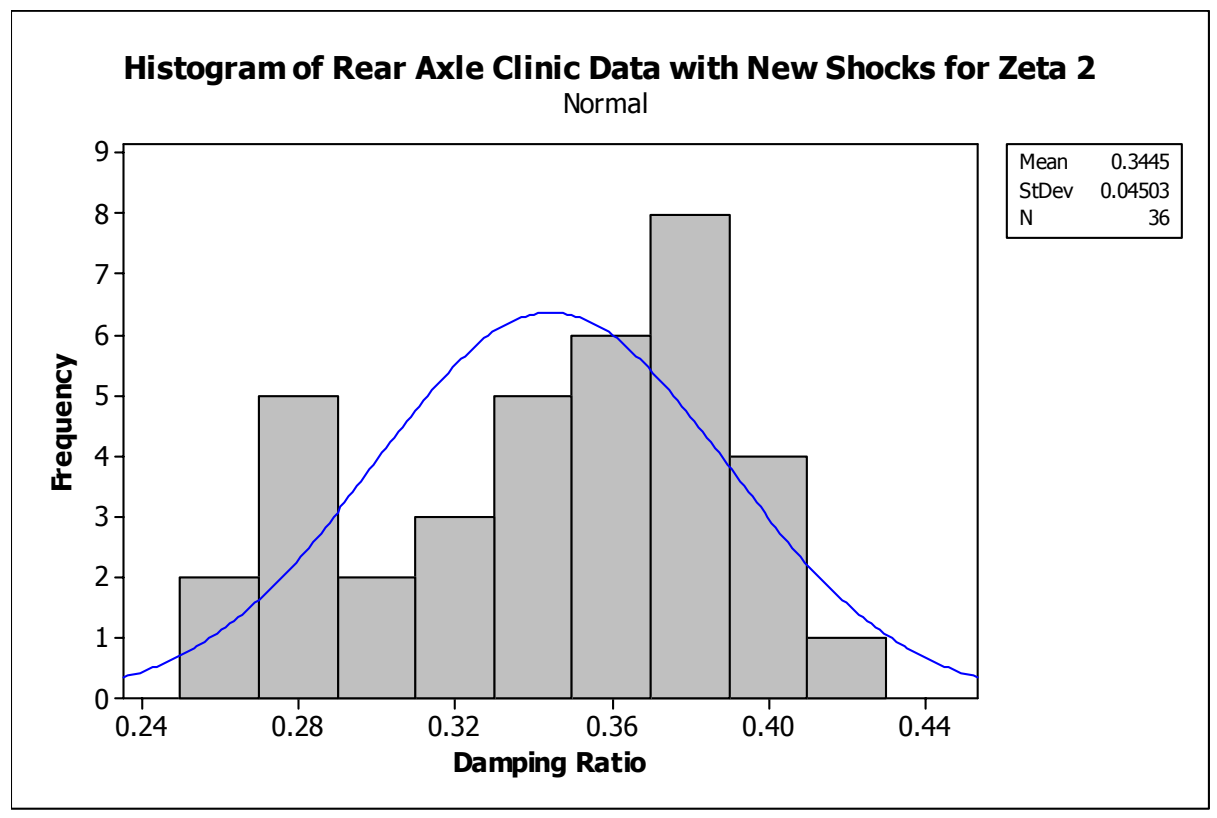

Figure A- 8: Clinic Histogram for Rear Axle New Shocks 


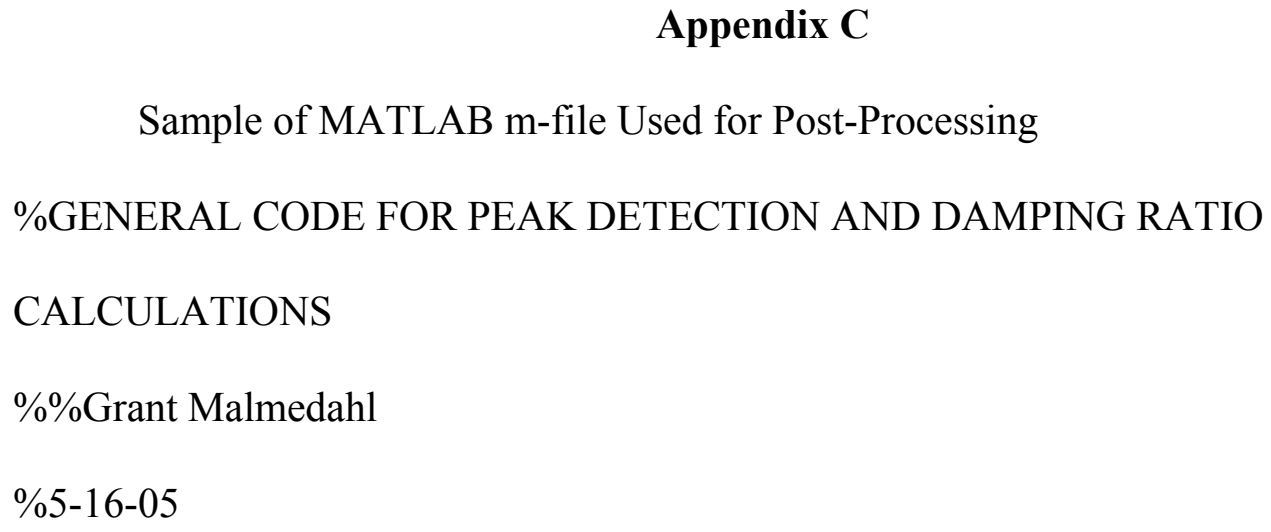

Sample of MATLAB m-file Used for Post-Processing \%GENERAL CODE FOR PEAK DETECTION AND DAMPING RATIO CALCULATIONS

$\% \%$ Grant Malmedahl

$\% 5-16-05$

clear all; close all; clc

$\mathrm{dt}=.004 ; \quad \% \mathrm{dt}$ is the sampling rate,

$\mathrm{tF}=5.996 ; \mathrm{N}=\mathrm{tF} / \mathrm{dt} ; \quad \% \mathrm{tF}$ is the total time from data colection (1500 samples)

$\mathrm{fs}=1 / \mathrm{dt} ; \%$ sampling rate

A=load('Rancho_1_1.1vm'); \%LOADING THE DATA- THIS IS THE ADJUSTADLE DAMPER

$\mathrm{t}=\mathrm{A}(:, 1)$;

$\mathrm{AccelB}=\mathrm{A}(:, 3) * 9.81 ; \quad \% \mathrm{MEMS}$ accelerometer

\section{\%MODIFYING THE ACCELERATION SIGNAL}

$\min \_a=$ find $($ AccelB $==\min ($ AccelB $))-10 ; \%$ FINDING THE DROP BY THE LARGE INITIAL SPIKE 
$\mathrm{N}=$ length(AccelB);

$A c c e l B=A c c e l B\left(\min \_a: N\right)-m e a n\left(A c c e l B\left(m i n \_a: N\right)\right) ; \% e l i m i n a t e s$ the dc value

$\mathrm{N}=1024 ; A c c e l B=A c c e l B(1: \mathrm{N}) ; \quad$ \%USING A FILE LENGTH OF BASE 2

$\mathrm{t}=\mathrm{t}(1: \mathrm{N}) ; \quad$ \%TIME MUST BE SAME LENGTH AS ACCEL

\%FREQUENCY ANALYSIS

$\mathrm{df}=1 /\left(\mathrm{N}^{*} \mathrm{dt}\right) ; \mathrm{f}=\left[0: \mathrm{df}:(\mathrm{N}-1)^{*} \mathrm{df}\right] ; \%$ FOR PLOTTING AGAINST FREQUENCY $(\mathrm{Hz})$

$\mathrm{n}=[1: \mathrm{N}]$;

y_ab=fft(AccelB,1024); \%FFT OF THE ACCELERATION SIGNAL

cutoff $=4 ; \quad$ \%Cutoff Frequency $(\mathrm{Hz})=$ cutoff $/(\mathrm{fs} / 2)(\mathrm{N}$ ' is the number of

samples)

\%HERE THE CUTOFF FREQ IS $4 \mathrm{~Hz}$

cutoff_freq= cutoff*df;

$\mathrm{N}=2 ; \mathrm{Wn}=$ cutoff $/ 125 ; \quad \% \mathrm{Wn}$ is the cutoff freq divided by half the sampling freq \& N IS THE ORDER OF THE FILTER

$\%$ (ie 0.1 is $25 \mathrm{~Hz} / 250 \mathrm{~Hz}$ : so the cutoff is $25 \mathrm{~Hz}$ when the Sampling

rate is $250 \mathrm{~Hz}$ )

$[\mathrm{B}, \mathrm{A}]=$ butter(N,Wn); $\quad$ \%BUILD THE FILTER AS 2ND ORDER LOW-PASS

filt_a=filtfilt(B,A,AccelB); \%use 'filtfilt'

t_stable $=2.5 ; \quad$ \%APPROX TIME THE SYSTEM STABILIZES

$\% \% \% \%$ FINDING THE PEAKS AND VALLEYS OF THE FILTERED

ACCELEROMETER

\%FIND THE PEAKS VALUES, TIME, AND INDEX WITH THE ACCELERATION ARRAY 
filt_a=real(filt_a); \%USE THE REAL PARTS OF THE FILTERED SIGNAL L_a=length(filt_a);

a1=min(filt_a); $\quad$ \%gives the output at the first valley

a1_ind $=$ find(filt_a $==\mathrm{a} 1)$; $\%$ index calc

a1_t $=\mathrm{t}\left(\mathrm{a} 1 \_\right.$ind $\left.(1)\right) ; \quad$ \%gives the time for the first valley min

$\mathrm{a} 2=\max ($ filt_a(a1_ind(1):L_a $))$;

a2_ind=find(filt_a(a1_ind(1):L_a $)==a 2)+a 1 \_i n d(1)-1$;

a2_t $=\mathrm{t}\left(\mathrm{a} 2 \_\right.$ind $\left.(1)\right)$;

$\mathrm{a} 3=\min ($ filt_a(a2_ind(1):a2_ind(1)+.6*fs));

a3_ind $=$ find(filt_a(a2_ind(1):L_a $)==a 3)+a 2$ ind(1)-1;

a3_t=t(a3_ind (1));

a4 $=\max ($ filt_a(a3_ind(1):L_a $)$;

a4_ind $=$ find(filt_a(a3_ind $\left.\left.(1): L \_a\right)==a 4\right)+a 3$ ind(1)-1;

$\mathrm{a} 4 \_\mathrm{t}=\mathrm{t}(\mathrm{a} 4$ _ind $(1))$;

$\mathrm{a} 5=\min ($ filt_a(a4_ind(1):a4_ind $+.6 * \mathrm{fs}))$;

a5_ind=find(filt_a(a4_ind(1):a4_ind(1)+.6*fs)==a5) $+\mathrm{a} 4$ _ind(1) 1 ;

a5_t=t(a5_ind(1));

$\mathrm{a} 6=\max ($ filt_a(a5_ind:a5_ind $+.6 * \mathrm{fs}))$;

a6_ind=find(filt_a(a5_ind(1):a5_ind(1)+.6*fs) $==\mathrm{a} 6)+\mathrm{a} 5$ _ind(1) 1 ;

a6_t=t(a6_ind(1));

Sfinal_a=mean(filt_a(t_stable*fs:L_a ) $; \quad$ \%average trim value once settled, $\%$ it WILL be non-zero 
$\%$ Calculation of Peak Magnitudes

a1_a=Sfinal_a-a1;

a2_a=a2-Sfinal_a;

a3_a=Sfinal_a-a3;

$\mathrm{a} 4$ a $=\mathrm{a} 4-$ Sfinal_a;

a5_a=Sfinal_a-a5;

a6_a=a6-Sfinal_a;

\%Peak Picker Points Plotted

figure(1)

$\operatorname{plot}\left(\mathrm{a} 1 \_\mathrm{t}, \mathrm{a} 1,{ }^{\prime} \cdot \mathrm{k}^{\prime}\right)$;

plot(a2_t,a2,'.k'); hold on;

$\operatorname{plot}\left(a 3 \_t, a 3, ' \cdot k^{\prime}\right)$;

$\operatorname{plot}\left(\mathrm{a} 4 \_\mathrm{t}, \mathrm{a} 4,{ }^{\prime} \cdot \mathrm{k}^{\prime}\right)$;

plot(a5_t_a,a5,'.k');

plot(a6_t,a6,'.k');

\%DAMPING RATIOS

zeta_s1 $=\log (\mathrm{a} 1 / \mathrm{a} 3) / \operatorname{sqrt}\left(4 * \mathrm{pi}^{\wedge} 2+(\log (\mathrm{a} 1 / \mathrm{a} 3))^{\wedge} 2\right)$;

zeta_s2 $=\log (\mathrm{a} 2 / \mathrm{a} 4) / \operatorname{sqrt}\left(4 * \mathrm{pi}^{\wedge} 2+(\log (\mathrm{a} 2 / \mathrm{a} 4))^{\wedge} 2\right)$;

zeta_s3 $=\log ($ a3 $/ \mathrm{a} 5) / \operatorname{sqrt}\left(4 * \mathrm{pi}^{\wedge} 2+(\log (\mathrm{a} 3 / \mathrm{a} 5))^{\wedge} 2\right)$;

zeta_s4 $=\log (\mathrm{a} 4 / \mathrm{a} 6) / \operatorname{sqrt}\left(4 * \mathrm{pi}^{\wedge} 2+(\log (\mathrm{a} 4 / \mathrm{a} 6))^{\wedge} 2\right)$;

zeta $1 \mathrm{a} 2=\log (\mathrm{a} 1 / \mathrm{a} 2) / \operatorname{sqrt}\left(4 * \mathrm{pi}^{\wedge} 2+(\log (\mathrm{a} 1 / \mathrm{a} 2))^{\wedge} 2\right)$;

zeta2a3 $=\log (\mathrm{a} 2 / \mathrm{a} 3) / \operatorname{sqrt}\left(4 * \mathrm{pi}^{\wedge} 2+(\log (\mathrm{a} 2 / \mathrm{a} 3))^{\wedge} 2\right) ;$

zeta3a4 $=\log (\mathrm{a} 3 / \mathrm{a} 4) / \operatorname{sqrt}\left(4 * \mathrm{pi}^{\wedge} 2+(\log (\mathrm{a} 3 / \mathrm{a} 4))^{\wedge} 2\right)$;

zeta4a5 $=\log (\mathrm{a} 4 / \mathrm{a} 5) / \operatorname{sqrt}\left(4 * \mathrm{pi}^{\wedge} 2+(\log (\mathrm{a} 4 / \mathrm{a} 5))^{\wedge} 2\right) ;$

zeta5a6 $=\log (\mathrm{a} 5 / \mathrm{a} 6) / \operatorname{sqrt}\left(4 * \mathrm{pi}^{\wedge} 2+(\log (\mathrm{a} 5 / \mathrm{a} 6))^{\wedge} 2\right) ;$ 
$\% \% \% \% \% \% \% \% \% \% \% \% \% \% \% \%$

$\%$ WORK ANALYSIS

\%\%\%\%\%\%\%\%\%\%\%\%\%\%\%\%\%\%\%\%\%\%\%\%\%\%\%\%\%\%\%\%\%\%\%\%\%\%\%\%\%\%\%

$\%$ method for the "work analysis", this method looks at the decay rate of the area

above (or below) the trim valuewhich will work efficiently for a filtered signal, but can't

work on raw data since this seeks the zero crossings

\%\%\%\%\%\%\%\%\%\%\%\%\%\%\%\%\%\%\%\%\%\%\%\%\%\%\%\%\%\%\%\%\%\%\%\%\%\%\%\%\%\%\%

Area_below $=$ find(filt_a $<0$ );

Area_above $=$ find(filt_a $>0$ );

\%NEGATIVE AREA

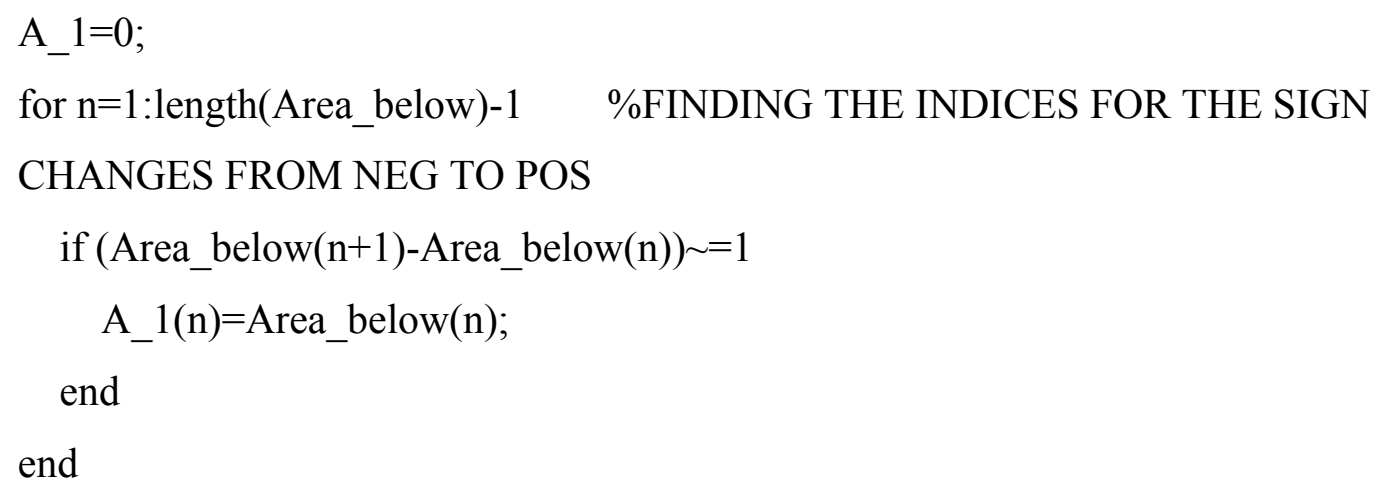

find(A_1 =0) ;

A_2 $=0$;

for $\mathrm{m}=1$ :length(ans)

A_2(m) $=$ A_1 $(\operatorname{ans}(m)) ; \quad \%$ collects the points before a sign change into 'A_2' end

$\% \quad \%$ figure(1)

$\% \quad$ plot(t(A_2),filt_a(A_2),'g*') 
$\%$ POSITIVE AREA

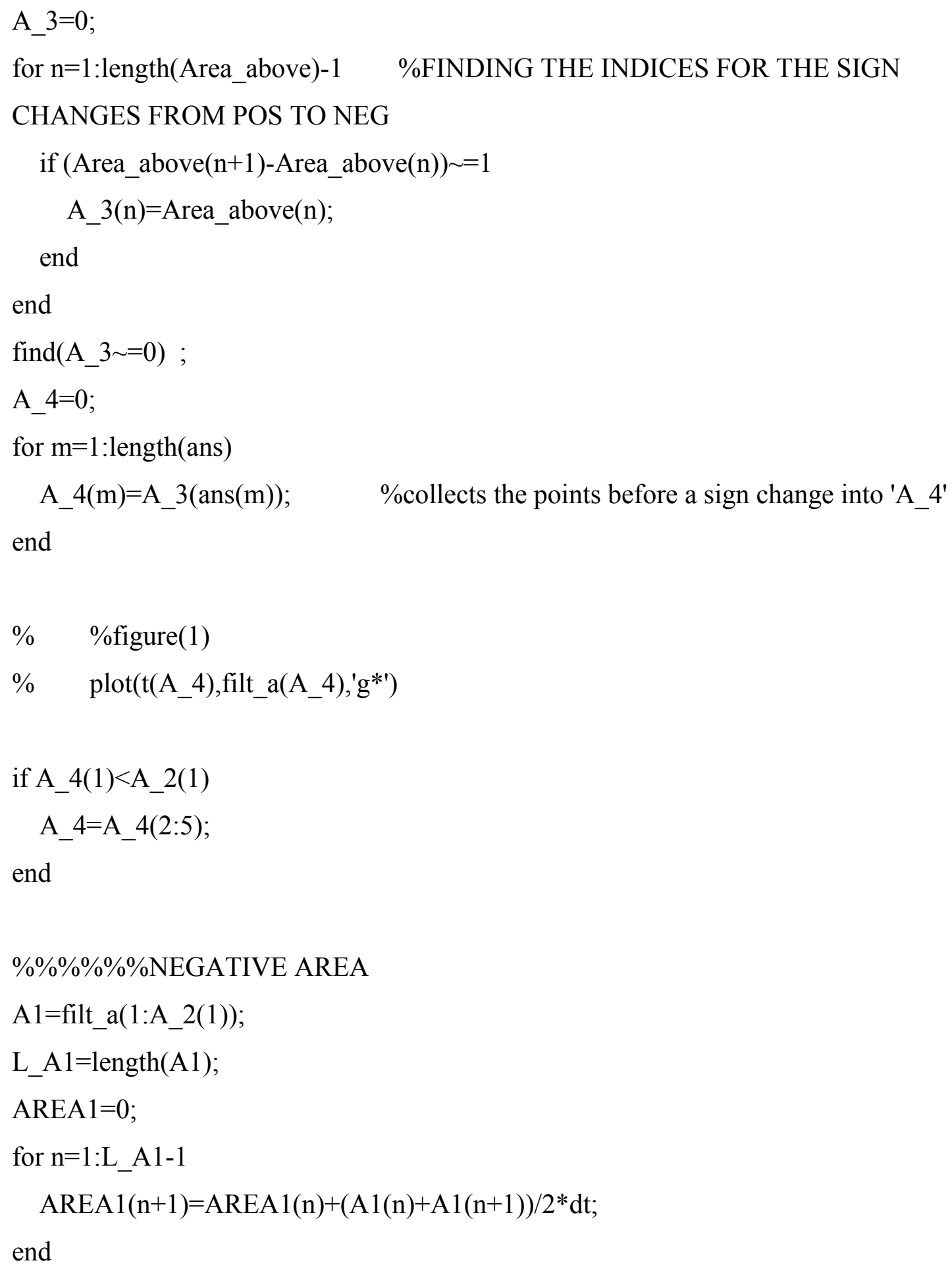


$\operatorname{area1}=\operatorname{abs}\left(\operatorname{AREA} 1\left(\mathrm{~L}_{-} \mathrm{A} 1\right)\right)$;

\% $\% \% \% \% \% \% \% \% \% \% \% \% \% \% \% \% \% \% \% \% \% \% \% \% \% \% \% \% \% \% \% \% \% \% \% \% \% \% \% \% \% \% \% \%$ $\% \% \% \%$ POSITIVE AREA

A2=filt_a(A_2(1)+1:A_4(1));

L_A2=length(A2);

AREA2 $=0$;

for $\mathrm{n}=1: \mathrm{L} \_\mathrm{A} 2-1$

$\operatorname{AREA} 2(\mathrm{n}+1)=\operatorname{AREA} 2(\mathrm{n})+(\mathrm{A} 2(\mathrm{n})+\mathrm{A} 2(\mathrm{n}+1)) / 2 * \mathrm{dt}$;

end

$\operatorname{area} 2=\operatorname{abs}($ AREA2(L_A2) $)$;

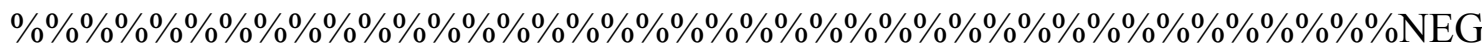

ATIVE AREA

A3 =filt_a(A_4(1)+1:A_2(2));

L_A3=length(A3);

AREA3 $=0$;

for $n=1: L_{-} A 3-1$

$\operatorname{AREA} 3(\mathrm{n}+1)=\operatorname{AREA} 3(\mathrm{n})+(\mathrm{A} 3(\mathrm{n})+\operatorname{A} 3(\mathrm{n}+1)) / 2 * d t$

end

area3 $=\operatorname{abs}($ AREA3(L_A3) $)$;

\% $\% \% \% \% \% \% \% \% \% \% \% \% \% \% \% \% \% \% \% \% \% \% \% \% \% \% \% \% \% \% \% \% \% \% \% \% \% \% \%$ POSI

TIVE AREA

A4=filt_a(A_2(2)+1:A_4(2));

L_A4=length(A4);

AREA4=0;

for $n=1: L \_A 4-1$

$\operatorname{AREA} 4(\mathrm{n}+1)=\operatorname{AREA} 4(\mathrm{n})+(\mathrm{A} 4(\mathrm{n})+\mathrm{A} 4(\mathrm{n}+1)) / 2 * d t ;$

end

$\operatorname{area} 4=\operatorname{abs}($ AREA4(L_A4) $)$;

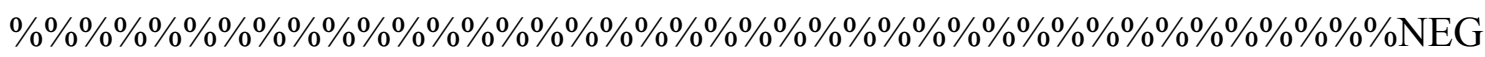
ATIVE AREA 
A5 $=$ filt_a(A_4(2)+1:A_2(3));

L_A5=length(A5);

AREA5 $=0$;

for $\mathrm{n}=1: \mathrm{L} \_\mathrm{A} 5-1$

$\operatorname{AREA} 5(\mathrm{n}+1)=\operatorname{AREA} 5(\mathrm{n})+(\mathrm{A} 5(\mathrm{n})+\operatorname{A} 5(\mathrm{n}+1)) / 2 * \mathrm{dt}$;

end

area5 $=\operatorname{abs}\left(\operatorname{AREA5}\left(\mathrm{L}_{-} \mathrm{A} 5\right)\right)$;

$\% \quad \%$ figure $(1)$

\%plot(t(1:A_2(1)),A1,'y');plot(t(A_2(1)+1:A_4(1)),A2,'b');plot(t(A_4(1)+1:A_2(2)),A3,' $\left.\mathrm{y}^{\prime}\right) ; \operatorname{plot}\left(\mathrm{t}\left(\mathrm{A} \_2(2)+1: \mathrm{A} \_4(2)\right), \mathrm{A} 4,{ }^{\prime} \mathrm{b}^{\prime}\right) ; \operatorname{plot}\left(\mathrm{t}\left(\mathrm{A} \_4(2)+1: \mathrm{A} \_2(3)\right), \mathrm{A} 5,{ }^{\prime} \mathrm{y}^{\prime}\right)$;

$\%$ WORK RATIOS

Z_AREA $1=\log ($ area $1 /$ area3 $) / \operatorname{sqrt}\left(4 * \mathrm{pi}^{\wedge} 2+(\log (\text { area } 1 / \text { area3 }))^{\wedge} 2\right)$;

Z_AREA2 $=\log (\operatorname{area} 2 / \operatorname{area} 4) / \operatorname{sqrt}\left(4 * \mathrm{pi}^{\wedge} 2+(\log (\operatorname{area} 2 / \text { area } 4))^{\wedge} 2\right)$;

Z_AREA3 $=\log ($ area3/area5 $) / \operatorname{sqrt}\left(4 * \mathrm{pi}^{\wedge} 2+(\log (\text { area3/area5 }))^{\wedge} 2\right)$;

Z_AREA23 $=\log ($ area2 $/$ area3 $) / \operatorname{sqrt}\left(4 * \mathrm{pi}^{\wedge} 2+(\log (\text { area2 } / \text { area3 }))^{\wedge} 2\right)$;

Z_AREA34 $=\log ($ area3/area4 $) / \operatorname{sqrt}\left(4 * \mathrm{pi}^{\wedge} 2+(\log (\text { area3/area4 }))^{\wedge} 2\right)$;

Z_AREA45 $=\log ($ area $4 /$ area5 $) / \operatorname{sqrt}\left(4 * \mathrm{pi}^{\wedge} 2+(\log (\text { area4/area5 }))^{\wedge} 2\right)$;

\%\%\%\%\%\%\%\%\%\%\%\%\%\%\%\%\%\%\%\%\%\%\%\%\%\%\%\%\%\%\%\%\%\%\%\%\%\%\%\%\%\%\%

\%\%\%\%\%\%\%\%\%\%\%\%\%\%\%\%\%\%\%\%\%\%\%\%\%\%\%\%\%\%\%\%\%\%\%\%\%\%\%\%\%\%\% $\% \% \%$

\%Time for ZERO CROSSINGS (PERIOD)

$\mathrm{Z} \_1=\left(\mathrm{t}\left(\mathrm{A} \_2(1)\right)+\mathrm{t}\left(\mathrm{A} \_2(1)+1\right)\right) / 2$;

$\mathrm{Z} \_2=\left(\mathrm{t}\left(\mathrm{A} \_4(1)\right)+\mathrm{t}\left(\mathrm{A} \_4(1)+1\right)\right) / 2$;

$\mathrm{Z} \_3=\left(\mathrm{t}\left(\mathrm{A} \_2(2)\right)+\mathrm{t}\left(\mathrm{A} \_2(2)+1\right)\right) / 2$; 
Z_4=(t(A_4(2)) $+\mathrm{t}($ A_4(2)+1) $) / 2$;

$\mathrm{Z} \_5=(\mathrm{t}($ A_2(3) $)+\mathrm{t}($ A_2(3)+1) $) / 2$;

$\%$ Half periods

hp_1=Z_2-Z_1; $\quad$ hp_2=Z_3-Z_2;

\%Period

p_1 $=$ Z_3-Z_1; $\quad$ p_2 $=$ Z_4-Z_2; $\quad$ p_3 $=$ Z_5-Z_3;

\section{\%COLECTING THE DATA}

$\%$ Want to collect all the data into one column for easy statistical analysis

RL_1(:,1)=[zeta_s1;zeta_s2;zeta_s3;zeta_s4;zeta1a2;zeta2a3;zeta3a4;zeta4a5;zeta5a6;Z_ AREA1;Z_AREA2;Z_AREA3;Z_AREA23;Z_AREA34;Z_AREA45];

RL_CURVE_1(:,1)=AccelB; \%ORGANIZE THE ACCEL CURVE TO BE AVERAGED LATER

RL_FILTCURVE_1(:,1)=filt_a; \%ORGANIZE THE FILTERED CURVE TO BE AVERAGED LATER 